Universidade de São Paulo

Faculdade de Economia, Administração e Contabilidade de Ribeirão Preto

Departamento de Economia

Programa de Pós-graduação em Economia

Área: Economia Aplicada

\title{
Estudo da disposição a pagar por eficiência energética: o caso dos refrigeradores no Brasil
}

Versão Corrigida. A original encontra-se disponível na FEA-RP/USP

Orientador: Prof. Dr. Cláudio Ribeiro de Lucinda

\section{Ribeirão Preto}


Prof. Dr. Marco Antonio Zago

Reitor da Universidade de São Paulo

Prof. Dr. Dante Pinheiro Martinelli

Diretor da Faculdade de Economia, Administração e Contabilidade de Ribeirão Preto

Prof. Dr. Renato Leite Marcondes

Chefe do Departamento de Economia

Prof. Dr. Cláudio Ribeiro de Lucinda

Coordenador do Programa de Pós-Graduação em Economia Aplicada 
André Ribeiro Cardoso

\section{Estudo da disposição a pagar por eficiência energética: o caso dos refrigeradores no Brasil}

Versão Corrigida. A original encontra-se disponível na FEA-RP/USP

Dissertação apresentada ao Programa de Pós-Graduação em Economia - Área de Concentração: Economia Aplicada, da Faculdade de Economia, Administração e Contabilidade de Ribeirão Preto da Universidade de São Paulo, para obtenção do título de Mestre em Ciências.

Universidade of São Paulo - USP

Orientador: Prof. Dr. Cláudio Ribeiro de Lucinda

Ribeirão Preto

2015 


\section{Autorizo a reprodução e divulgação total ou parcial deste}

trabalho, por qualquer meio convencional ou eletrônico, para fins de estudo e pesquisa, desde que citada a fonte.

\section{Ficha Catalográfica}

André Ribeiro Cardoso

Estudo da disposição a pagar por eficiência energética: o caso dos refrigeradores no Brasil

Versão Corrigida. A original encontra-se disponível na FEA-RP/USP -

Ribeirão Preto, 2015

116 p. : il.; $30 \mathrm{~cm}$.

Orientador: Prof. Dr. Cláudio Ribeiro de Lucinda

Dissertação de Mestrado - Universidade of São Paulo - Faculdade de Economia, Admnistração e Contabilidade - FEA/USP - Campus Ribeirão Preto; Departamento de Economia

Programa de Pós-Graduação em Economia; Área de Concentração: Economia Aplicada, 2015.

1. Logit Condicional. 2. Mixed Logit 3. Demanda por Eletrodomésticos. 4. Eficiência Energética.

I. Orientador: Prof. Dr. Cláudio Ribeiro de Lucinda. II. Universidade of São Paulo - USP - Campus Ribeirão Preto. III. Faculdade de Economia, Administração e Contabilidade. IV. Estudo da Disposição a Pagar por Unidade de Eficiência Energética: O caso dos Refrigeradores no Brasil 


\title{
Estudo da disposição a pagar por eficiência energética: o caso dos refrigeradores no Brasil
}

\author{
Versão Corrigida. A original encontra-se disponível na FEA-RP/USP \\ Dissertação apresentada ao Programa de \\ Pós-Graduação em Economia - Área de Con- \\ centração: Economia Aplicada, da Faculdade \\ de Economia, Administração e Contabilidade \\ de Ribeirão Preto da Universidade de São \\ Paulo, para obtenção do título de Mestre em \\ Ciências.
}

Trabalho Aprovado. Ribeirão Preto, 17 de Junho de 2015

Prof. Dr. Cláudio Ribeiro de

Lucinda(Orientador)

Universidade de São Paulo

Prof. Dr. Cristian Huse

Escola de Economia de Estocolmo

Prof. Dr. Daniel Domingues dos

Santos

Universidade de São Paulo

Ribeirão Preto

2015 


\section{Agradecimentos}

Eu acredito que tudo na vida tem um momento certo para acontecer, e que nada ocorre por puro acaso. Não foi o acaso que me fez, após um bom período de tempo, voltar aos estudos, à vida acadêmica. Também não foi o acaso que me fez vir a Ribeirão Preto, nesta época, conhecer os professores que conheci e poder fazer parte da melhor turma que eu poderia desejar. Agradeço a Deus, acima de tudo, por esta oportunidade e por tudo o que vivenciei nesses últimos 27 meses.

Acredito também que todas as pessoas passam por nossas vidas por um motivo. algumas se demoram mais, e tornam nossa caminhada mais fácil e simples. Outras nos trazem desafios e nos fazem crescer rapidamente. Outras simplesmente se tornam como parte da família, no convívio, na confidencialidade, no trabalho quase que diário e contínuo. Sou grato por ter encontrado bons amigos entre os professores e entre os colegas de turma aqui em Ribeirão.

Agradeço também aos meus amigos de turma, sem os quais eu jamais poderia ter vivido um momento tão bom e agradável nesses últimos anos. Por todas as vezes que agüentaram minhas perguntas infinitas em aula, por todas as vezes que me apoiaram, por todas as discussões que tivemos em aula, e que mostravam o quanto crescíamos, juntos. Muito obrigado, turma de 2013! Principalmente pela companhia e pela união e amizade.

Agradeço também, em especial, ao professor Cláudio Lucinda. Sem seus conselhos, sua orientação, sua ajuda e parceria, eu não poderia ter chegado tão longe, nem aprendido tanto quanto aprendi. Cada conversa, cada discussão, cada café ou almoço juntos se tornaram uma fonte de motivação para que eu tivesse forças para continuar trabalhando.

Agradeço também em especial ao Cristian Huse por todo o apoio, conselho e ajuda nestes últimos meses. Nada disto seria possível sem sua ajuda. Obrigado também pela ajuda com as bases de dados.

Obrigado em especial à Fundação Getúlio Vargas/IBRE pela disponibilização das bases de dados de preços, sem as quais este trabalho seria muito mais limitado. Obrigado também ao professor Cristian pela intermediação e ajuda.

Agradeço em especial aos professores ligados ao CEPER, principalmente ao professor Rudinei, pela oportunidade que tive de trabalhar neste grupo de estudos e aprender tanto nesses últimos meses.

Agradeço aos professores Daniel, Sakurai e Elaine pela força que me deram em vários momentos desta jornada. Agradeço também o professor Kannebley pela oportunidade de trabalhar com as monitorias de econometria, com as quais aprendi muito ao 
mesmo tempo em que ensinei.

Em especial, agradeço à Gabi pelas inúmeras e incontáveis vezes em que me apoiou, em que me deu forças e motivação para continuar. Jamais poderia ter chegado aqui sem a sua ajuda e a sua inspiração, principalmente nos momentos mais difíceis.

Agradeço também à minha família pela apoio e suporte incondicional, mesmo que esta aventura, por vezes, parecesse sem sentido no começo.

Agradeço por fim, à minha mãe, sem a qual nenhum dos meus sonhos jamais poderia ter sido realizado. 
"If I have seen further, it is only by standing on the shoulders of giants" (Isaac Newton)

"Tell me, and I'll forget.

Show me, and I may remember. But involve me, and I'll understand" (Xunzi, Chinese Confucian philosopher)

"Shounen yo shinwa ni nare"

(Hidetoshi Sato) 


\section{Resumo}

CARDOSO, A. R. Estudo da Disposição a Pagar por Unidade de Eficiência Energética: O caso dos Refrigeradores no Brasil. Dissertação (Mestrado) - Universidade de São Paulo, 2015 .

O presente trabalho pretende estudar a disposição a pagar do consumidor brasileiro por produtos com maior eficiência energética. Entender o quanto o consumidor está disposto a pagar por um ganho de eficiência pode contribuir na elaboração de políticas públicas para o setor elétrico, e na criação de incentivos à indústria para produção e investimentos neste tipo de tecnologia. O trabalho utiliza-se de uma pesquisa de campo sobre posse de equipamentos e hábitos de uso, realizada pela Eletrobrás/Procel em 2005. A metodologia empregada segue a linha de trabalhos já realizados em outros países, a exemplo dos estudos realizados por Dubin e McFadden (1984) e Sammer e Wüstenhagen (2006). Os resultados encontrados apontam para uma subestimação dos consumidores quanto à avaliação da economia proporcionada por produtos mais eficientes. Sendo assim, abre-se espaço para campanhas de conscientização e valorização dessas tecnologias ou incentivos monetários para consumo dos mesmos.

Palavras-chave: Modelos de Demanda Mixed Logit. Demanda de Eletrodomésticos. Eficiência Energética. 


\section{Abstract}

CARDOSO, A. R. Willigness to Pay for more Efficient Energy-Saver Household Appliances: the Case of Refrigerators in Brazil. Dissertação (Mestrado) — University of São Paulo, 2015.

The focus of this research is to investigate the Brazilian consumer's willingness to pay for products with more energy efficiency. Measuring how much the consumer is willing to pay could provide us with good insights that may help in discussing politics regarding the electric sector, plus it may guide politics in taking actions and decisions on incentives in order to promote this kind of more efficient technological products. This investigation is based on a field research regarding the possess of appliances and their uses, consisting of 4310 household questionnaires. The methodology applied follows previous work on this field and similar studies made for other countries. Examples are Dubin e McFadden (1984) for space and water heating in the USA and Sammer e Wüstenhagen (2006) for washing machines in the Switzerland. The results make clear an underestimation of the monetary economy due to the use of more efficient products. Therefore, there's an opportunity for the government to motivate and promote this kind of technology, either through advertising for and awareness of the general population, or through subsides to the industry to produce more efficient products or monetary incentives for the their purchases.

Key-words: Mixed Logit Demand Models. Appliance Demand. Energetic Efficiency. 


\section{Lista de ilustrações}

Figura 1 - Número de Domicílios por Classe de Renda e Consumo Energético . . . 36

Figura 2 - Número de Aparelhos Comprados por Classe de Renda . . . . . . . . . 37

Figura 3 - Número de Aparelhos Comprados por Classe de Renda . . . . . . . . . 37

Figura 4 - Pretensão de Compra de Aparelhos Comprados por Classe de Renda . 38

Figura 5 - Pretensão de Compra de Aparelhos Comprados por Classe de Renda . 39 


\section{Lista de tabelas}

Tabela 1 - Penetração dos Principais Eletrodomésticos e Eletroeletrônicos . . . . . 18

Tabela 2 - Consumo Médio de um aparelho Refrigerador . . . . . . . . . . . . . 18

Tabela 3 - Evolução do Consumo Médio de aparelhos Refrigeradores . . . . . . . . 18

Tabela 4 - Número de Domicílios por Classe de Renda e Consumo Energético . . 36

Tabela 5 - Consumidor utilizou a informação do Selo Procel para decidir sobre a última compra de Refrigerador . . . . . . . . . . . . . . . . . 40

Tabela 6 - Entrevistado conhece o Selo de Eficiência Energética da Procel . . . . . 40

Tabela 7 - Entrevistado sabe o que o significa o Selo da Procel . . . . . . . . . . 41

Tabela 8 - Resumo das Principais Características Observadas . . . . . . . . . 50

Tabela 9 - Modelos de Preços Hedônicos . . . . . . . . . . . . . . . . . . 52

Tabela 10 - Resumo Refrigeradores: Preço Médio por Característica . . . . . . . . . 53

Tabela 11 - Modelos Logit Condicional: Variáveis Alternative-Specific Contínuas . . 56

Tabela 12 - Modelos Logit Condicional: Inclusão de Alternative-Specific Discretas . 58

Tabela 13 - Modelos Mixed Logit . . . . . . . . . . . . . . . . . . . 60

Tabela 14 - Cálulo do Valor Presente do Fluxo de Economia de Energia . . . . . . 61

Tabela 15 - Disposição a Pagar por unidade de Eficiência Energética de Refrigeradores............................... 62

Tabela 16 - Descrição de Modelos Brastemp presentes na base PPH/Procel de 200571

Tabela 17 - Descrição de Modelos Consul presentes na base PPH/Procel de 2005 • 72

Tabela 18 - Descrição de Modelos Electrolux/Prodóscimo presentes na base PPH/Procel de 2005 . . . . . . . . . . . . . . . . . . . . . . 72

Tabela 19 - Descrição de Outros Modelos presentes na base PPH/Procel de 2005 • 72

Tabela 20 - Modelos Logit Condicional . . . . . . . . . . . . . . . . 73

Tabela 21 - Modelos Logit Condicional . . . . . . . . . . . . . . . . . . . . 74

Tabela 22 - Modelos Logit Condicional . . . . . . . . . . . . . . . . . 75

Tabela 23 - Modelos Logit Condicional . . . . . . . . . . . . . . . . . 76

Tabela 24 - Modelos Logit Condicional: Inclusão de Alternative-Specific Discretas . 77 


\section{Sumário}

INTRODUÇÃO $\ldots \ldots \ldots \ldots \ldots \ldots \ldots \ldots$

1.1 Os Refrigeradores e a Demanda Residencial por Eletricidade

REVISÃO DA LITERATURA . . . . . . . . . . . . . . . . . 21

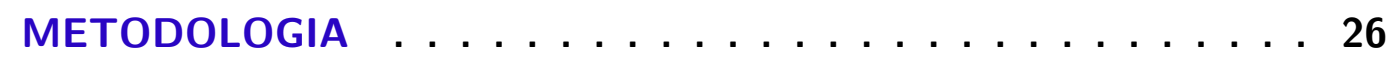

BANCO DE DADOS . . . . . . . . . . . 34 

Mixed Logit . . . . . . . . . . . . . . . . . . . . . . 59

5.3

Medindo a Economia de Energia dos Refrigeradores 60

5.4 Considerações Finais

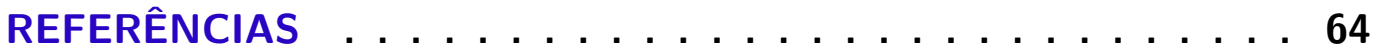

APÊNDICES $\quad 66$

APÊNDICE A - IDENTIFICAÇÃO DOS SKUS . . . . . . . 67

A.0.1 SKUs Identificáveis . . . . . . . . . . . . . . . . 67

A.0.2 SKUs Parcialmente Identificáveis . . . . . . . . . . . 68

A.0.3 SKUs Não Identificáveis . . . . . . . . . . . . . . . . . . . . . 69

APÊNDICE B - TABELAS CONSUMO ENERGÉTICO . . . . . . 71 APÊNDICE C - TABELAS LOGIT MULTINOMIAL . . . . . 73

$\begin{array}{ll}\text { ANEXOS } & 78\end{array}$

ANEXO A - QUESTIONÁRIO PPH/PROCEL $2005 \ldots \ldots$ 
Parte I

Introdução 


\section{Introdução}

O foco deste projeto é o estudo da disposição a pagar do consumidor por produtos com maior eficiência energética, mais especificamente, os refrigeradores domésticos. Este estudo vêm ao encontro das políticas de longo prazo de diversificação e ampliação da matriz energética brasileira, assim como políticas de incentivo ao consumo de bens e produtos mais eficientes.

Nas últimas três décadas, o consumo de energia elétrica no Brasil tem-se acentuado num ritmo mais acelerado que os investimentos de infraestrutura para geração, distribuição e transmissão de eletricidade. Tanto pelos aspectos econômicos diretos, como a redução imediata do consumo de eletricidade e os efeitos sobre a venda e uso de bens eletroeletrônicos, quanto pelos aspectos mais de longo prazo, como os possíveis impactos negativos sobre futuros investimentos que a incerteza do fornecimento de energia pode gerar, o equilíbrio entre oferta e demanda de eletricidade pode ser considerada como fundamental para o bom funcionamento da economia.

Segundo apontou Bardelin (2004), o desequilíbrio entre oferta e demanda de energia não é algo inédito no Brasil. Desde os anos 80, o Brasil passou por duas crises de racionamento de energia localizadas, uma em 1986 na região Sul e outra em 1987 na região Nordeste, além de uma crise mais abrangente em 2001, que levou todas as regiões do país, exceto a Sul, a sofrerem racionamentos de energia.

À época, a oferta de energia elétrica foi seriamente comprometida, o que levou o governo a adotar medidas mais drásticas e urgentes para conter a demanda. Entre essas medidas, figuraram incentivos econômicos e sociais, largamente estudados por Gerard (2013), para estimular a redução do uso da eletricidade, sendo que o racionamento total de energia seria usado somente em última instância.

Dentre as medidas tomadas, destacam-se metas de racionamento para os consumidores residenciais, comerciais e industriais de baixa tensão, que deveriam reduzir entre $10 \%$ e $20 \%$ do consumo médio, a depender da região do país. Metas de racionamento para consumidores industriais de média e alta tensão também foram adotadas, assim como a concessão de bônus para quem cumprisse a meta e a aplicação de penalidades a quem não as cumprisse.

Foi a partir deste contexto de redução do consumo de energia elétrica e pressão para o cumprimento das metas de racionamento que os equipamentos com maior eficiência energética ganharam destaque. Além da obrigatoriedade da redução do consumo de energia, o governo tomou outras medidas, como o aumento das tarifas de eletricidade, políticas de redução de impostos para equipamentos mais eficientes, aumentando impostos 
para os de menor eficiência, além de promover campanhas para ampliar o conhecimento e a conscientização da população sobre os métodos para reduzir o consumo de eletricidade.

Uma medida particularmente importante foi a Lei 10.295 de 17/10/2001 que estabelece, entre outras coisas, os padrões mínimos de eficiência energética e padrões máximos de consumo de energia para equipamentos elétricos. Nesse contexto, o Selo Procel ganha destaque por indicar aos consumidores as categorias de produtos mais eficientes no mercado. Junto às campanhas promovidas pela mídia e governo, da maior adesão de produtos ao Selo Procel, e das campanhas de conscientização e informação realizadas, a eficiência energética dos produtos desde então tornou-se um conceito mais próximo da população em geral.

Além da conscientização do consumidor sobre a questão da eficiência, o ganho real de renda, a partir de 2004, veio dar ao consumidor brasileiro um incentivo extra para a melhoria dos padrões de vida e aquisição de novos eletrodomésticos. Se, por um lado, esse ganho real favoreceu o aumento da demanda por energia, por outro, possibilitou a troca de equipamentos menos eficientes por outros mais eficientes.

Segundo aponta Neri et al. (2008), o aumento das transferências de renda, como expansão do Bolsa-Família e as transferências previdenciárias não contributivas, junto do aumento da renda do trabalho têm contribuído fortemente para a melhora dos rendimentos da população na última década. Em especial, o forte aumento do emprego formal a partir de 2006 veio delinear, segundo Neri, uma "Nova Classe Média", consolidando o aumento da renda familiar per capita com as garantias de manutenção da renda que o trabalho assalariado oferece, e contribuindo para manter o nível de consumo mais elevado.

Neri estima que o aumento da renda real per capita, no período entre Abril de 2004 e Abril de 2008, tenha sido em torno de 6,5\% ao ano, com destaque para o biênio 2004-2005 no qual a renda, calculada pela PNAD, apresentou um crescimento na faixa de 16,4\%. Estes aumentos expressivos na renda elevam o consumo por bens das famílias, e em particular, elevam a demanda por bens duráveis. Associado à maior conscientização da população quanto à questão energética, a demanda por eletrodomésticos mais eficientes aumenta.

De acordo com Bardelin (2004), houve grande procura por equipamentos de maior eficiência energética no período da crise de 2001/2002, e muitos dos consumidores continuaram economizando energia e utilizando os Selos Procel como forma de diferenciar produtos, mesmo após o término do racionamento. No entanto, ao mesmo tempo que houve uma melhora na margem intensiva - pois os eletrodomésticos adquiridos nos últimos anos são bem mais eficientes em termos de consumo do que os mais antigos - houve uma piora na margem extensiva - com uma enorme quantidade de domicílios adquirindo eletrodomésticos pela primeira vez. 
Para além da situação econômico-social crítica proporcionada pelo período de racionamento, a forte estiagem de 2014, com redução drástica de muitos reservatórios importantes, culminando em possíveis períodos de racionamento de água e possibilidades de novos racionamentos de energia, trouxe à tona novamente a relevância de incentivar a economia de energia, de forma a suavizar situações de crises e evitar que novos racionamentos venham a ocorrer.

Todos estes fatores, antigos e recentes, aumentam a importância do presente trabalho, cujo objetivo é mensurar como o consumidor avalia esse ganho de eficiência e quanto está disposto a gastar para adquirir produtos com maior eficiência energética.

Para enfrentar esta questão, o presente trabalho está estruturado em seis seções, sendo que a primeira é a presente introdução. A seção 1.1 explora melhor o campo de estudos e explicita a proposta deste trabalho. A seção 2 contém uma breve revisão da literatura a respeito da demanda por eletricidade e por eletrodomésticos. A metodologia a ser utilizada é definida na seção 3. Apresenta-se também na seção 4 a base de dados a ser utilizada por este trabalho. Por fim, a seção 5 apresenta os resultados e a conclusão do trabalho.

\subsection{Os Refrigeradores e a Demanda Residencial por Eletricidade}

Existem vários fatores que justificam a escolha de refrigeradores nesta pesquisa.

Em primeiro lugar, é um eletrodoméstico amplamente disseminado. A tabela 1, formulada a partir dos dados das PNADs de 2001 a 2009 e 2011 a 2013, e dos Censos de 2000 e 2010, fornecem uma série de informações acerca da penetração de alguns dos principais eletrodomésticos nos domicílios brasileiros. Conforme podemos observar, os Refrigeradores e Televisores, além dos aparelhos de Rádio, estão entre os bens com maior penetração nos domicílios.

Outro motivo importante é a forma de utilização desse bem. Em geral, refrigeradores são utilizados de forma intensiva e permanente dentro dos domicílios, i.e., estão conectados o tempo todo à rede elétrica. Isto faz com que a participação do refrigerador dentro do consumo total de eletricidade do domicílio seja grande. A tabela 2 calcula, ponderando pelos tipos de refrigeradores descritos na PNAD 2005, o consumo médio de um aparelho refrigerador, enquanto que a tabela 3 destaca, com base no consumo médio calculado, a evolução do consumo energético dos refrigeradores nos domicilios brasileiros.

Um outro motivo, igualmente significativo, é que a renovação do estoque de refrigerador se dá em um contexto de maior eficiência energética. Além disso, este bem apresenta um preço médio mais elevado (em torno de $\mathrm{R} \$ 1000,00$ para modelos de 1 porta e cerca de $R \$ 1950,00$ para modelos de 2 portas). 
Tabela 1: Penetração dos Principais Eletrodomésticos e Eletroeletrônicos

\begin{tabular}{lcccccc}
\hline \multicolumn{5}{c}{ Penetração de Eletrodomésticos nos } & Domicílios Particulares Permanentes \\
\hline Ano & Refrigeradores & Freezer & Lavadoras & Televisão & Radio & Microcomputador \\
$\mathbf{2 0 0 0}$ & $84,8 \%$ & - & $33,9 \%$ & $88,2 \%$ & $88,5 \%$ & $11,0 \%$ \\
$\mathbf{2 0 0 1}$ & $85,1 \%$ & $18,7 \%$ & $33,6 \%$ & $89,0 \%$ & $88,0 \%$ & $12,6 \%$ \\
$\mathbf{2 0 0 2}$ & $86,6 \%$ & $18,4 \%$ & $33,9 \%$ & $89,9 \%$ & $87,9 \%$ & $14,2 \%$ \\
$\mathbf{2 0 0 3}$ & $87,3 \%$ & $17,6 \%$ & $34,3 \%$ & $90,0 \%$ & $87,8 \%$ & $15,3 \%$ \\
$\mathbf{2 0 0 4}$ & $87,3 \%$ & $17,1 \%$ & $34,3 \%$ & $90,2 \%$ & $87,7 \%$ & $16,3 \%$ \\
$\mathbf{2 0 0 5}$ & $87,8 \%$ & $16,7 \%$ & $35,6 \%$ & $91,2 \%$ & $87,9 \%$ & $18,5 \%$ \\
$\mathbf{2 0 0 6}$ & $89,0 \%$ & $16,4 \%$ & $37,3 \%$ & $92,9 \%$ & $87,8 \%$ & $22,0 \%$ \\
$\mathbf{2 0 0 7}$ & $90,6 \%$ & $16,3 \%$ & $39,2 \%$ & $94,3 \%$ & $88,0 \%$ & $26,5 \%$ \\
$\mathbf{2 0 0 8}$ & $92,0 \%$ & $16,1 \%$ & $41,5 \%$ & $95,0 \%$ & $88,9 \%$ & $31,2 \%$ \\
$\mathbf{2 0 0 9}$ & $93,3 \%$ & $15,3 \%$ & $44,4 \%$ & $95,6 \%$ & $87,8 \%$ & $34,7 \%$ \\
$\mathbf{2 0 1 0}$ & $93,7 \%$ & - & $47,3 \%$ & $95,1 \%$ & $81,4 \%$ & $38,3 \%$ \\
$\mathbf{2 0 1 1}$ & $95,8 \%$ & $16,4 \%$ & $51,0 \%$ & $96,9 \%$ & $83,5 \%$ & $42,9 \%$ \\
$\mathbf{2 0 1 2}$ & $96,7 \%$ & $16,7 \%$ & $55,2 \%$ & $97,2 \%$ & $80,9 \%$ & $46,4 \%$ \\
$\mathbf{2 0 1 3}$ & $97,2 \%$ & $17,0 \%$ & $57,5 \%$ & $97,2 \%$ & $75,7 \%$ & $48,9 \%$ \\
\hline
\end{tabular}

Fonte: PNAD/Censo, elaboração própria

Tabela 2: Consumo Médio de um aparelho Refrigerador

\begin{tabular}{lcc}
\hline & Penetração (\%) & $\begin{array}{c}\text { Consumo Médio } \\
\text { (kwh/mês) }\end{array}$ \\
\hline Refrigerador de 1 Porta & $70,2 \%$ & 24,4 \\
Refrigerador de 2 Portas & $17,6 \%$ & 53,2 \\
\hline Refrigerador Médio & $87,8 \%$ & 26,5 \\
\hline Fonte: PNAD, elaboração própria &
\end{tabular}

Tabela 3: Evolução do Consumo Médio de aparelhos Refrigeradores

\begin{tabular}{cccc}
\hline Ano & 1 Porta & 2 Portas & Consumo Médio \\
\hline $\mathbf{2 0 0 1}$ & $72,4 \%$ & $12,8 \%$ & 24,5 \\
$\mathbf{2 0 0 2}$ & $73,0 \%$ & $13,5 \%$ & 25,0 \\
$\mathbf{2 0 0 3}$ & $72,5 \%$ & $14,8 \%$ & 25,5 \\
$\mathbf{2 0 0 4}$ & $71,8 \%$ & $15,5 \%$ & 25,8 \\
$\mathbf{2 0 0 5}$ & $70,2 \%$ & $17,5 \%$ & 26,5 \\
$\mathbf{2 0 0 6}$ & $69,7 \%$ & $19,4 \%$ & 27,3 \\
$\mathbf{2 0 0 7}$ & $68,7 \%$ & $21,8 \%$ & 28,4 \\
$\mathbf{2 0 0 8}$ & $66,7 \%$ & $25,3 \%$ & 29,7 \\
$\mathbf{2 0 0 9}$ & $65,8 \%$ & $27,5 \%$ & 30,7 \\
$\mathbf{2 0 1 1}$ & $63,3 \%$ & $32,5 \%$ & 32,7 \\
$\mathbf{2 0 1 2}$ & $60,2 \%$ & $36,5 \%$ & 34,1 \\
$\mathbf{2 0 1 3}$ & $58,2 \%$ & $39,0 \%$ & 35,0 \\
\hline
\end{tabular}

Fonte: PNAD, elaboração própria 
Finalmente, o avanço tecnológico no setor de refrigeradores foi mais sutil do que em outros segmentos, como televisores. Segmentos com grandes mudanças tecnológicas criam questões adicionais de comparatibilidade de dados que aqui não se apresentam. A seguir, iremos rever a literatura teórica e empírica com a que a presente dissertação se relaciona. 
Parte II

\section{Literatura}




\section{Revisão da Literatura}

\subsection{Revisão Bibliográfica}

O processo de aquisição de um bem eletrodoméstico consiste não apenas da decisão de compra em si, na qual já se leva em consideração as características desejáveis do produto (capacidade, eficiência, versatilidade, preços, etc), mas também da expectativa de uso futuro do equipamento, ou seja, a intensidade de uso desejada e, com isto, os fatores que derivam da sua utilização (custo da eletricidade corrente e futura ou custo de outro combustível utilizado ${ }^{1}$ ). O problema, então, resume-se à combinação de uma escolha discreta (compra do aparelho) e de uma escolha contínua (intensidade de uso). Este trabalho focará a decisão de compra (parte discreta) dos consumidores. Sobre a parte contínua, as hipóteses que definiremos mais adiante devem tornar esta questão menos relevante para a decisão de compra de refrigeradores, permitindo a análise da decisão dsicreta, mesmo sem o estudo da parte contínua.

Estamos, então, interessados em responder à questão de como o consumidor realiza o processo de compra e como ele avalia o ganho de eficiência energética na decisão de compra de novos refrigeradores. A literatura sobre a disposição a pagar por produtos mais eficientes está intrinsicamente ligada às campanhas sobre conscientização do consumo de energia, racionalização das fontes de energia renováveis e à necessidade de promover uma mudança nos padrões de consumo e comportamento dos consumidores.

Neste contexto, a introdução de etiquetas com informação de consumo energético e/ou nível de eficiência, juntamente das campanhas de promoção destas ações vieram a ampliar o conhecimento dos consumidores acerca da necessidade de se observar nos produtos o nível de consumo dos mesmos (HEINZLE; WÜSTENHAGEN, 2009; MILLS; SCHLEICH, 2010). Os trabalhos apresentados nesta seção discorrerão sobre como a maior conscientização dos consumidores, seja por meio de selos e etiquetas de eficiência, ou outros meios, moldaram o comportamento dos consumidores de forma que estes passassem a considerar as questões de consumo energético nas suas decisões de compra.

As etiquetas com informações de consumo energético podem ser vistas como uma forma de transpor barreiras informacionais e reduzir custos de coletas de informações ou "search costs" (MILLS; SCHLEICH, 2010; SUTHERLAND, 1991). Assim, as etiquetas funcionam como um mecanismo informativo para conscientizar os consumidores dos níveis de eficiência dos equipamentos. No entanto, Mills e Schleich (2010) propõem que a efe-

$\overline{1}$ Muitos trabalhos relacionam o uso de gás liquefeito de petróleo (GLP) para a obtenção de energia, usada para o aquecimento de ambientes e/ou aquecimento de água 
tividade dos selos de eficiência no sentido de conscientizar os consumidores a escolherem produtos tecnologicamente mais eficientes pode ser medida por meio de dois fatores: em primeiro lugar, é necessário que os consumidores estejam conscientes da existência do selo e de sua forma de classificação energética; e em segundo lugar, é preciso que o utilizem efetivamente na decisão de compra.

Se as etiquetas de eficiência servem para informar e guiar os consumidores para o consumo de bens mais eficientes, a mudança na escala usada na classificação energética pode vir a tornar a interpretação das etiquetas mais complexa. Heinzle e Wüstenhagen (2009) procuram investigar o efeito das duas formas de classificação energética vigentes em 2009 na união européia sobre a decisão de compra de televisores. Relatam que a forma tradicional de classificação (com letras, de A a G) tem um impacto superior à nova escala $(\mathrm{A}, \mathrm{A}+, \mathrm{A}++)$. Mensuram também o impacto em termos de disposição a pagar, de acordo com cada escala de classificação.

O trabalho de Ward et al. (2011b) mostra como a introdução de selos atestando a eficiência energética de um refrigerador influencia a decisão de compra do agente. Relatam que consumidores estão dispostos a pagar entre US\$249,82 a US\$ 349,30 a mais por um refrigerador mais eficiente que tenha recebido o selo Energy Star ${ }^{2}$. Segundo os autores, esta mudança de atitude está relacionada não apenas aos ganhos privados de redução de gastos com eletricidade, mas também em parte relaciona-se a questões ambientais e benefícios públicos decorrente do menor consumo energético. Em outro trabalho semelhante, Ward et al. (2011a) encontram evidências que os consumidores têm uma disposição a pagar positiva em relação a produtos que são manufaturados por fabricantes associados a questões ambientais e de energia limpa.

Murray e Mills (2011) examinam os fatores associados ao maior ou menor conhecimento dos selos de eficiência, e os fatores ligados à compra de produtos com certificação da Energy Star. Eles encontram que características familiares têm maior associação com o conhecimento dos selos do que com a escolha dos bens de maior eficiência.

O trabalho de Sammer e Wüstenhagen (2006), em particular, procura investigar o impacto das etiquetas de eficiência energética introduzidas em produtos na Suíça, decorrente das novas normas da União Europeia. Eles comparam o impacto das novas etiquetas ('eco-labels') com outras características dos produtos (marca, preços, etc) e estudam como a introdução dos selos de eficiência influenciaram a decisão de compra do consumidor para dois bens em específico (lâmpadas e máquinas de lavar). Já o trabalho de Gerard (2013) estuda os impactos da política de redução de energia adotada no Brasil durante a crise energética de 2001/2002, tomando como foco o papel dos incentivos econômicos e dos incentivos sociais associados ao programa governamental. Ele estima que os incentivos so-

2 Energy Star é um padrão internacional para o consumo eficiente de energia, originado nos Estados Unidos 
ciais, em particular, tiveram grande importância na redução do consumo de eletricidade e, principalmente, na mudança de comportamento do consumidor brasileiro quanto ao consumo de energia.

Baseados no mercado norte-americano, Banerjee e Solomon (2003) estudam e avaliam os cinco maiores programas de classificação energética e seus respectivos selos de eficiência. Dentre os resultados encontrados, indicam que etiquetas de eficiência do tipo "selo de aprovação" por serem mais claros e diretos na transmissão da informação acabam por se tornar mais eficientes em informar os consumidores do que etiquetas repletas de dados e informações gerais. Segundo os autores, poucos consumidores conseguem entender a linguagem técnica e/ou estão interessados em fazê-lo. Destacam também a importância de campanhas de promoção para disseminar a existência e a utilização dos selos de eficiência, além de recomendarem a criação de incetivos junto aos produtores para a promoção e fabricação de produtos mais eficientes.

A introdução dos selos de eficiência e sua correspondente promoção trouxe aos consumidores uma nova fonte de informação, de modo que pudessem utilizá-los como insumo para suas decisões de compra. No Brasil, o Selo Procel foi amplamente promovido após a crise de racionamento energético de 2001/2002, e da Lei 10.295/2001 sobre a fixação de padrões mínimos de eficiência energética. Além de informar aos consumidores uma classificação (de A a F), representando o nível de consumo, os selos trazem consigo informações acerca do próprio nível de consumo energético.

Este trabalho está baseado na premissa de que os consumidores podem obter informações acerca dos respectivos consumos energéticos, seja através dos próprios selos de eficiência, seja através de outras fontes de informação, e que, de posse desses dados, podem decidir sobre a questão da compra de bens mais eficientes. Assim, ao analisarmos a disposição a pagar por unidade de eficiência energética, estamos ao mesmo tempo analisando o quanto o consumidor internalizou a importância da redução de consumo de energia, e a efetividade das políticas de etiquetagem e de promoção das tecnologias mais eficientes.

\subsection{Energy Paradox}

Apesar de equipamentos mais modernos e eficientes apresentarem uma relação custo-benefício favorável, a literatura econômica reporta uma série de casos em que a difusão dessas tecnologias se faz de forma muito aquém do esperado. Assim, os consumidores tendem a aderir de forma mais lenta e gradual a novas tecnologias mais eficientes, mesmo que elas forneçam um ganho de utilidade significativo. Este problema é conhecido na literatura como energy paradox ou energy gap.

Jaffe e Stavins (1994) indica algumas possíveis causas para este aparente paradoxo. 
Em primeiro lugar, sugere que possa haver falhas de mercado, como a falta de informação sobre as inovações tecnológicas. Argumentam que é custoso aos agentes buscarem por inovações, e aprenderem o bastante a respeito a ponto de notarem o ganho econômico de adotá-las. Outra falha possível seria associada ao problema de agente/principal. Neste caso, o agente que toma as decisões de aquisição dos aparelhos pode ser diferente dos agentes que se utilizam do mesmo, o que pode distorcer os incentivos na compra de produtos mais modernos e eficientes.

Segundo Sutherland (1991), os consumidores ainda podem se deparar com preços muito baixos, que explicam seu desinteresse em optar por tecnologias mais eficientes. Neste quesito se enquandram, como comentam Jaffe e Stavins (1994), os preços de eletricidade e gás natural, os quais são precificados pelo custo médio de produção, e impõem ao consumidor um custo marginal constante, o que pode desincentivar o uso consciente de energia. Além disso, subsídios ao setor energético podem baixar ainda mais os preços, também desincetivando o consumo consciente.

Outra possível causa desse energy gap são possíveis custos de aprendizado e adaptação às novas tecnologias. Os agentes também podem ser mais avessos às novas tecnologias, apresentado altas taxas de desconto implícitas, justamente por serem investimentos em certa medida irreversíveis, com payback incerto ou ainda por não conseguirem precificar corretamente os preços futuros de energia (JAFFE; STAVINS, 1994).

Por último, Jaffe e Stavins (1994) citam que, mesmo que a adoção dessas tecnologias seja, em média, econômicamente viável e eficiente, as mesmas tecnologias não o são para todos os consumidores. Num modelo com heterogeneidade de consumidores, podem haver aqueles para os quais não é lucrativo a aquisição dos equipamentos mais modernos e eficientes.

Outros trabalhos que enfatizam esta questão do energy gap são Allcott e Wozny (2014), investigando mercado de automóveis, e Sallee, West e Fan (2011) que investigam leilões de carros usados. Estes últimos encontram que os consumidores conseguem prever adequadamente os ganhos de eficiência dos veículos leiloados. No caso de subvalorização dos gastos com consumo energético, abre-se espaço para políticas de incentivos aos consumidores e à indústria, de forma a tornar as tecnologias mais eficientes mais acessíveis aos consumidores, e ampliar a conscientização destes acerca da importância do uso racional de energia. 


\section{Parte III}

Metodologia e Bases de Dados 


\section{Metodologia}

\subsection{O Processo de Escolha do Produto}

A compra de um eletrodoméstico, envolve a escolha de um bem entre outras alternativas de consumo. O consumidor pode optar por consumir um bem $x$ por um dado preço, ou outro bem substituto (caso disponível), ou ainda pode optar por não consumir esse tipo de produto (vindo a gastar sua renda em outros bens). $\mathrm{Na}$ análise de disposição a pagar, em teoria, tanto o consumidor que efetivamente realizou a compra, quanto o consumidor que deixou de fazê-la, seja por questão de preços ou gosto pessoal (decorrente das características do produto não satisfatórias), ambos os consumidores são importantes para que tenhamos uma medida mais exata do quanto o consumidor valora um certo produto.

Em termos práticos, no entanto, para os consumidores que deixaram de efetivamente realizar a compra, somente uma pesquisa baseada em preferências declaradas nos revelaria informações úteis sobre sua disposição a pagar. Usualmente, observamos as compras efetivadas (preferências reveladas) e nem sempre dispomos, conjuntamente, de declarações sobre possíveis compras não realizadas.

No caso de bens duráveis, como já citado anteriormente, a demanda surge a partir do conjunto de serviços e utilidades que a posse dos aparelhos oferece. Assim, a utilidade provida por um bem durável é mais bem caracterizada como uma função utilidade indireta. Além disso, a decisão de compra ainda envolve uma escolha entre um número de alternativas de bens similares. Logo, cada bem apresentará um conjunto de características específicas e, portanto, o nível de utilidade auferido deve variar de acordo com as especificações de cada eletrodoméstico.

Dessa forma, o problema do consumidor pode ser reduzido à maximização de uma função de utilidade (indireta) de modo a obter o serviço de que precisa de um eletrodoméstico, dentre um conjunto de modelos de produtos disponíveis. Hanemann (1984) formula o problema a partir de uma função utilidade da seguinte maneira: suponha que os consumidores tenham uma função utilidade sobre bens duráveis $u(x, b, z, s)$ e que devem decidir qual bem $x_{1}, \ldots, x_{n}, z$ comprar e qual a intensidade de uso. Por questões de padronização, seja $z$ o bem numerário, i.e., $P_{z}=1$.

A utilidade de um bem pode ainda depender de outros fatores, como os atributos específicos de cada bem $b_{1}, \ldots, b_{n}$, ou ainda características e gostos dos próprios consumidores, representado por um vetor de características $s$. Por simplificação, vamos considerar 
que um bem oferece alguma utilidade somente se ele for comprado. Assim, temos

$$
x_{j}=0 \Rightarrow \partial u / \partial b_{j}=0
$$

Isto significa que o consumidor somente pode usufruir das características do produto caso o compre e o consuma $\left(x_{j}>0\right)$. Esta propriedade é conhecida como "weak complimentary". A escolha do bem $(x, z)$ está sujeita a uma restrição orçamentária:

$$
\sum_{i} P_{i} x_{i}+P_{z} z=y \Rightarrow \sum_{i} P_{i} x_{i}+z=y
$$

com as restrições adicionais:

$$
x_{j} \geq 0, z \geq 0
$$

Uma hipótese adicional que impõe-se é que o consumidor pode escolher somente um bem em cada decisão de compra. Isto é o mesmo que dizer que os bens são mutuamente exclusivos. Uma forma alternativa de entender esta premissa é assumir que o consumidor prefere escolher somente uma opção. Note que isto não impede que um mesmo indivíduo compre mais de um bem, mas define que, para a compra de cada um dos bens, o indivíduo enfrenterá a mesma decisão de escolha, considerando sua propensão a ter ou não a posse de mais de um aparelho. Com estas hipóteses e supondo que a função utilidade seja linear ou côncava, temos o caso de bens substitutos. Matematicamente, expressamos esta hipótese adicional como:

$$
x_{i}>0 \Rightarrow x_{j}=0, \forall j \neq i
$$

Portanto, conforme aponta Hanemann (1984), a escolha de $x_{j}$ implica uma decisão ao mesmo tempo discreta e contínua. A escolha discreta consiste na decisão de qual bem $x_{j}$ será escolhido, isto é, dentre $j=1, \ldots, n$, o consumidor decide quais bens não serão comprados $\left(x_{j}=0\right)$ e qual será o único escolhido $\left(x_{j}>0\right)$. A parte contínua depende da magnitude de $x_{j}$, ou seja, $x_{j}$ mede diretamente a intensidade de uso do aparelho (demanda por eletricidade). Dada a premissa de que a intensidade de uso não deve se alterar após a compra, a própria decisão do modelo $x_{j}$ a ser comprado e, portanto, do consumo que este modelo energético tem, contém a decisão sobre a parte contínua,i.e., sobre o consumo futuro esperado de eletricidade. 


\subsection{Random Utility Models}

Um modelo de utilidade aleatória é definido como um modelo em que, embora seja determinista para o consumidor em si, não o é para o pesquisador. Posto de outra forma, deve haver algumas características do consumidor que, para ele são observáveis e determinadas, mas que para o pesquisador são componentes não observáveis e, portanto, são tratadas como variáveis aleatórias. Incluímos este componente no modelo como uma variável $\epsilon$ com densidade conjunta $f_{\epsilon}\left(\epsilon_{1}, \ldots, \epsilon_{m}\right)$.

Admitimos, por construção, que a função utilidade indireta é quase-convexa, e podemos calculá-la como

$$
v_{i}\left(p_{i}, b_{i}, y, s, \epsilon\right)=u_{i}\left(x\left(p_{i}, b_{i}, y, s, \epsilon\right), b_{i}, z\left(p_{i}, b_{i}, y, s, \epsilon\right), s, \epsilon\right)
$$

sendo $x\left(p_{i}, b_{i}, y, s, \epsilon\right)$ e $z\left(p_{i}, b_{i}, y, s, \epsilon\right)=y-x\left(p_{i}, b_{i}, y, s, \epsilon\right)$ as demandas condicionais dos bens $x$ e $z$. Sendo a utilidade indireta $v_{i}$ quase-convexa e decrescente em $p_{i}$, podemos recuperar a demanda pelo bem $i$ pela identidade de Roy como segue:

$$
x\left(p_{i}, b_{i}, y, s, \epsilon\right)=-\frac{\partial v_{i}\left(p_{i}, b_{i}, y, s, \epsilon\right) / \partial p_{i}}{\partial v_{i}\left(p_{i}, b_{i}, y, s, \epsilon\right) / \partial y}
$$

Podemos então definir a escolha de qual bem comprar como uma escolha binária, definindo as variáveis indicativas $\delta_{1}, \ldots, \delta_{n}$, tal que

$$
\delta_{i}= \begin{cases}1 & \text { se } x_{i}>0 \\ 0 & \text { se } x_{i}=0\end{cases}
$$

Juntando com a hipótese de que a escolha de $x_{i}>0$ advém da decisão de comprar (somente) o bem $x_{i}$ e que esta decisão foi gerada a partir de uma maximização de utilidade, podemos simplificar o problema acima escrevendo $\delta_{i}$ como função das utilidades condicionais indiretas:

$$
\delta_{i}(p, b, y, s, \epsilon)= \begin{cases}1 & \text { se } v_{i}\left(p_{i}, b_{i}, y, s, \epsilon\right)>v_{j}\left(p_{j}, b_{j}, y, s, \epsilon\right) \\ 0 & \text { caso contrário }\end{cases}
$$

A esperança da variável indicativa $\delta_{i}$ pode ser entendida como a probabilidade de se escolher o bem $i$ dentre todas as alternativas possíveis, isto é:

$$
E\left[\delta_{i}\right]=\operatorname{Pr}\left\{v_{i}\left(p_{i}, b_{i}, y, s, \epsilon\right)>v_{j}\left(p_{j}, b_{j}, y, s, \epsilon\right), \forall j \neq i\right\}
$$


Logo, podemos escrever a demanda incondicional $x$ como um produto da probabilidade de se escolher o bem $i$ pelo valor $x_{i}$ :

$$
x(p, b, y, s, \epsilon)=\delta_{i}(p, b, y, s, \epsilon) * x\left(p_{i}, b_{i}, y, s, \epsilon\right)
$$

De forma mais geral, podemos expressar a demanda por eletricidade como:

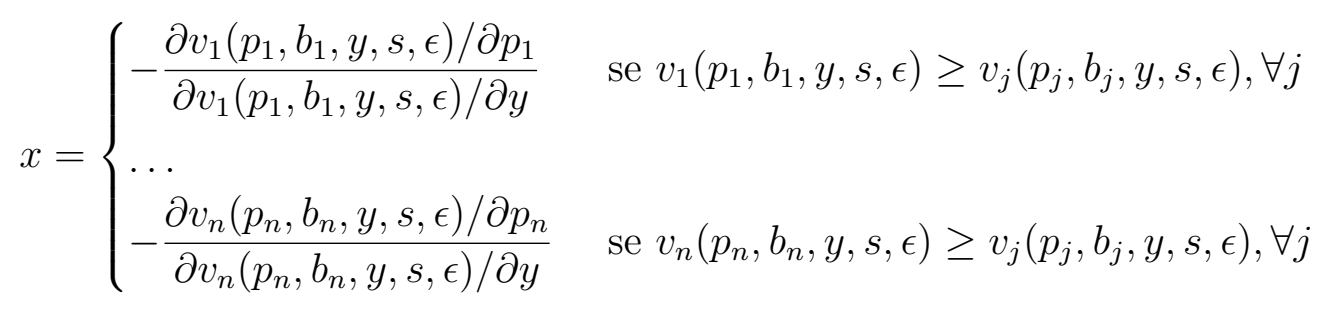

Hanemann (1984) cita este tipo de modelo mais geral como um exemplo de uma classe de modelos conhecidos como switching regression model, uma vez que a demanda da parte contínua depende de como escolhemos a parte discreta, i.e., a demanda exata por eletricidade depende do resultado da maximização da utilidade do problema da escolha discreta.

Uma vez que o uso de refrigeradores se faz de forma permanente e contínua, e que a grande maioria dos consumidores já possuíam um refrigerador e, portanto, o processo de compra neste caso é um processo de troca de aparelho, assumiremos a hipótese de que o hábito de uso dos refrigeradores não deve mudar em decorrência da compra (troca) do novo equipamento.

Sendo assim, hábitos de utilização e outros fatores (não-observados) que alterem de modo significativo a intensidade de uso no dia a dia permanecerão constantes após a compra. Logo, a decisão de escolha do aparelho (parte discreta) já inclui em si a otimização do uso futuro (parte contínua), o que justifica o foco deste trabalho somente na decisão de compra, ou seja, o foco na função utilidade.

\subsection{Logit Condicional}

Para a abordagem prática do nosso problema em questão, no qual o indivíduo deve tomar uma decisão de compra baseado num conjunto de alternativas possíveis, resolvemos partir de um modelo de escolha binária do tipo Logit Condicional, segundo a linha adotada por McFadden (1974) e Dubin e McFadden (1984).

Na linha de modelos multinomiais, o modelo Logit Condicional talvez seja um dos casos mais genéricos por permitir tanto regressores do tipo Alternative Specific, que variam com cada alternativa, quanto regressores do tipo Case Specific, que variam somente com 
o indivíduo. Um modelo de probabilidades logit condicional, segundo Greene (2008) e Cameron (2005), pode ser representado por:

$$
p_{i j}=\operatorname{Pr}\left[y_{i}=j\right]=\frac{\mathrm{e}^{\left(x_{i j}^{\prime} \beta+\sum_{k=1}^{m} d_{i j k} w_{i}^{\prime} \gamma_{j}\right)}}{\sum_{l=1}^{m} \mathrm{e}^{\left(x_{i l}^{\prime} \beta+\sum_{k=1}^{m} d_{i l k} w_{i}^{\prime} \gamma_{l}\right)}}, \operatorname{para} \mathrm{j}=1,2, \ldots, \mathrm{m}
$$

em que os regressores $x_{i j}$ representam as variáveis alternative specific, como preço dos bens e outras carascterísticas dos produtos, e os regressores $w_{i}$ são os regressores case specific, como renda e outras condições socio-demográficas ligadas aos indivíduos. Para tornar o modelo compatível com o logit condicional tradicional, que possui somente regressores que variam nas alternativas, é introduzida uma dummy de interação $d_{i j k}$ com as variáveis case specific e que assume o valor 1 caso $k=j$ e zero caso contrário.

A estimação se procede por meio do método de máxima verossimilhança. A partir da decisão de escolha de um indivíduo, montamos a função densidade de probabilidade individual como $f(y)=\prod_{j=1}^{m} p\left(x_{i j}, w_{i j}\right)_{j}^{y}$ e, assumindo independência entre as observações, chegamos à função de log-verossimilhança da densidade conjunta em:

$$
\ln \mathcal{L}=\ln \mathcal{L}(\beta, \gamma)=\sum_{i=1}^{n} \sum_{j=1}^{m} y_{i j} \ln \left(p\left(x_{i j}, w_{i j}\right)\right)
$$

em que $y_{i j}=1$ se $j$ for a opção escolhida pelo indivíduo $i$ e $y_{i k}=0$ para $k \neq j$.

Para calcular o impacto de cada variável $x_{j}$ ou $w_{j}$, podemos proceder à análise dos efeitos marginais. Como nosso interesse neste trabalho se resume à análise da disposição a pagar, que pode ser calculado como $E\left(\beta_{\text {Consumo }} \mid x_{i j}, w_{i j}\right) /\left|\beta_{\text {preço }}\right|$, não desenvolveremos os cálculos do efeito marginal aqui ${ }^{1}$.

Desenvolvendo a equação 3.13, obtemos a seguinte expressão:

$$
\ln \mathcal{L}(\beta, \gamma)=\sum_{i=1}^{n} \sum_{j=1}^{m} y_{i j}\left(\left(x_{i j}^{\prime} \beta+\sum_{k=1}^{m} d_{i j k} w_{i}^{\prime} \gamma_{j}\right)-\ln \left(\sum_{i=1}^{n} \sum_{l=1}^{m} \mathrm{e}^{\left(x_{i l}^{\prime} \beta+\sum_{k=1}^{m} d_{i l k} w_{i}^{\prime} \gamma_{l}\right)}\right)\right)
$$

Dentre as variáveis testadas, temos tanto variáveis do tipo Alternative Specific quanto variáveis do tipo Case Specific. Para averiguarmos os melhores modelos e os fatores que mais influenciam o consumidor na hora da tomada de decisão, começaremos investigar pelos modelos mais simples (somente com alternative specific) e aos poucos vamos acrescentando outros fatores.

As variáveis alternative specific testadas são: consumo energético, preço, volume, índice de eficiência, dummies de marca e forma de degelo e número de portas. Dentre as case specific contínuas, testamos a renda familiar, o nível de consumo total do domicílio, o número de moradores e a quantidade de refrigeradores e de freezeres no domicílio. Dentre

$\overline{1}$ Os efeitos marginais podem ser calculado conforme indicado em Greene (2008) e Cameron (2005) 
as cases discretas, temos peso da conta de luz no orçamento, região do domicílio (luxo, classe média, pobre), região geográfica e área construída.

A partir desta formulação, podemos recuperar a disposição a pagar dos consumidores por um bem, considerando certo atributo deste, simplesmente convertendo os coeficientes da função utilidade em unidades monetárias, segundo Sammer e Wüstenhagen (2006). Isto é feito dividindo o impacto marginal do atributo do bem, pelo valor absoluto do impacto marginal de preço. Em outras palavras, estamos calculando a utilidade marginal de um certo atributo dividido pela utilidade marginal do preço (em valor absoluto).

\subsubsection{O problema das Alternativas Irrelevantes}

Uma das maiores limitações do modelo logit condicional ocorre devido ao fato de que a questão da escolha entre as diversas alternativas se faz por meio de comparações em pares de bens. Dada a forma funcional do logit, essa comparação em par se torna independente das demais alternativas disponíveis. Esse problema, segundo Greene (2008), surge a partir da premissa de que os erros são independentes e homocedásticos entre as alternativas.

Embora em termos analíticos e para estimação esta propriedade possa vir a ser conveniente, é uma restrição muito forte que se impõe sobre o comportamento dos consumidores. Suponha, por exemplo, que tivésse apenas os modelos $A$ e $B$ para serem escolhidos. Espera-se que a introdução de um terceiro modelo $C$, similar aos modelos $A$ e $B$, tenha algum impacto na forma como o consumidor passa a escolher entre as possíveis alternativas.

Embora o uso de características específicas dos modelos de refrigeradores melhorem os padrões de substitutibilidade, aproximando modelos semelhantes no espaço de características, por meio de utilidades mais elevadas, devido às restrições do modelo Logit, os problemas decorrente da IIA permanecem. Para contornar esta questão, introduziremos uma forma alternativa de modelagem, em que permitimos que os parâmetros de certas variáveis assumam valores aleatórios, de modo que cada indivíduo perceba os bens de uma forma única, ampliando os padrões de substituição entre modelos distintos de refrigeradores.

\subsection{Mixed Logit ou Random Coefficient Logit}

Os modelos logit multinomiais e condicionais possuem a limitação da independência das alternativas irrelevantes. Assim, o acréscimo ou a retirada de uma terceira alternativa não teria impacto na forma como o indivíduo decide sobre a compra das duas 
primeiras. No entanto, em termos de mercado, impor uma restrição deste tipo pode limitar muito os padrões de substitutibilidade entre produtos semelhantes.

Há pelo menos duas formas práticas de lidar com as limitações do modelo logit multinomial. Uma delas é quebrar a decisão de compras em uma série de pequenas decisões sobre as características que se desejam no produto final. Assim, teremos um esquema de decisão do tipo aninhado, em que os produtos de cada subgrupo possuem características mais semelhantes entre si do que os produtos nos grupos/ramos superiores. Esta forma de modelagem é o que se conhece por modelo Nested Logit.

Embora o nested logit reduza o problema de IIA, ele não o corrige completamente. Dentro de cada subgrupo, os produtos ainda mantém um padrão de substituição mais restrito, embora o problema seja mitigado quando a inclusão de um novo produto se faz em um ramo distinto.

A outra modelagem possível é através de um modelo com coeficientes aleatórios, como o Mixed Logit. Segundo Greene (2008), este modelo nos fornece uma forma simples de generalizar os modelos logit multinonal e condicional de forma a permitir que as utilidades de cada alternativa sejam correlacionadas.

A utilidade do indivíduo $i$ pelo bem $j$ pode ser obtida como:

$$
U_{i j}=x_{i j}^{\prime} \beta_{i}+\epsilon_{i j}, \mathrm{j}=1,2, \ldots, \mathrm{m}
$$

em que os erros $\epsilon_{i j}$ seguem uma distribuição de Valor Extremo i.i.d.. Adicionalmente, permitimos que o vetor de parâmetros $\beta_{i}$ seja aleatório. Definimos então $\beta_{i} \mathcal{N}\left[\beta, \sum_{\beta}\right]$. Também podemos assumir uma distribuição log-normal para os parâmetros, uma vez que saibamos a priori o sinal dos mesmos.

Segundo Cameron (2005), em modelos não lineares, os estimadores que não levam em consideração os parâmetros aleatórios se tornam inconsistentes. Se o DGP for da forma como apresentada em 3.15, os estimadores de máxima verossimilhança apresentados no caso do Logit Condicional não fornecerão resultados confiáveis. Neste caso, nossa função de verossimilhança deve explicitamente cuidar da questão do processo estocástico nos termos $\beta_{i}$.

Assim, conforme indicam Cameron (2005), precisaremos integrar a função:

$$
p_{i j}=\operatorname{Pr}\left[y_{i}=j\right]=\int \frac{\mathrm{e}^{x_{i j}^{\prime} \beta_{i}}}{\sum_{l=1}^{m} \mathrm{e}^{x_{i l}^{\prime} \beta_{i}}} \phi\left(\beta_{i} \mid \beta, \sigma_{\beta}\right)
$$

em que $p_{i j}$ é uma integral multidimensional, e $\phi\left(\beta_{i} \mid \beta, \Sigma_{\beta}\right)$ representa a função densidade de probabilidade normal de $\beta_{i}$, com média $\beta$ e variância $\sigma_{\beta}$. Nossa função de máxima verossimilhança incorpora então a parte aleatória, se tornando da forma: $\mathcal{L}_{\mathcal{N}}=\sum_{i=1}^{N} \sum_{j=1}^{m} y_{i j} p_{i j}$. 
Parte IV

Bases de Dados 


\section{Banco de Dados}

\subsection{Mercado de Bens Diferenciados}

A compra de um aparelho refrigerador se enquadra perfeitamente no caso de um mercado de bens diferenciados, i.e., um mercado em que cada modelo diferente de refrigerador possui uma série de características que o torna único. Assim, um refrigerador pode ser diferenciado pelo número de portas que possui, pela forma de degelo (manual ou frost free), pela capacidade de armarzenamento do aparelho, pela disposição interna das prateleiras, presença de freezer ou congelador, dispenser de água e material das portas (inox, chapa metálica ou prateada), entre outras características.

Além disso, um outro fator relevante é que, uma vez que este bem já está presente na maioria dos domicílios, as novas compras se tornam um processo de troca e não de aquisição de um equipamento pela primeira vez. Isto é relevante pois implica que os compradores já possuem uma experiência com estes aparelhos, conhecendo de antemão a qualidade de cada marca, além de já terem estabelecido ou adquirido certos hábitos e comportamentos quanto ao uso dos equipamentos.

Assim, a escolha dos novos bens também deve ser influenciada pela marca, como sinônimo de qualidade, dos aparelhos. Mais importante, dado o padrão de uso já estabelecido, pode-se supor que o mesmo padrão deve ser mantido com o novo refrigerador. Assim, a própria escolha do modelo de refrigerador a ser comprado já imbute em si a questão do consumo esperado de eletricidade. Sob esta hipótese, suporemos então que não haja mudanças bruscas no comportamento e hábitos de uso dos consumidores, o que torna a estimação da parte discreta (do processo de compra) independente da parte contínua (intensidade de uso), e torna nossa estimação da parte discreta consistente e, sob esta hipótese, também eficiente.

\subsection{Bancos de Dados}

Para a realização deste trabalho, dispomos de duas fontes de dados. A primeira são as informações coletadas pela Pesquisa de Posse de Eletrodomésticos e Hábitos de Uso (PPH/Procel), uma pesquisa de campo realizada em 2005 pelo Programa Nacional de Conservação de Energia Elétrica (Procel), agência subordinada à Eletrobrás, e responsável por promover a racionalização da produção e do consumo de energia elétrica no Brasil.

De âmbito nacional, essa pesquisa é composta de informações de 4310 domicílios e compreende 16 Estados brasileiros mais o Distrito Federal. Colaboraram ainda com a 
pesquisa, ao todo, 21 empresas concessionárias de energia elétrica. O Sudeste é a região mais bem representada, contando com a participação de 5 grandes concessionárias e cerca de 2100 domicílios pesquisados. As regiões Nordeste e Sul vêm logo depois, com cerca e $23 \%$ e $16 \%$ da amostra dos domicílios, respectivamente. Dentro de cada região, esses domicílios ainda foram divididos entre 8 classes de consumo, de acordo com o nível de consumo energético de cada residência. Ademais, a pesquisa consta de informações sócioeconômicas dos domicílios pesquisados, de informações de posse e uso de bens duráveis, assim como questões específicas acerca do período do racionamento de 2001 (medidas tomadas, comportamento antes, durante e após esse período, etc.).

A pesquisa, tendo como foco o estudo da posse de equipamentos eletrodomésticos e os hábitos de consumo das famílias brasileiras, traz ainda informações relevantes sobre a eficiência dos aparelhos utilizados, além de informações sobre trocas de equipamentos realizados nos últimos anos. Assim, insere-se dentro do projeto de avaliação do mercado de eficiência energética no Brasil e fornece-nos o insumo necessário para aprofundarmos nossa análise.

A segunda fonte de informações refere-se aos dados de preços dos eletrodomésticos, providos pela pesquisa de preços da FUNDAÇÃO GETULIO VARGAS - IBRE. Abrangendo 16 capitais, além do Distrito Federal, essa base de dados reporta informações de preços de 248 modelos de eletrodomésticos no período de 1998 a 2005.

As demais fontes de dados referem-se a informações de consumo energético, obtido junto aos catálogos do Selo Procel e outros trabalhos acadêmicos ${ }^{1}$; e características específicas dos diversos modelos de refrigeradores, obtidos por meio de manuais de uso e boletins técnicos. Começaremos falando em detalhes da primeira das bases de dados.

\subsection{Base de Dados PPH/Procel}

Como ressaltado anteriormente, a base de dados da PPH/Procel contém informações detalhadas por domicílios, acerca dos moradores e dos equipamentos eletrodomésticos que estes possuem. Antes de detalharmos os equipamentos, é importante situar exatamente as famílias, caracterizando-as segundo seu poder aquisitivo e nível de consumo energético. Resumimos estas informações no gráfico a seguir:

Como podemos notar a partir da figura 1, a maior parcela dos domicílios de nossa amostra está concentrada na faixa de consumo até $100 \mathrm{kWh}$ (colunas azuis) e na faixa de renda de até 3 salários mínimos. Já os consumidores com consumo energético entre 101 e 200 kWh estão mais ou menos bem distribuídos nas faixas de renda até 7 salários mínimos. A concentração de consumo acima de 500 kWh é mais alta entre famílias com

1 Como os trabalhos de Melo (2009) e Jannuzzi (2002) por exemplo, em que se reportam tabelas com os níveis de consumo e suas respectivas classificações energéticas 
Figura 1: Número de Domicílios por Classe de Renda e Consumo Energético

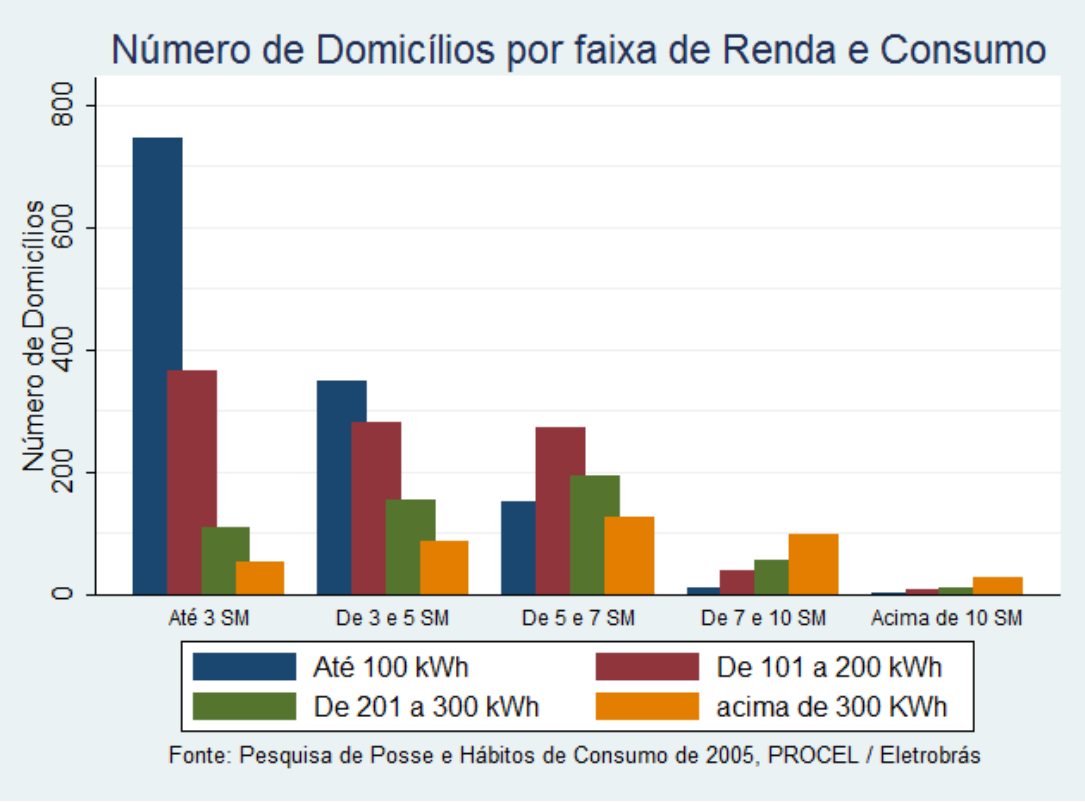

renda entre 3 e 10 salários mínimos. A tabela 4 mostra a distribuição dos domicílios entre as diversas faixas de renda e consumo energético.

Tabela 4: Número de Domicílios por Classe de Renda e Consumo Energético

\begin{tabular}{|c|c|c|c|c|c|}
\hline \multicolumn{2}{|c|}{ Classe de Renda } & \multicolumn{4}{|c|}{ Classe de Consumo } \\
\hline $\begin{array}{l}\text { Em Salários } \\
\text { Mínimos }\end{array}$ & Em Reais $(\mathbf{R} \$)$ & $\begin{array}{c}\text { Até } \\
100 \mathrm{kWh}\end{array}$ & $\begin{array}{l}\text { De } 101 \mathrm{a} \\
200 \mathrm{kWh}\end{array}$ & $\begin{array}{l}\text { De } 201 \text { a } \\
300 \mathrm{kWh}\end{array}$ & $\begin{array}{c}\text { Acima de } \\
300 \mathrm{kWh}\end{array}$ \\
\hline Até $3 \mathrm{SM}$ & Até $\mathrm{R} \$ 900$ & 745 & 364 & 108 & 51 \\
\hline De 3 a $5 \mathrm{SM}$ & De $\mathrm{R} \$ 900$ a $\mathrm{R} \$ 1500$ & 348 & 281 & 154 & 87 \\
\hline De 5 a 7 SM & De $R \$ 1500$ a $R \$ 2700$ & 100 & 162 & 106 & 60 \\
\hline De 7 a $10 \mathrm{SM}$ & De $R \$ 2700$ a $R \$ 3000$ & 51 & 111 & 88 & 65 \\
\hline Acima de $10 \mathrm{SM}$ & Acima de $\mathrm{R} \$ 3000$ & 13 & 47 & 65 & 125 \\
\hline
\end{tabular}

Como ressalta Neri et al. (2008), o aumento da renda média na década passada, beneficiando principalmente os trabalhadores assalariados, trouxe nova dinâmica ao mercado ao permitir que famílias que antes não possuíam condições, agora possam adquirir um bem eletrodoméstico ou mesmo trocar um aparelho obsoleto. Pelos dados da Procel, podemos ver isso de duas formas diferentes: tanto através dos aparelhos efetivamente comprados quanto por meio das pretensões de compra declarados. Os gráficos das figuras 2 e 3 resumem parte dos aparelhos comprados entre 2002 e 2005, enquanto as figuras 4 e 5 resumem as intenções de compras das famílias entrevistadas entre 2004 e 2005.

Pela figura 2, vemos que os itens eletrodomésticos mais comprados no período entre 2002 e 2005 são os televisores, refrigeradores, aparelhos de som e lavadoras de roupa. Um ponto interessante sobre este gráfico é que, dentre os itens mais procurados, figuram 
Figura 2: Número de Aparelhos Comprados por Classe de Renda

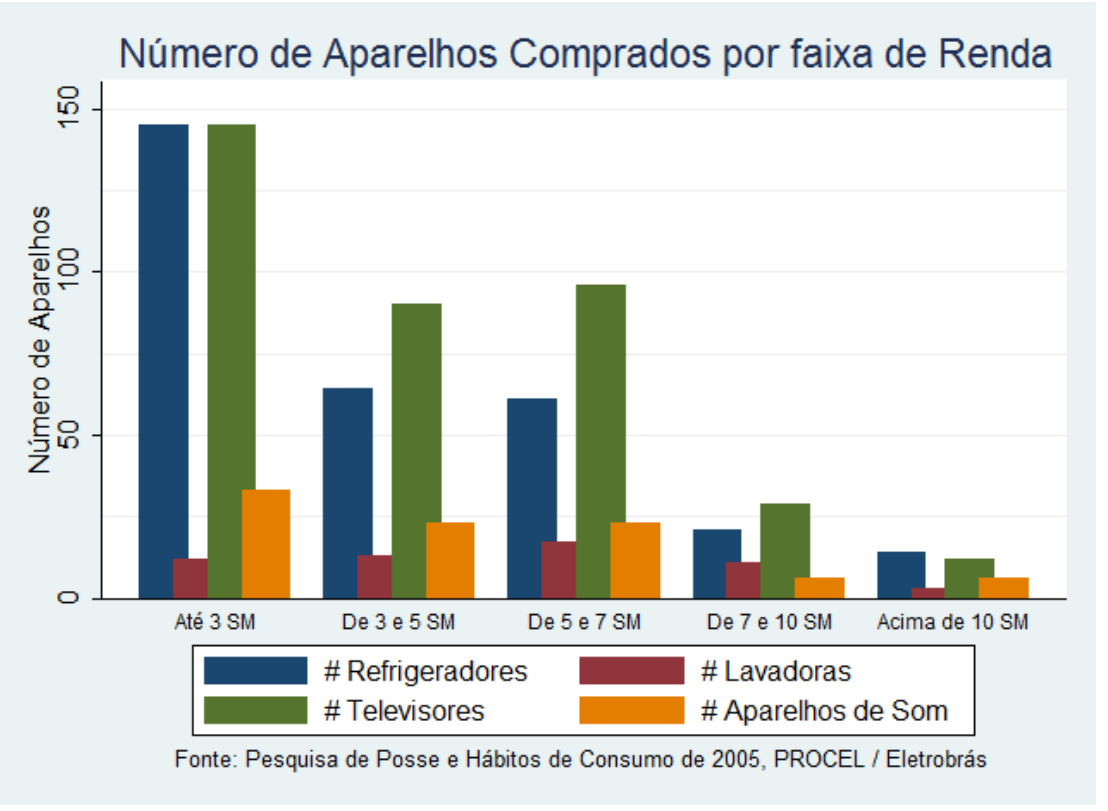

eletrodomésticos com preço médio mais elevado, tais como refrigeradores e lavadoras de roupa. Além disso, outro ponto interessante a se observar é que a penetração de refrigeradores nos domicílios já era, no começo dos anos 2000, acima de 90\%. Muitas dessas compras são, portanto, substituições de aparelhos, e não aquisição de novos. O mesmo vale para os aparelhos televisivos. Já para máquinas de lavar, ocorre o contrário: como sua penetração é pequena, boa parte das compras identificadas nesse período se devem à aquisição de um aparelho, e não à troca por outro mais moderno e eficiente.

Figura 3: Número de Aparelhos Comprados por Classe de Renda

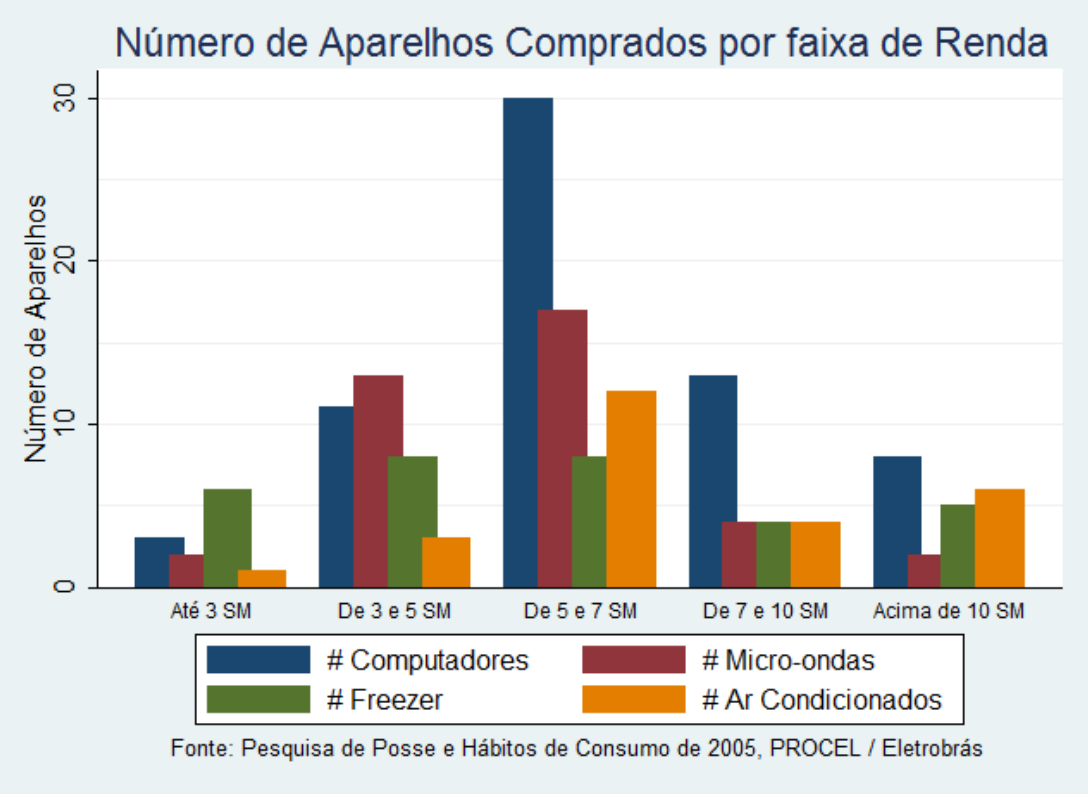


A figura 3, por sua vez, mostra informações de outros aparelhos menos demandados declarados na base da pesquisa Procel de 2005. Via de regra, o argumento persiste: com a melhora da renda no começo da década de 2000, os bens de valor médio mais elevado foram os que mais atraíram os consumidores. Aqui, no entanto, vemos um padrão diferente de consumidores. Os aparelhos menos essenciais (como computadores pessoais, micro-ondas, ar condicionados e freezeres) são adquiridos, em sua grande maioria, pelas famílias com renda entre 5 e 7 salários mínimos, enquanto que os bens refrigeradores e lavadoras de roupas foram mais procurados por famílias de classes de renda mais baixas.

Além disso, foram pesquisadas também as intenções de compra das famílias. Conforme podemos verificar na figura 4 , os bens mais desejados, caso haja um aumento de renda familiar, são os aparelhos refrigeradores, lavadoras de roupas, aparelhos de TV e DVD. Aqui, inusitadamente, vemos DVD como uma das principais intenções de compra por ser um produto aspiracional à época da pesquisa, uma vez que o pico de vendas de aparelhos de DVD se deu em meados de 2006.

Figura 4: Pretensão de Compra de Aparelhos Comprados por Classe de Renda

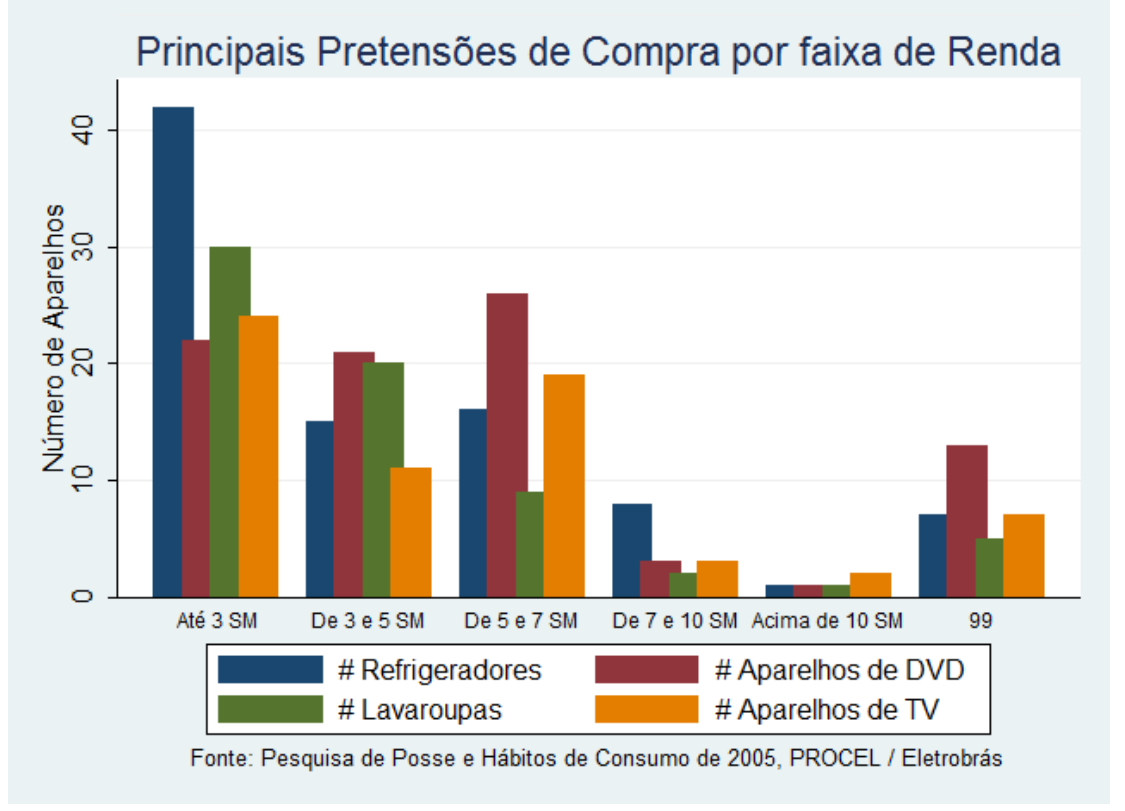

Dentre outros produtos que aparecem nas pretensões de compra, temos, por exemplo, aparelhos de som, computadores e micro-ondas, conforme mostra a figura 5. Em ambas as figuras 4 e 5, podemos notar uma predominância das classes de renda mais baixas quanto às pretensões de compra. Isto faz sentido quando temos em mente toda a ascensão da clase C da qual Neri et al. (2008) faz menção.

Nosso estudo focará, em especial, à análise da disposição a pagar por refrigeradores mais eficientes. A escolha deste eletrodoméstico leva em conta alguns pontos importantes: (i) a quantidade de informações de novas compras é a mais significativa dentre todos os eletrodomésticos (excetuando-se aparelhos de TV), e contém cerca de mais de 1317 novos 
Figura 5: Pretensão de Compra de Aparelhos Comprados por Classe de Renda

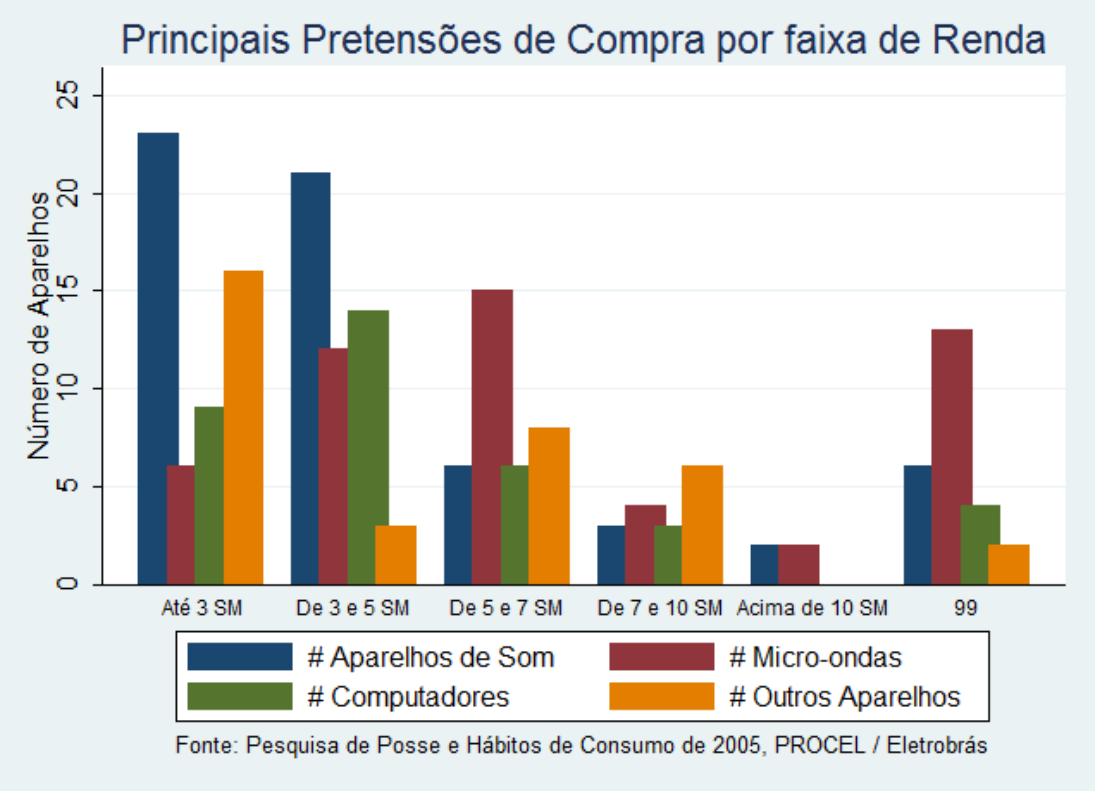

refrigeradores comprados entre 1998 e 2005; (ii) devido ao alto nível de penetração da categoria, boa parte das compras podem ser consideradas como feitas com intenção de trocar do aparelho obsoleto por outro mais moderno e eficiente; (iii) e, dentre os aparelhos pesquisados pela $\mathrm{PPH} /$ Procel, o refrigerador é um dos eletrodomésticos com maior preço médio, o que implica que sua troca, em geral, envolve um processo de análise de custobenefício mais acurado que outros bens menos essenciais e de menor valor.

Escolhemos não estudar a disposição a pagar por aparelhos de TV por alguns motivos. Embora seja o bem com maior presença em termos de compras na pesquisa da Procel de 2005, e possuir alto nível de penetração nos domicílios, os motivos de compra em geral não estão ligados diretamente à análise de custo-benefício em termos de eficiência energética. As razões para compra de um novo aparelho de TV, de forma geral, variam desde a expectativa da Copa do Mundo (e.g., como em 2002), até mesmo à aspiração de um televisor com tela maior ou de melhor qualidade.

Além disso, outro motivo importante para excluí-lo de nossa análise é a perda de validade externa para esta categoria, dadas todas as mudanças tecnológicas ocorridas entre 2000 e 2010. De aparelhos de TV do tipo CRT ("de tubo") com tela "curva", passouse a televisores CRT com tela plana de melhor qualidade de imagem e maiores tamanhos de tela. A partir disso, houve um grande salto tecnológico com a introdução de TV de tela de cristal líquido (LCD) ou mesmo tela de plasma. Recentemente, os televisores de tela de LED e outros modelos com imagens em 3 dimensões têm sido os aparelhos de ponta desse mercado. Com esta evolução, o mercado de televisores praticamente extinguiu os aparelhos tipo CRT das lojas. 
Assim, estudar aparelhos de TV do tipo CRT (único tipo de modelo disponível à época da pesquisa) parece-nos um trabalho cuja validade e importância para os dias atuais se fazem mínimas. Já os refrigeradores, por sua vez, apesar de terem apresentado avanços tecnológicos com redução do consumo energético e outras melhorias, não sofreram uma mudança tecnológica tão drástica quanto à observada no mercado de televisores.

Outra razão para estudarmos os aparelhos de refrigeradores é devido ao relativo peso que a PPH/Procel coloca sobre este bem. Dentre as questões formuladas, uma delas relaciona diretamente a decisão de compra com o uso ou conhecimento do Selo Procel. Os dados são resumidos na tabela 5 a seguir, e são referentes às compras de refrigeradores no período de 1994 a 2005.

Tabela 5: Consumidor utilizou a informação do Selo Procel para decidir sobre a última compra de Refrigerador

\begin{tabular}{lcc}
\hline & Freqüência & Percentual \\
\hline Utilizou o Selo Procel & 1159 & $43,4 \%$ \\
Não utilizou o Selo Procel & 638 & $23,9 \%$ \\
Não se lembra & 510 & $19,1 \%$ \\
Não tinha o Selo Procel & 75 & $2,8 \%$ \\
Não sabia da existência do Selo Procel & 286 & $10,7 \%$ \\
\hline Percentual dentre os respondentes sobre refrigerador comprado entre 1994 e 2005 \\
Total de missings na base: 1642
\end{tabular}

Se nos restringirmos somente à amostra de respondentes, verificamos pela tabela 5 que boa parte dos consumidores levaram em consideração o Selo Procel ao comprarem seu último aparelho de refrigerador. Para as compras efetivadas no nosso período de análise, de 1998 a 2005, o percentual de respondentes que compraram um refrigerador e utilizaram-se do Selo Procel como indicador de eficiência sobe para 46,2\%, sendo que a obrigatoriedade do Selo nos bens eletrodomésticos só passou a existir a partir da Lei de Eficiência Energética, de 2001.

No entanto, apesar de o conhecimento do Selo ser amplo dentre os que adquiriram um novo refrigerador, este mesmo conhecimento não o é no total de entrevistados. Da nossa amostra de 4310 domicílios, cerca de $53 \%$ afirmam não conhecer o selo, enquanto que outros $61 \%$ afirmam não saber o que este significa, conforme mostram as tabelas 6 e 7 :

Tabela 6: Entrevistado conhece o Selo de Eficiência Energética da Procel

\begin{tabular}{lcc}
\hline & Freqüência & Percentual \\
\hline Conhece o Selo Procel & 1.915 & $44,4 \%$ \\
Não conhece o Selo Procel & 2.293 & $53,2 \%$ \\
Não sabe responder & 102 & $2.4 \%$ \\
\hline
\end{tabular}

Fonte: PPH/Procel/Eletrobrás, elaboração própria 
Tabela 7: Entrevistado sabe o que o significa o Selo da Procel

\begin{tabular}{lcc}
\hline & Frequiência & Percentual \\
\hline Sim & 1442 & $33,5 \%$ \\
Não & 2654 & $61,6 \%$ \\
Não Sabe & 214 & $5,0 \%$ \\
\hline \multicolumn{2}{l}{ Fonte: PPH/Procel/Eletrobrás, elaboração própria }
\end{tabular}

Sendo assim, apesar da importância do Selo Procel e da enorme divulgação do mesmo durante o período de racionamento de energia em 2001 / 2002, uma parcela significativa da nossa amostra, e provavelmente da população, ainda desconhece o selo ou seu significado. Isto certamente reduz a efetividade do uso do Selo Procel na compra dos bens eletrodomésticos, mas não necessariamente reduz a importância de se conhecer a disposição dos consumidores por produtos mais eficientes.

Mesmo desconhecendo o selo, deve haver um consenso geral de que produtos mais novos e recentes são "melhores" ou mais "econômicos" e eficientes. Além disso, o consumo de energia pode vir a ser um dos requisitos a ser checados quando da decisão de compra, mesmo não se sabendo da existência ou significado do Selo Procel. Portanto, mesmo com o relativo desconhecimento do selo, estudar o quanto os consumidores estão dispostos a pagar por um produto mais eficiente é de grande importância.

A base Procel/PPH detalha também a posse, a intensidade de uso, o período (horário) do dia em que há maior utilização em cada um dos dias da semana, além de informações de idade estimada dos aparelhos ou compras recentes, dentre outras informações correlatas. O conjunto de bens analisados pela pesquisa inclui aparelhos de $\mathrm{Ar}$ Condicionado, Chuveiro elétrico, Freezer, Refrigeradores, Televisores e Iluminação com lâmpadas incandescentes e fluorescentes.

Desse conjunto de dados, as informações referentes aos modelos disponíveis de refrigeradores estão resumidas nas duas primeiras colunas das tabelas 16, 17, 18 e 19, no apêndice. Os modelos de refrigeradores da base da pesquisa PPH da Procel não possuem os respectivos códigos de SKU (Stock Keeping unit) para sua exata identificação. Em vez disso, a base conta somente com o "nome fantasia", i.e., o nome comercial do produto, pelo qual é usualmente identificado nas propagandas e comerciais. No entanto, esse mesmo nome comercial pode variar muito entre os modelos de refrigeradores, não possuem uma padronização e nem sempre dispõem de todas ou de algumas das informações relevantes como litragem, número de portas e forma de degelo. A identificação dos SKU demandou, portanto, um trabalho adicional. 


\subsection{Identificação dos modelos de SKU na Base PPH/Procel e informações de Consumo Energético}

O primeiro trabalho sobre esta base se resumiu à tentativa de identificação mais precisa dos modelos de SKU pesquisados, de tal forma a tornar factível ou a obtenção do correspondente preço médio da base FGV/IBRE, ou a estimação do preço por meio de um modelo de preços hedônicos.

Para esta identificação, foram investigadas informações de diversas fontes, tais como comparação das descrições dos modelos da base PPH/Procel, quando disponíveis, com as descrições dos modelos da base de preços da FGV/IBRE, ou ainda a comparação com os nomes e características presentes em manuais de uso e/ou boletins técnicos dos refrigeradores. Dos 67 "modelos" de refrigeradores, em que 8 são simplesmente a descrição genérica das marcas pesquisadas, 49 modelos tiveram um matching positivo com alguma das fontes pesquisadas. A coluna "Modelo/SKU" das tabelas 16, 17, 18 e 19 no apêndice mostra os SKUs identificados. Pelo fato de a base PPH/Procel não conter tantas informações detalhadas da descrição dos modelos, foram ignorados as diferenças de versões de um mesmo modelo, criando uma espécie de "SKU simplificada".

Dos modelos que não obtiveram uma identificação da SKU simplificada, 11 têm somente informação de marca; para 5 foi adotado uma terminologia mais geral, contendo, quando disponível, informação de marca, o tipo duplex ou simples e litragem (e.g. BRASTEMPDUPLEX340); e dois modelos em específico, de códigos 240 e 280, foram deixados como classificação genérica "OUTROS" porque não constavam esses códigos no questionário da PPH/Procel, e a única forma de descrição eram os próprios códigos. Possivelmente estes dois códigos se devem a erros de digitação dos questionários. Por via das dúvidas, não foram utilizados na modelagem.

As informações referentes ao consumo energético e demais características dos refrigeradores vieram de pelo menos uma das quatro fontes de dados disponíveis: (i) do trabalho de dissertação de mestrado de Melo (2009), que trabalha com a mesma base de dados da PPH/Procel, e identifica quase todos as informações para os modelos da base em questão; (ii) dos catálogos do Selo Procel do período de 2001 a 2005, que continham informações de volume, consumo energético e número de portas para todos os modelos que, nesse período, já continham o Selo Procel; (iii) dos manuais de uso e/ou dos boletins técnicos dos refrigeradores ${ }^{2}$;

(iv) de outros trabalhos acadêmicos, tais como Jannuzzi (2002) e Cardoso (2008).

2 Dentre as fontes para este tipo de informação, citamos: http://admebranding.brastemp.com.br/Documentos/Brastemp/ http://admebranding.brastemp.com.br/Documentos/Consul/ e http://www.portaldoeletrodomestico.com.br/boletim/boletim_brastemp/ 
As informações necessárias foram coletadas e utilizadas na ordem estabelecida acima, e contribuíram não apenas para a identificação de consumo energético e outras características dos modelos da própria base PPH/Procel, mas também para a identificação de algumas das características dos modelos da base FGV/IBRE.

No caso específico dos dados de consumo energético, foi adotado primeiramente os valores disponíveis no trabalho de Melo (2009) por este desenvolver um trabalho exatamente com a mesma pesquisa da PPH/Procel. Já os dados de consumo presentes nos catálogos do Selo da Procel podem variar para um mesmo modelo por duas razões: ou são versões diferentes do mesmo modelo ou são medições feitas em anos distintos.

Como na identificação aproximada dos modelos da base PPH/Procel não foi possível recuperar informações de versões dos modelos, foi aplicada uma denominação mais simples de SKU e adotada a hipótese de que a posse/compra se tratava do modelo com menor consumo possível, independente do ano de fabricação. A idéia por trás desta hipótese é que o phasing out das linhas mais antigas pode ser concorrente no tempo com o lançamento de novas, seja por questão de estoques ou antecipação de lançamentos e, dessa forma, em teoria, para o mesmo modelo e versões diferentes, o consumidor poderia sempre optar entre o aparelho de maior ou menor consumo.

Ao final destes ajustes, a base de dados da Procel/PPH com os modelos de refrigeradores ficaram identificados como o reportado nas tabelas 16, 17, 18 e 19 no apêndice: foi possível recuperar informações de SKU para a grande maioria dos modelos, além de informações de consumo energético e classe de consumo para quase todos os SKUs.

\subsection{Base de Dados FGV/IBRE}

Complementando as informações de compra, contempladas na base da PPH/Procel, estão as informações de preço, da FUNDAÇÃO GETULIO VARGAS - IBRE. Com dados de preços coletados para o período de 1998 a 2011, e informações para uma série de eletrodomésticos e eletroeletrônicos, pudemos refinar e obter as informações necessárias para a realização deste trabalho de pesquisa.

Por restrições de tempo e de informações disponíveis das compras da Base PPH/Procel, o escopo deste trabalho foi concentrado na análise dos refrigeradores domésticos e no período de 1998 a 2005. Dessa forma, descreveremos somente os trabalhos realizados no ajustes das informações referentes à base de refrigeradores.

Após uma análise e um filtro inicial da base de preços de refrigeradores ${ }^{3}$, foram

3 O primeiro filtro realizado foi a retirada dos elementos que não eram Refrigeradores propriamente, a saber, Freezers (horizontal ou vertical) e outros poucos bens estranhos à base. Sobre os freezeres, o próprio Censo 2000 os enquadra junto da categoria de Refrigeradores, não diferenciando um bem do outro. As pesquisas da PNAD, no entanto, diferenciam um bem do outro, e o Censo de 2010 
obtidos um total de 57.417 informações de preços coletados no período de 1998 a 2005.

O trabalho então se subdividiu em algumas partes:

(i) identificação dos códigos dos modelos ou, de forma mais abrangente, da SKU (simples) para identificação de cada tipo de modelo disponível no período de análise;

(ii) tratamento especial para os SKUs que são parcialmente, ou não explicitamente, identificáveis;

(iii) tratamento especial para os SKUs que não podem ser identificados ou são genéricos o bastante para não serem identificados;

(iv) tratamento de outros casos especiais;

(v) identificação dos respectivos consumos de energia e suas classificações energéticas segundo o Selo Procel;

(vi) identificação de demais características (marca, número de portas, capacidade bruta e de armazenamento, capacidade do freezer/congelador e do refrigerador, forma de degelo (manual ou frost free), existência de dispenser de água, porta inox, etc);

(vii) estimação dos índices de eficiência energética para obtenção de proxy para classificação energética, quando esta não foi encontrada ou não estava disponível.

A seguir, detalhamos um algortimo utilizado para a identificação dos SKUs. Cada etapa do procedimento e dos ajustes realizados pode ser visto com maiores explicações no apêndice.

\subsubsection{Algoritmo de identificação dos SKUs}

A partir da base original de coleta de preços de refrigeradores obtida junto ao IBRE / FGV, utilizamos os seguintes filtros a fim de obtermos os SKUs pesquisados pelo referido instituto:

1. Exclui-se da base todos os itens que não tinham como descrição "REFRIGERADOR"

2. Em seguida, foi identificado a marca do refrigerador, conforme as respectivas descrições dos aparelhos

3. Foram então eliminados os tags com descrição duplicadas

já traz também essa diferenciação. Como o próprio IBRE possui uma base específica de Freezer, resolvemos diferenciar as duas categorias e focar somente nos refrigeradores, bem mais comum e de maior penetração. 
4. Foi extraído dos tags, quando disponível, o código do SKU. Quando não disponível, foi associado um nome genérico contendo marca, número de portas (simples, duplex ou biplex) e litragem (ou intervalo de litragem)

No total, foram encontrados cerca de 326 "SKUs" diferentes. Destes, uma parcela não pôde ter o nome genérico exatamente identificada, e outros continham nomes de marcas incompatíveis com os códigos SKU apresentados nos tags. Após a filtragem dessas informações incompletas,foi possível obter os códigos (SKUs ou genéricos) de cerca de 220 SKUs (143 exatamente identificados e 77 genéricos).

\subsection{Conferência das Informações de Compra}

A base da PPH/Procel contém algumas informações específicas sobre refrigeradores, como por exemplo, as derivas de perguntas diretas sobre compras de novos aparelhos nos últimos 2 anos anteriores à entrevista. Dentre os 4310 domicílios de nossa amostra, 351 entrevistados declararam terem comprado um novo refrigerador entre 2002 e 2005. Para estes casos, foram anotados informações de Ano e, quando possível, o Mês exato da compra.

Além dessas informações declaradas, há outra informação importante referente à idade estimada dos refrigeradores. Esta variável, em teoria, perguntada e medida em anos, foi igualmente utilizada para balizar todas as compras ocorridas entre 1998 e 2005.

Alguns problemas surgiram com ambas as variáveis. Com relação às declarações de compra, nem todos os entrevistados souberam informar o mês específico de compra. Assim, resolvemos considerar somente a informação de ano de compra para as estimações. Já com relação aos dados de idade estimada, embora o questionário traga explicitamente a informação de que esta pergunta deveria ser considerada em anos, muitos questionários a informaram em meses.

Essa mistura de anos e meses pôde ser observada ao compararmos os dados dos domicílios que informaram ter comprado nos últimos dois anos e as estimativas de idade. Para quase todos os casos em que a compra declarada havia sido realizada em menos de um ano em relação à entrevista, as informações de idade estimada variavam de 3 a 6 meses em geral. Como nestes casos havia disponível o ano da compra declarada, consideramos esta informação para definir o ano de compra.

Para os casos em que a compra não foi explicitamente declarada, adotou-se um outro critério. Para identificar o ano da compra, subtraiu-se o ano da pesquisa (2004 ou 2005) da idade estimada. Como medida conservadora, e supondo que a grande maioria dos valores de idade estimada seja referente a anos e que haja algum grau de confiança, principalmente se a compra foi recente, considerou-se para este cálculo somente os refrigeradores 
com menos de 6 anos (que é o intervalo de tempo entre 1998 e 2004). Os refrigeradores com mais de 6 anos de idade estimada foram desconsiderados da análise, seja por conta das restrições de informações de preços, seja por conta de perda de confiabilidade dos dados.

Também foram considerados os domicílios com mais de um refrigerador. A investigação do segundo ou mesmo do terceiro refrigerador nesses domicílios se procedeu da mesma forma, de modo a identificar os respectivos anos de compra. No total, foram identificados 2.148 compras de refrigeradores entre 1998 e 2005. Desses, 828 foram retirados da amostra por ser possível recuperar informações de preços (se incluem nos casos em que há somente informação de marcas ou nos casos em que não havia disponível características suficientes para estimar o respectivo preço médio). Outros 3 casos foram igualmente excluídos por não termos obtido as informações de consumo energético correspondente.

Assim, restou-nos um total de 1317 casos de compras de novos refrigeradoes, sendo 13 modelos da marca Brastemp, 9 da marca Consul, 15 da marca Electrolux e 1 de outras marcas, totalizando 38 modelos distintos de refrigeradores dentre os 67 "modelos" inicialmente encontrados na base PPH/Procel.

\subsection{Imputação de Preço: o Modelo de Preços Hedônicos}

A base de dados da Pesquisa de Posse e Hábitos de Consumo da Procel de 2005 nos fornece uma gama de informações relativas aos aparelhos eletrodomésticos presentes nos domicílios, juntamente de informações referentes às compras e novas aquisições destes ao longo de alguns anos anteriores à pesquisa. No entanto, ela não nos fornece o nível energético dos aparelhos ou mesmo seu valor de mercado ou o preço pago pelos equipamentos recentemente adquiridos nos domicílios entrevistados.

Como já detalhando anteriormente, com relação aos dados de consumo energético, aproveitamo-nos de estudo previamente realizado por Melo (2009), no qual ele discorre sobre os padrões de eficiência energética de uma série de equipamentos eletrodomésticos. Por utilizar dados do mesmo período da pesquisa da Procel, os modelos de refrigeradores pesquisados são os mesmos. Desta forma, obtemos uma fonte de informação sobre o consumo energéticos dos modelos disponíveis em nossa base de dados.

Sobre a base de preços, conforme destacado acima e amplamente discutido, foram obtidas informações a partir da pesquisa de preços da Fundação Getúlio Vargas / IBRE, baseada em coletas de preços de diversos modelos ao longo de 16 capitais federais mais o Distrito Federal, no período de 1998 a 2005.

Após todos os ajustes necessários, restaram-nos cerca de 143 SKUs exatamente identificados, mais outros 77 genericamente identificados. No cruzamento das informações 
das bases de preço IBRE e das bases de compras PPH/Procel, pudemos encontrar 31 modelos comuns a ambas às bases. Do total de modelos identificados na base PPH/Procel (54 modelos), 23 modelos tinham SKU correspondente na base de preços IBRE.

Desses 31 modelos identificados, um deles (de SKU "CQG22D") foi excluído da base por ser o único modelo a gás. Para os 23 modelos sem matching exato de preços, estimamos uma modelagem de preços hedônicos para imputar os preços baseada nas principais características desses modelos.

O modelo de preços hedônicos, conforme Goodman (1998) comenta sobre o trabalho pioreiro de Andrew Court, tinha como objetivo principal estimar um índice de preços de automóveis com base em características ou qualidades observáveis dos mesmos. O uso de variáveis dummy para a presença (ou não) de alguma característica tem a intenção de mensurar uma espécie de importância relativa dos vários componentes dos produtos analisados. O mesmo procedimento aplicamos com os dados de refrigeradores.

Com o auxílio dos manuais de compra mais as descrições presentes nos próprios tags da base de preços, pudemos identificar uma série de informações relevantes como marca (Brastemp, Eletrolux, Consul, Outros), capacidade bruta e de armazenamento (ajustada para indicar baixa, média ou alta capacidade), capacidade do Freezer/Congelador e do Refrigerador, tipo de degelo (frost free ou degelo manual, número de portas (separados em modelos com 1 ou 2 portas), além de indicações de portas modelos com portas especiais (em prata, inox ou em zyrium) e presença de dispenser de água. Da base de preços pudemos ainda identificar o mês e ano exatos da coleta. Os dados de consumo e classificação energética vieram de outros trabalhos acadêmicos e dos catálogos do Selo Procel.

Sobre a classificação energética, não foi possível encontrar a classe de muitos modelos. No entanto, pudemos aproximar a classificação Procel estimando os Índices de Eficiência Energética (IEE) e utilizando a tabela de classificação da Procel para identificar as respectivas classes de consumo. Para a estimação do IEE, partimos de algumas hipótises como segue:

- O cálculo dos respectivos índices de eficiência foram realizados da seguinte forma:

1. Refrigeradores de 1 Porta degelo manual $=0,0346 * \mathrm{AV}+19,117$

2. Refrigeradores Combinados (2 Portas) degelo manual $=0,0916 * \mathrm{AV}$ $+17,083$

3. Refrigeradores Combinados (2 Portas) Frost Free $=0,1059 *$ AV + 74,862

(i) Refrigeradores de 1 Porta degelo manual $=0,0346 * \mathrm{AV}+19,117$ 
(ii) Refrigeradores Combinados (2 Portas) degelo manual $=0,0916 * \mathrm{AV}$ $+17,083$

(iii) Refrigeradores Combinados (2 Portas) Frost Free $=0,1059 *$ AV + 74,862

em que $A V$ é o Volume Ajustado do aparelho, que considera o nível de temperatura atingido em cada um dos seus compartimentos (refrigerador e freezer/congelador). Para o cálculo dos respectivos Volumes Ajustados (AV), foi adotada a seguinte regra:

1. Modelos de Degelo Manual: Volume do Refrigerador + Volume Freezer/Congelador * Fator de Correção

2. Modelos de Degelo Frost Free: $1,2 *$ (Volume do Refrigerador + Volume Freezer/Congelador * Fator de Correção)

(i) Modelos de Degelo Manual: Volume do Refrigerador + Volume Freezer/Congelador * Fator de Correção

(ii) Modelos de Degelo Frost Free: 1,2* (Volume do Refrigerador + Volume Freezer/Congelador * Fator de Correção)

sendo que os fatores de correção têm a seguinte regra:

1. 1 Estrela: 1,41 (para temperaturas até -6 graus Celsius)

2. 2 Estrelas: 1,63 (para temperaturas entre $-6{ }^{\circ} \mathrm{C}$ e $-12^{\circ} \mathrm{C}$ )

3. 3 Estrelas: 1,85 (para temperaturas entre $-12^{\circ} \mathrm{C}$ e $-18^{\circ} \mathrm{C}$ )

(i) 1 Estrela: 1,41 (para temperaturas até -6 graus Celsius)

(ii) 2 Estrelas: 1,63 (para temperaturas entre $-6{ }^{\circ} \mathrm{C}$ e $-12^{\circ} \mathrm{C}$ )

(iii) 3 Estrelas: 1,85 (para temperaturas entre $-12^{\circ} \mathrm{C}$ e $-18^{\circ} \mathrm{C}$ )

- Para o fator de correção, foram adotadas as seguintes hipóteses:

(i) Refrigeradores 1 Porta Degelo Manual: 1 Estrela

(ii) Refrigeradores 1 Porta Degelo Frost Free: 1 Estrela

(iii) Refrigeradores 2 Portas Degelo Manual: 2 Estrelas

(iv) Refrigeradores 2 Portas Degelo Frost Free: 3 Estrelas

- Adicionalmente, assumimos um valor médio fixo para cada compartimento como segue:

1. Compartimento Freezer/Congelador para Refrigeradores de 1 Porta: 10\% da Capacidade Bruta 
2. Compartimento Freezer/Congelador para Refrigeradores de 2 Porta: $23 \%$ da Capacidade Bruta

3. Compartimento Freezer/Congelador para Refrigeradores de 2 Portas: 23\% da Capacidade Bruta

O número de estrelas de cada compartimento depende diretamente da temperatura atingida pelo mesmo. No entanto, não conseguimos obter a exata classificação para todos os modelos. Baseados nos modelos cuja classificação fora encontrada, assumimos as hipóteses destacadas acima. Para o cálculo do volume de cada compartimento, utilizamos as informações encontradas nos manuais de uso e boletins técnicos. Como os manuais e boletins estavam disponíveis apenas para uma parcela dos modelos/SKUs existentes na base de preços, calculamos um valor médio do compartimento de freezer/congelador para os refrigeradores de 1 porta e para os de 2 portas.

Para a devida classificação, agrupamos as classes A e B em uma categoria de produtos mais eficientes, e as classes C, D e E em uma segunda categoria, de menos eficientes. As regras utilizadas para tais classificações são próximas das que o Procel utiliza, a saber:

Classe AB: IEE $\leq 0,98$

Classe CDE: IEE > 0.98

A diferença da regra de classificação adotada aqui e a da Procel/eletrobrás é que nossa regra assume um mesmo valor de corte para todas as categorias, enquanto que a regra da Procel especifica para cada tipo de refrigerador (1Porta, Combinados e Combinados Frost Free) um valor de corte diferente.

No entanto, uma vez que esta variável servirá como proxy, e os cortes de cada categoria são bem próximos um do outro, simplificamos o cálculo adotando um corte único. Ao compararmos a classe obtida por meio desta proxy com as classes disponíveis em nosso banco de dados, verificamos que a proxy acertava em $100 \%$ dos casos se o modelo pertencia a uma classe de alta eficiência (AB) ou de mais baixa eficiência (CDE).

A tabela 8 resume as principais características utilizadas, o número de observações para cada uma delas e os preços médios segundo cada característica.

Como era de se esperar, os modelos das classes AB são, em média, mais caros que os modelos das classes CDE, assim como o preço dos modelos de 2 portas são bem superiores aos de 1 porta. A forma de degelo também apresenta uma diferença significativa entre modelos manuais e de degelo Frost Free (tecnologia nova à epoca da pesquisa). 
Tabela 8: Resumo das Principais Características Observadas

\begin{tabular}{lcc}
\hline & Número de Observações & Preço Médio Observado \\
\hline Classe AB & 5.441 & $\mathrm{R} \$ 1.575,71$ \\
Classe CDE & 2.993 & $\mathrm{R} \$ 1.166,09$ \\
1 Porta & 4.641 & $\mathrm{R} \$ 1.001,99$ \\
2 Portas & 3.793 & $\mathrm{R} \$ 1.954,47$ \\
Frost Free & 2.031 & $\mathrm{R} \$ 2.218,48$ \\
Degelo Manual & 6.403 & $\mathrm{R} \$ 1.180,35$ \\
Inox & 255 & $\mathrm{R} \$ 2.425,75$ \\
Dispenser de Água & 291 & $\mathrm{R} \$ 2.120,47$ \\
Brastemp & 2.310 & $\mathrm{R} \$ 2.017,74$ \\
Consul & 2.879 & $\mathrm{R} \$ 1.099,27$ \\
Electrolux & 2.969 & $\mathrm{R} \$ 1.311,27$ \\
Bosch/Continental & 179 & $\mathrm{R} \$ 1.260,90$ \\
Outras Marcas & 97 & $\mathrm{R} \$ 1.225,62$ \\
\hline
\end{tabular}

Dentre as marcas, nota-se que os modelos Brastemp possuem um preço médio bem maior que as demais concorrentes. Consul é a marca de preço mais popular, e os preços de outras marca, Bosch/Continental e Electrolux são bem semelhantes entre si.

Como esperado, as marcas Brastemp, Consul e Electrolux são as mais bem representadas na base. Os modelos como informações de portas em inox ou com dispenser de água são poucas, comparadas às demais informações. No total, há 8434 informações de coleta dos 248 SKUs identificados nos quais todas as características acima são perfeitamente identificadas (i.e., não possuem missings).

Com base nessas características, o modelo de preços hedônicos estimado será:

$$
\begin{array}{r}
\text { Preço }_{i}=\gamma_{1} * \text { Marca }_{i}+\gamma_{2} * \text { Capacidade }_{i}+\gamma_{3} * \text { Degelo }_{i}+\gamma_{4} * \text { Portas }_{i}+ \\
\gamma_{5} * \text { Consumo }_{i}+\gamma_{6} * \text { Dispenser }_{i}+\gamma_{7} * \text { Inox }_{i}+\gamma_{8} * \text { Ano }_{i}+\epsilon
\end{array}
$$

\subsubsection{Resultado do Modelo de Preços Hedônicos}

Para o modelo de preços hedônicos, testamos duas especificações diferentes, uma em semi-logarítmo e outra com a variável dependente en nível. A diferença, em termos de ajuste aos dados, é mínima, conforme indicado pelo $R^{2}$. A tabela 9 resume os resultados das estimações.

Os modelos 1 e 2 da tabela 9 se referem à equação com variável dependente em nível, enquanto que os modelos 3 e 4 são os resultados dos modelos na forma semi-log. Como observamos, ambas as formas de modelagem atingem um valor de $R^{2}$ elavado, tendo as principais variáveis explicativas altamente significantes.

Os modelos 2 e 4 utilizam uma dummy pós-crise de racionamento (pós-2001) ao invés de uma dummy por ano, como o fazem os modelos 1 e 3 . Ao detalharmos as 
dummies de ano, verificamos que alguns anos não são estatisticamente significativos para explicar os preços, enquanto que outros anos têm uma importância maior. No entanto, ao definirmos uma única dummy para a questão temporal, o impacto pós-crise se torna menor, possivelmente devido aos anos de 2002 e 2003 que tiveram um impacto menor ou não significativo nos modelos com mais variáveis de tempo.

Das variáveis de marca, percebemos que o impacto da marca Brastemp é sempre superior aos das demais, como era de se esperar, dado os preços médios por marca já investigados anteriormente. Electrolux aparece em segundo lugar em termos de impacto, enquanto Consul em terceiro.

Apesar de a marca Consul ter um preço médio inferior ao da marca Bosch e de outras marcas, seu impacto é superior ao delas, possivelmente devido a uma questão de credibilidade e confiança dos consumidores nessa marca. Ao compor seus refrigeradores com características mais simples, reduzindo seu preço médio e adequando-se a um padrão de consumidores, em geral, de mais baixa renda, a marca acaba por se tornar mais popular entre as classes mais baixas, tornando então o peso da marca maior que o de outras marcas menos conhecidas.

Como esperado, um refrigerador Frost Free tem um impacto positivo e relevante no preço do produto, assim como refrigeradores de média e alta capacidade ${ }^{4}$. Quanto à classificação energética, o impacto negativo foi algo inesperado. Consistentemente, em todos os modelos testados o impacto se manteve negativo e singificante. Isto implica que, controladas pelas demais caracteríticas, um modelo da classe A ou B possui um preço médio menor que um modelo das classes CDE.

Pela tabela 8, vemos que, de fato, o preço médio de um modelo das classes AB é superior ao de um modelo das classes CDE. Pelo fato de, controladas pelas demais características, o impacto de ser classe $\mathrm{AB}$ ser negativo, isso sugere que, possivelmente, deve haver algum ganho de escala ou escopo na produção de modelos com maior tecnologia, de forma que sua produção em série tenha um custo unitário menor que o custo de se produzir um produto com uma tecnologia inferior. Esse ganho de escala pode estar ligado à forma de produção, à adequação dos padrões de produção dos motores e componentes que acabam por reduzir o consumo energético dos produtos.

Por último, em termos de portas de material especial ${ }^{5}$ (portas pratas, em inox ou em zyrium), a contribuição foi positiva, assim como a de dispenser de água, sendo que este último tem um impacto de 3,5 a 4 vezes maior.

4 Foram considerados de baixa capacidade os refrigeradores de até 250 litros no total, de média capacidade os refrigeradores entre 251 litros e 400 litros, e de alta capacidade os refrigeradores acima de 400 litros

5 em nossa base, encontram-se modelos com portas em prata, portas em material inox e portas em zyrium, sendo que este último fora incluído em nossa classificação de portas especiais por ser um material mais resistente que as portas dos modelos tradicionais. 
Tabela 9: Modelos de Preços Hedônicos

\begin{tabular}{|c|c|c|c|c|}
\hline & $\begin{array}{c}\text { Modelo } 1 \\
\text { b/se }\end{array}$ & $\begin{array}{l}\text { Modelo } 2 \\
\text { b/se }\end{array}$ & $\begin{array}{l}\text { Modelo } 3 \\
\text { b/se }\end{array}$ & $\begin{array}{c}\text { Modelo } 4 \\
\text { b/se }\end{array}$ \\
\hline Brastemp & $\begin{array}{c}839,7907^{* * *} \\
(20,8362)\end{array}$ & $\begin{array}{c}830,6059 * * * \\
(13,4269)\end{array}$ & $\begin{array}{c}6,6719^{* * *} \\
(0,0135)\end{array}$ & $\begin{array}{c}6,6702^{* * *} \\
(0,0088)\end{array}$ \\
\hline Consul & $\begin{array}{c}736,6801^{* * *} \\
(18,6686)\end{array}$ & $\begin{array}{c}729,7094^{* * *} \\
(10,1127)\end{array}$ & $\begin{array}{c}6,5984^{* * *} \\
(0,0121)\end{array}$ & $\begin{array}{c}6,5987^{* * *} \\
(0,0066)\end{array}$ \\
\hline Electrolux & $\begin{array}{c}770,4043^{* * *} \\
(19,7643)\end{array}$ & $\begin{array}{c}766,4602^{* * *} \\
(11,1491)\end{array}$ & $\begin{array}{c}6,6026^{* * *} \\
(0,0129)\end{array}$ & $\begin{array}{c}6,6058^{* * *} \\
(0,0073)\end{array}$ \\
\hline Bosch / Continental & $\begin{array}{c}491,4739 * * * \\
(33,1853)\end{array}$ & $\begin{array}{c}516,8777^{* * *} \\
(29,0559)\end{array}$ & $\begin{array}{c}6,4365^{* * *} \\
(0,0216)\end{array}$ & $\begin{array}{c}6,4710^{* * *} \\
(0,0190)\end{array}$ \\
\hline Outras Marcas & $\begin{array}{c}465,1847^{* * *} \\
(34,8823)\end{array}$ & $\begin{array}{c}493,5221^{* * *} \\
(30,9570)\end{array}$ & $\begin{array}{c}6,3987^{* * *} \\
(0,0227)\end{array}$ & $\begin{array}{c}6,4361^{* * *} \\
(0,0203)\end{array}$ \\
\hline Degelo Frost Free & $\begin{array}{c}426,1048^{* * *} \\
(11,3945)\end{array}$ & $\begin{array}{c}408,3043^{* * *} \\
(11,3093)\end{array}$ & $\begin{array}{c}0,2230^{* * * *} \\
(0,0074)\end{array}$ & $\begin{array}{c}0,2058^{* * *} \\
(0,0074)\end{array}$ \\
\hline 2 Portas & $\begin{array}{c}374,2554^{* * *} \\
(9,5269)\end{array}$ & $\begin{array}{c}377,7099 * * * \\
(9,5480)\end{array}$ & $\begin{array}{c}0,3214^{* * *} \\
(0,0062)\end{array}$ & $\begin{array}{c}0,3252^{* * * *} \\
(0,0063)\end{array}$ \\
\hline Capacidade Média & $\begin{array}{c}292,4100^{* * *} \\
(10,1415)\end{array}$ & $\begin{array}{c}296,6662^{* * *} \\
(10,2196)\end{array}$ & $\begin{array}{c}0,3378^{* * *} \\
(0,0066)\end{array}$ & $\begin{array}{c}0,3406^{* * *} \\
(0,0067)\end{array}$ \\
\hline Capacidade Alta & $\begin{array}{c}774,3463^{* * *} \\
(14,2252)\end{array}$ & $\begin{array}{c}784,6781^{* * *} \\
(14,3217)\end{array}$ & $\begin{array}{c}0,5799 * * * \\
(0,0093)\end{array}$ & $\begin{array}{c}0,5888^{* * *} \\
(0,0094)\end{array}$ \\
\hline Classe AB & $\begin{array}{c}-60,7132^{* * *} \\
(7,8471)\end{array}$ & $\begin{array}{c}-44,4667^{* * *} \\
(7,6775)\end{array}$ & $\begin{array}{c}-0,0602^{* * *} \\
(0,0051)\end{array}$ & $\begin{array}{c}-0,0441^{* * *} \\
(0,0050)\end{array}$ \\
\hline Ano 1999 & $\begin{array}{c}7,0982 \\
(19,6136)\end{array}$ & & $\begin{array}{c}0,0191 \\
(0,0128)\end{array}$ & \\
\hline Ano 2000 & $\begin{array}{l}44,5863^{* *} \\
(19,0221)\end{array}$ & & $\begin{array}{c}0,0417^{* * * *} \\
(0,0124)\end{array}$ & \\
\hline Ano 2001 & $\begin{array}{l}-13,4612 \\
(17,6773)\end{array}$ & & $\begin{array}{l}-0,0043 \\
(0,0115)\end{array}$ & \\
\hline Ano 2002 & $\begin{array}{c}6,8301 \\
(18,1503)\end{array}$ & & $\begin{array}{c}0,0048 \\
(0,0118)\end{array}$ & \\
\hline Ano 2003 & $\begin{array}{c}45,0966^{* *} \\
(19,0715)\end{array}$ & & $\begin{array}{c}0,0475^{* * *} \\
(0,0124)\end{array}$ & \\
\hline Ano 2004 & $\begin{array}{c}160,9274 * * * \\
(20,7232)\end{array}$ & & $\begin{array}{c}0,1192^{* * * *} \\
(0,0135)\end{array}$ & \\
\hline Ano 2005 & $\begin{array}{c}114,5462^{* * *} \\
(18,0022)\end{array}$ & & $\begin{array}{c}0,1090^{* * *} \\
(0,0117)\end{array}$ & \\
\hline Portas de Inox & $\begin{array}{c}111,0304^{* * *} \\
(19,0012)\end{array}$ & $\begin{array}{c}110,0914^{* * *} \\
(19,1870)\end{array}$ & $\begin{array}{c}0,0506^{* * *} \\
(0,0124)\end{array}$ & $\begin{array}{c}0,0485^{* * *} \\
(0,0126)\end{array}$ \\
\hline Dispenser de Água & $\begin{array}{c}364,3302^{* * *} \\
(18,2743)\end{array}$ & $\begin{array}{c}403,0401^{* * *} \\
(17,6361)\end{array}$ & $\begin{array}{c}0,1624^{* * *} \\
(0,0119)\end{array}$ & $\begin{array}{c}0,2026^{* * *} \\
(0,0116)\end{array}$ \\
\hline Anos pós-Crise & & $\begin{array}{c}65,1243^{* * *} \\
(6,5407) \\
\end{array}$ & & $\begin{array}{c}0,0518^{* * *} \\
(0,0043) \\
\end{array}$ \\
\hline Log-Likelihood & $-57652,65$ & $-57744,50$ & $2.475,95$ & $2.320,75$ \\
\hline$R^{2}$ & 0,969 & 0,969 & 0,999 & 0,999 \\
\hline № Observações & 8.194 & 8.194 & 8.194 & 8.194 \\
\hline
\end{tabular}

${ }^{*} \mathrm{p}<0.10,{ }^{* *} \mathrm{p}<0.05,{ }^{* * *} \mathrm{p}<0.01$ 
Todos os modelos apresentaram um bom resultado em termos de significância para as principais variáveis, além de um bom ajuste, segundo o $R^{2}$. Sendo assim, a escolha de um dos modelos para a estimação dos preços será em decorrência do resultado da otimização (log-likelihood) e da agregação ou não das variáveis de ano. Os modelos 3 e 4, na forma de semi-log, apresentam um $R^{2}$ ligeiramente melhor, enquanto que os modelos mais desagregados (modelos 1 e 3) ponderam melhor os impactos de cada ano. Optou-se pelo modelo semi-log, e dentre estes, o modelo 3.

Para o ajuste final dos preços, utilizaremos a média dos preços observados de cada SKU no período de tempo estudado e, para as SKUs nos quais não há observação de preços, utilizaremos a estimativa dos preços das mesmas.

A tabela 10 mostra, para as observações que foram utilizadas nos modelos, o preço médio observado e estimado, segundo cada conjunto de características. Como podemos ver, para cada conjunto de fatores, ambos os preços médios observados e estimados são bem próximos, à exceção para a marca Bosch-Continental.

Tabela 10: Resumo Refrigeradores: Preço Médio por Característica

\begin{tabular}{lcc}
\hline & $\begin{array}{c}\text { Preço Médio } \\
\text { Observado }\end{array}$ & $\begin{array}{c}\text { Preço Médio } \\
\text { Estimado }\end{array}$ \\
\hline Classes AB & $1.575,91$ & $1.572,03$ \\
Classes CDE & $1.167,44$ & $1.148,08$ \\
1 Porta & $1.002,54$ & 978,81 \\
2 Portas & $1.955,63$ & $1.931,78$ \\
Frost Free & $2.219,20$ & $2.186,42$ \\
Degelo Manual & $1.181,18$ & $1.164,44$ \\
Portas de Inox & $2.425,75$ & $2.411,43$ \\
Dispenser de Água & $2.124,53$ & $2.102,78$ \\
Brastemp & $2.018,91$ & $2.003,43$ \\
Consul & $1.100,27$ & $1.083,33$ \\
Electrolux & $1.311,71$ & $1.274,60$ \\
Bosch-Continental & $1.260,90$ & $1.395,35$ \\
Outras Marcas & $1.225,62$ & $1.221,78$ \\
\hline
\end{tabular}

Após todos os ajustes detalhados, finalmente temos um banco de dados de preço com todas as informações e características necessárias para procedermos às análises empíricas da questão da escolha do consumidor. 
Parte V

Resultados e Conclusões 


\section{Resultados}

\subsection{Logit Condicional}

Conforme já comentado anteriormente, para a estimação dos modelos de Logit Condicional, dividiremos a análise em algumas etapas, começando com as variáveis alternative specifics, i.e., as variáveis específicas dos modelos de refrigeradores.

O modelo de demanda que temos em mente incorporará as principais características observadas pelos consumidores quando da decisão de compra dos refrigeradores. Assim, tomaremos por base um modelo que apresente dummies de marca, número de portas (ou dummy para 2 portas), volume (capacidade), consumo energético, dummy para degelo e preço. Além disso, nosso modelo ideal deve contemplar, como controles, algumas características dos indivíduos, isto é, das famílias / residências pesquisadas, tais como renda familiar, número de moradores do domicílio, consumo total de energia ou área construída. A seguir, estudaremos como o modelo se comporta à medida que vamos acrescentando cada controle / variável de decisão.

Dentre as principais variáveis nessa categoria, temos o preço dos modelos, o consumo energético, o volume/capacidade de cada bem, o índice de eficiência calculado (proxy), além de dummies de marca, número de portas e forma de degelo. A tabela 11 mostra os principais resultados obtidos com as variáveis em questão.

O modelo 1, mais simples possível, contém apenas consumo energético, preço e volume (bruto) dos produtos. Todos os coeficientes são estatisticamente significativos ao nível de 1\%, e nosso parâmetro de interesse (a disposição a pagar, ou willingness to pay) está estimada em torno de $\mathrm{R} \$ 18,96$. O modelo 2 inclui a proxy calculada para o índice de eficiência energética. Aqui, esta nova variável não se mostra significativa, embora os demais coeficientes se mantenham significantes. Já o modelo 3, embora apresente outras duas variáveis significativas (dummies para as marcas electrolux e brastemp), o consumo energético não se mostra significativo. Como consequência, a disposição a pagar se mostra igualmente não significativa.

A disposição a pagar no modelo 4 se mostra significativa, porém este modelo apresenta um sinal oposto ao esperado para a categoria de 2 portas. Embora o beta apresentado na tabela não seja o efeito marginal e, portanto, não tenha uma interpretação clara e direta, o sinal do coeficiente nos indica a direção na qual o efeito deve contribuir para a probabilidade de se comprar um modelo (em relação ao modelo baseline). Como modelo padrão, fixamos o SKU CRA30, que é um refrigerador Consul de 1 porta, com degelo manual e 276 litros brutos (261 de armazenamento). Assim, ceteris paribus, o sinal 
Tabela 11: Modelos Logit Condicional: Variáveis Alternative-Specific Contínuas Sem Variáveis Case-Specific

\begin{tabular}{|c|c|c|c|c|}
\hline & $\begin{array}{c}\text { Modelo } 1 \\
\text { b/se }\end{array}$ & $\begin{array}{c}\text { Modelo } 2 \\
\text { b/se }\end{array}$ & $\begin{array}{c}\text { Modelo } 3 \\
\text { b/se }\end{array}$ & $\begin{array}{c}\text { Modelo } 4 \\
\text { b/se }\end{array}$ \\
\hline Consumo Energético & $\begin{array}{c}-0,0140^{* * *} \\
(0,0028)\end{array}$ & $\begin{array}{c}-0,0145^{* * *} \\
(0,0028)\end{array}$ & $\begin{array}{c}-0,0043 \\
(0,0030)\end{array}$ & $\begin{array}{c}-0,0262^{* * *} \\
(0,0034)\end{array}$ \\
\hline Capacidade & $\begin{array}{c}0,0029 * * * \\
(0,0005)\end{array}$ & $\begin{array}{c}0,0030 * * * \\
(0,0005)\end{array}$ & $\begin{array}{c}0,0037^{* * *} * \\
(0,0004)\end{array}$ & $\begin{array}{c}0,0056^{* * *} \\
(0,0005)\end{array}$ \\
\hline Preço & $\begin{array}{c}-0,0007^{* * *} \\
(0,0001)\end{array}$ & $\begin{array}{c}-0,0007^{* * *} * \\
(0,0001)\end{array}$ & $\begin{array}{c}-0,0013^{* * *} \\
(0,0001)\end{array}$ & $\begin{array}{c}-0,0013^{* * *} \\
(0,0001)\end{array}$ \\
\hline Índice de Eficiência & & $\begin{array}{c}0,0862 \\
(0,0851)\end{array}$ & & \\
\hline Electrolux & & & $\begin{array}{c}-1,2357^{* * *} \\
(0,0863)\end{array}$ & \\
\hline Brastemp & & & $\begin{array}{c}0,4295^{* * *} \\
(0,0795)\end{array}$ & \\
\hline 2 Portas & & & & $\begin{array}{c}-1,0716^{* * *} \\
(0,1800)\end{array}$ \\
\hline Frost Free & & & & $\begin{array}{c}2,0033^{* * *} \\
(0,1700)\end{array}$ \\
\hline Willingness to Pay (WTP) & 18,96 & 20,03 & 3,30 & 19,73 \\
\hline WTP: p-value (p.p.) & 0,0001 & 0,0001 & 0,1755 & 0,0000 \\
\hline Log-Likelihood & $-4.653,95$ & $-4.653,44$ & $-4.434,59$ & $-4.546,21$ \\
\hline № Observações & 50.046 & 50.046 & 50.046 & 50.046 \\
\hline
\end{tabular}

${ }^{*} \mathrm{p}<0.10,{ }^{* *} \mathrm{p}<0.05,{ }^{* * *} \mathrm{p}<0.01$

do coeficiente da dummy para "2 portas" indica que um refrigerador Consul de 1 porta tem maior probabilidade de ser comprado do que um de 2 portas. Para os modelos apenas com alternative specific, a escolha do SKU baseline parece não ter efeito: os resultados são robustos, quaisquer que sejam os SKUs declarados como padrão.

Assim, não testaremos mais a variável de índice de eficiência e investigaremos melhor a de número de portas. As próximas especificações testarão as alternative specific contínuas juntamente com as case specific contínuas. Começamos nossa análise deste tipo de variável considerando as variáveis de renda familiar (salário real), nível máximo de consumo do domicílio, além do número de moradores e de aparelhos de refrigeração (outros refrigeradores e freezeres) presentes na residência.

Para não sobrecarregar esta parte do trabalho, as tabelas com as especificações intermediárias estarão no apêndice, deixando nesta seção apenas os comentários gerais sobre os modelos. Para as variáveis citadas acima, os resultados se encontram no apêndice C.

Dentre os modelos com variáveis case specifics indicadas acima, o primeiro modelo, com renda familiar, se mostrou o melhor em termos de convergência (log-likelihood maior), 
porém teve o coeficiente de consumo significativo apenas ao nível de 10\%, e a disposição a pagar foi não significativa. Já o segundo modelo, utilizando o nível de consumo energético total do domicílio se apresentou mais robusto, melhorando um pouco a otimização em relação aos modelos 1 a 4 .

O modelo 5, com variáveis de número de moradores e de aparelhos de refrigeração foi o pior de todos, apresentando apenas o consumo energético significativo. Também apresentou resultados ruins o modelo 6 , no qual se testa se o tamanho do domicílio, em metros quadrados de área construída. Neste, o coeficiente do consumo energético foi não significativo, o que levou a um viés de estimação do parâmetro de disposição a pagar.

Como nosso interesse se resume aos coeficientes dos drivers que variam nas alternativas (em particular, consumo energético e preço), e as variáveis cases serve mais como controles, omitimos os coeficientes específicos das tabelas nesta seção.

Os modelos 5 a 8 foram baseados na especificação do modelo 1, no qual incluíamos somente preço, consumo energético e volume como alternative specifics. Os próximos modelos incluirão ainda as variáveis de degelo, marca e número de portas na tentativa de obtermos um resultado mais robusto. No entanto, replicaremos somente as case specifics dos modelos 5 e 6 , que se mostraram melhores. A tabela se encontra no apêndice C.

Ambos os modelos controlados apenas com renda familiar não apreentaram estimativas significativas para o consumo energético. No modelo 9, mesmo a dummy para Brastemp não se mostrou significante. Embora tenham obtido um nível de otimização maior (menor log-likelihood), os modelos 9 e 11 possuem coeficientes menos robustos que os modelos 10 e 12 .

Uma das limitações dos modelos com renda familiar é que esta variável apresenta muitos missings, o que reduz o número de compras e, consequentemente, de informações disponíveis para as estimações. Antes de introduzirmos algumas variáveis case specific discretas, testaremos os modelos contendo ambas as variáveis de renda familiar e consumo máximo de energia. Os resultados se encontram no apêndice, tabela C. .

Neste conjunto de especificações, verificamos que Brastemp novamente não se mostra significativo, o consumo energético é relevante a $5 \%$, assim como a disposição a pagar nos modelos 13 e 14. No entanto, ambos os modelos com degelo e número de portas se mostraram não significativos agora. Apesar da limitação por conta dos missings da variável de renda, as log-likelihood destes modelos são melhores que as dos modelos anteriores. Como último teste com cases contínuas, replicaremos o modelo 13, acrescentando separadamente as variáveis de número de portas e degelo. Os resultados estão em tabela no apêndice, tabela $\mathrm{C}$.

Destes últimos testes com características específicas contínuas dos domicílios (indivíduos), verificamos que o modelo contendo dummy para marca Electrolux e degelo (Frost 
Free) possui um nível de convergência tão bom quanto os modelos anteriores (13 e 14), mas um nível de significância das principais variáveis muito melhor. Inclusive o p-valor da disposição a pagar se encontra significativo a 1\%. Os modelos seguintes introduzirão variáveis case specific discretas, o que dificulta substancialmente os cálculos numéricos utilizados para a convergência dos modelos, embora, como veremos, também melhora significativamente o nível de convergência quando convergem. Para cases discretas, testaremos acrescentar as dummies de Peso da Conta de Luz no orçamento (leve, pesada e muito pesada), região geográfica, região do domicílio (luxo, classe média, pobre), interesse em comprar refrigerador mais eficiente, e dummies para área construída. Os resultados se encontram no apêndice, na tabela C.

Este primeiro conjunto considera o modelo mais simples de variáveis alternative specifis. Como podemos notar, os níveis de convergência, considerados pelo grau de otimização da log-likelihood são melhores que nos modelos anteriores. Em termos de significância dos coeficientes, os modelos 27 e 31 mostram-se melhores para as principais variáveis de interesse (preço e consumo energético), mas os demais modelos são também significantes. As próximas especificações a serem testadas terão as mesmas variáveis alternative specific que o modelo 17 mostrado acima, e utilizarão os mesmos conjuntos de cases testados nos modelos 27 a 31.

Tabela 12: Modelos Logit Condicional: Inclusão de Alternative-Specific Discretas

\begin{tabular}{|c|c|c|c|c|c|}
\hline & $\begin{array}{c}\text { Modelo } 32 \\
\text { b/se }\end{array}$ & $\begin{array}{c}\text { Modelo } 33 \\
\text { b/se }\end{array}$ & $\begin{array}{c}\text { Modelo } 34 \\
\text { b/se }\end{array}$ & $\begin{array}{c}\text { Modelo } 35 \\
\text { b/se }\end{array}$ & $\begin{array}{c}\text { Modelo } 36 \\
\text { b/se }\end{array}$ \\
\hline Consumo Energético & $\begin{array}{c}-0,0560 * * * \\
(0,0171)\end{array}$ & $\begin{array}{c}-0,0240^{*} \\
(0,0124)\end{array}$ & $\begin{array}{c}-0,0545^{* * *} \\
(0,0199)\end{array}$ & $\begin{array}{c}-0,0560 * * * \\
(0,0144)\end{array}$ & $\begin{array}{c}-0,0573^{* * *} \\
(0,0178)\end{array}$ \\
\hline Capacidade & $\begin{array}{c}0,0069 * * * \\
(0,0019)\end{array}$ & $\begin{array}{c}0,0094^{* * *} \\
(0,0017)\end{array}$ & $\begin{array}{c}0,0072^{* * *} \\
(0,0026)\end{array}$ & $\begin{array}{c}0,0075^{* * *} \\
(0,0018)\end{array}$ & $\begin{array}{c}0,0095^{* * *} \\
(0,0019)\end{array}$ \\
\hline Preço & $\begin{array}{c}-0,0027^{* * *} \\
(0,0005)\end{array}$ & $\begin{array}{c}-0,0036 * * * \\
(0,0004)\end{array}$ & $\begin{array}{c}-0,0019 * * * \\
(0,0005)\end{array}$ & $\begin{array}{c}-0,0027^{* * *} \\
(0,0004)\end{array}$ & $\begin{array}{c}-0,0030 * * * \\
(0,0005)\end{array}$ \\
\hline Electrolux & $\begin{array}{c}-1,1152^{* * *} \\
(0,2720)\end{array}$ & $\begin{array}{c}-0,7845^{* * *} \\
(0,2065)\end{array}$ & $\begin{array}{c}-1,1362^{* * *} \\
(0,3796)\end{array}$ & $\begin{array}{c}-0,4653^{* *} \\
(0,2328)\end{array}$ & $\begin{array}{c}-0,9898^{* * *} \\
(0,2596)\end{array}$ \\
\hline Frost Free & $\begin{array}{c}1,2328 * * * \\
(0,4529)\end{array}$ & $\begin{array}{c}0,4064 \\
(0,4092) \\
\end{array}$ & $\begin{array}{c}1,2090^{* *} \\
(0,5075) \\
\end{array}$ & $\begin{array}{c}1,5434^{* * *} \\
(0,3872)\end{array}$ & $\begin{array}{c}0,5460 \\
(0,5032) \\
\end{array}$ \\
\hline Controles (Case-Spec.) & $\begin{array}{l}\text { Renda Familiar } \\
\text { Consumo Máx. } \\
\text { Peso da Conta }\end{array}$ & $\begin{array}{c}\text { Renda Familiar } \\
\text { Consumo Máx. } \\
\text { Região do } \\
\text { Domicílio }\end{array}$ & $\begin{array}{c}\text { Renda Familiar } \\
\text { Consumo Máx. } \\
\text { Região } \\
\text { Geográfica }\end{array}$ & $\begin{array}{l}\text { Renda Familiar } \\
\text { Consumo Máx. } \\
\text { Refrigerador } \\
\text { Mais Eficiente }\end{array}$ & $\begin{array}{l}\text { Renda Familiar } \\
\text { Consumo Máx. } \\
\text { Área Construída }\end{array}$ \\
\hline Willingness to Pay (WTP) & 20,61 & 6,65 & 28,73 & 20,78 & 19,08 \\
\hline WTP: p-value (p.p.) & 0,0083 & 0,0698 & 0,0440 & 0,0014 & 0,0113 \\
\hline Log-Likelihood & $-2.458,32$ & $-2.477,00$ & $-2.441,64$ & $-2.213,80$ & $-2.171,84$ \\
\hline № Observações & 32.908 & 32.832 & 33.630 & 28.614 & 29.678 \\
\hline
\end{tabular}

À exceção do modelo 33, os demais modelos da tabela 12 apresentam coeficientes de preço e consumo bem significativos (a 1\%), e seus resultados parecem igualmente mais robustos. Dentre estes modelos, prosseguiremos as análises baseados no modelo 35 por conta da sua maior log-likelihood e por apresentar uma estimativa para o willingness to pay melhor. 


\subsection{Mixed Logit}

Para contornarmos o problema de independência das alternativas irrelevantes, apenas a inclusão das características específicas dos SKUs dos refrigeradores não será o bastante para ampliar a substitutibilidade entre bens similares no espaço de características. Portanto, introduziremos aqui um outro método de modelagem que tenta corrigir esta questão.

O modelo Mixed Logit, ao permitir haver heterogeneidade nos coeficientes, amplia o padrão de substituição entre elas, evitando o problema de IIA. A especificação é semelhante aos modelos Logit Condicionais, porém agora permitimos que o parâmetro do preço apresente uma heterogeneidade nos indivíduos. Com a introdução dos parâmetros aleatórios, geralmente seguindo uma distribuição normal de média $\beta$ e variância $\sigma_{\beta}$, ou ainda uma distribuição lognormal, obtemos estimativas mais confiáveis e mais realistas.

Para os modelos Mixed Logit, utilizamos as especificações que tiveram melhores desempenhos ${ }^{1}$ no caso dos modelos de Logit condicional, fazendo os devidos ajustes necessários. Na tabela 13 a seguir mostramos alguns dos melhores modelos obtidos.

Como podemos observar, independente da especificação, os modelos Mixed Logit apresentam em geral um valor mais baixo para a disposição a pagar dos consumidores, quando comparados aos melhores modelos estimados por meio de Logit Condicional (tabela 12). É importante destacar aqui que especificamos apenas o preço dos produtos como tendo coeficientes aleatórios, e assumimos que esses parâmetros estocásticos se comportem conforme uma distribuição normal.

Para o nosso estudo, as duas variáveis de interesse são os coeficientes do preço e do consumo energético. Assim, testamos também especificações em que, além do preço, permitíamos que o consumo assumisse valores aleatórios, segundo uma normal. No entanto, os resultados apontavam para um desvio-padrão não singificativo, indicando que tornar o coeficiente do consumo em um parâmetro aleatório não tornaria os modelos melhores e não corrigiriam os problemas de IIA. Somente os coeficientes da variável de preço foram significantes.

Dos modelos da tabela 13, trabalharemos com base no modelo ML3: além de todos os parâmetros de interessse serem significativos, foi igualmente o modelo que atingiu o maior grau de otimização, e os resultados da disposição a pagar se mostram robustos e muito próximo do resultado alcançado no modelo ML2.

1 Adicionalmente, testamos, da mesma forma que no caso do Logit Condicinal, especificações mais simples, em que havia somente alternative specific. No entanto, estas especificações não reportaram resultados ou desvios-padrão significativos. Outras especificações incluindo case specific também foram testadas, porém algumas sem sucesso quanto à convergência dos modelos. Reportamos neste trabalho somente os principais resultados e os modelos em que acreditamos. 
Tabela 13: Modelos Mixed Logit Random Variable: Preço

\begin{tabular}{lccc}
\hline & Modelo ML1 & Modelo ML2 & Modelo ML3 \\
& $\mathrm{b} / \mathrm{se}$ & $\mathrm{b} / \mathrm{se}$ & $\mathrm{b} / \mathrm{se}$ \\
\hline Frost Free & $0,8466^{* * *}$ & $0,6999^{* * *}$ & $0,6397^{* * *}$ \\
& $(0,1649)$ & $(0,1446)$ & $(0,1780)$ \\
Brastemp & $0,4174^{* * *}$ & $0,4703^{* * *}$ & $0,5278^{* * *}$ \\
& $(0,1403)$ & $(0,1237)$ & $(0,1568)$ \\
Electrolux & $-0,6565^{* * *}$ & $-0,7818^{* * *}$ & $-0,5313^{* * *}$ \\
& $(0,1284)$ & $(0,1165)$ & $(0,1368)$ \\
Capacidade & $0,0117^{* * *}$ & $0,0079^{* * *}$ & $0,0112^{* * *}$ \\
& $(0,0012)$ & $(0,0010)$ & $(0,0013)$ \\
Consumo Energético & $-0,0460^{* * *}$ & $-0,0361^{* * *}$ & $-0,0471^{* * *}$ \\
& $(0,0061)$ & $(0,0054)$ & $(0,0067)$ \\
Preço & $-0,0028^{* * *}$ & $-0,0020^{* * *}$ & $-0,0026^{* * *}$ \\
& $(0,0003)$ & $(0,0003)$ & $(0,0003)$ \\
\hline Preço (S.D.) & $-0,0013^{* * *}$ & $-0,0010^{* * *}$ & $0,0013^{* * *}$ \\
& $(0,0002)$ & $(0,0002)$ & $(0,0003)$ \\
\hline Controles (Case-Spec.) & Renda Familiar & Consumo Máx. & Renda Familiar \\
& & & Consumo Máx. \\
\hline Willingness to Pay (WTP) & 16,41 & 17,86 & 17,83 \\
WTP: p-value (p.p.) & 0,0000 & 0,0000 & 0,0000 \\
Log-Likelihood & $-2.838,24$ & $-4.181,21$ & $-2.793,91$ \\
No Observações & 33.630 & 50.046 & 33.630 \\
\hline$*$ p $<0.10, * *$ p $<0.05, * * *$ p $<0.01$ & &
\end{tabular}

\subsection{Medindo a Economia de Energia dos Refrigeradores}

Com base nos resultados para a disposição a pagar, calculados tanto a partir dos modelos de Logit Condicional quanto a partir dos modelos Mixed Logit, podemos agora avaliar se os consumidores avaliam corretamente o ganho de economia derivado do consumo energético mais eficiente, i.e., se a disposição a pagar por unidade de eficiência energética é, de fato, próxima da economia real de energia, produzida pela redução de 1 kilowatt-hora/mês no consumo de eletricidade, ao longo de toda a vida útil do refrigerador.

Este passo do trabalho é importante porque, caso haja um desvio nesses valores e os consumidores sub-avaliem o custo de uma unidade de eficiência energética, teremos então um espaço para a promoção de políticas públicas visando o aumento da avaliação dos consumidores ou ainda uma promoção às políticas industriais voltadas à produção de equipamentos mais eficientes.

Para calcularmos o ganho monetário proporcionado pela redução do consumo de energia elétrica em 1 kilowatt-hora/mês, utilizaremos as informações de custo médio da tarifa de energia residencial, ao longo de todo o período de vida do refrigerador, trazidos 
a valor presente pela Taxa de Juros de Longo Prazo (TJLP).

Segundo o estudo realizado por Seiders et al. (2007), para o National Association of Home Builders e Bank of America Home Equity, o tempo médio estimado de uso de um refrigerador é em torno de 13 anos. Portanto, para o cálculo de vida útil, utilizaremos este período de 13 anos, ou 156 meses, contados a partir de Março/2002, que corresponde ao primeiro mês pós-crise de racionamento energético de 2001/2002.

Os dados de tarifa elétrica média foram obtidos através da Agência Nacional de Energia Elétrica (ANEEL), enquanto que os dados da TJLP foram obtidos junto ao site da Receita Federal. A título de robustez, calcularemos também o valor presente utilizando a taxa de juros da poupança desse mesmo período. A tabela 14 mostra as estimativas de economia de energia obtidas.

Tabela 14: Cálulo do Valor Presente do Fluxo de Economia de Energia

A valores reais de 2005

\begin{tabular}{ccccccc}
\hline Ano & Meses & TJLP & Poupança & Tarifa $(\mathbf{R} \$ /$ Kwh) & VPL (TJLP) & VPL (Poupança) \\
\hline mar/02 & 1 & $0,83 \%$ & $0,68 \%$ & $\mathrm{R} \$ 0,20$ & $\mathrm{R} \$ 0,32$ & $\mathrm{R} \$ 0,32$ \\
abr/02 & 2 & $0,79 \%$ & $0,74 \%$ & $\mathrm{R} \$ 0,20$ & $\mathrm{R} \$ 0,31$ & $\mathrm{R} \$ 0,31$ \\
mai/02 & 3 & $0,79 \%$ & $0,71 \%$ & $\mathrm{R} \$ 0,21$ & $\mathrm{R} \$ 0,31$ & $\mathrm{R} \$ 0,31$ \\
jun/02 & 4 & $0,79 \%$ & $0,66 \%$ & $\mathrm{R} \$ 0,21$ & $\mathrm{R} \$ 0,31$ & $\mathrm{R} \$ 0,31$ \\
jul/02 & 5 & $0,83 \%$ & $0,77 \%$ & $\mathrm{R} \$ 0,21$ & $\mathrm{R} \$ 0,30$ & $\mathrm{R} \$ 0,30$ \\
ago/02 & 6 & $0,83 \%$ & $0,75 \%$ & $\mathrm{R} \$ 0,21$ & $\mathrm{R} \$ 0,30$ & $\mathrm{R} \$ 0,30$ \\
set/02 & 7 & $0,83 \%$ & $0,70 \%$ & $\mathrm{R} \$ 0,21$ & $\mathrm{R} \$ 0,29$ & $\mathrm{R} \$ 0,30$ \\
out/02 & 8 & $0,83 \%$ & $0,78 \%$ & $\mathrm{R} \$ 0,21$ & $\mathrm{R} \$ 0,29$ & $\mathrm{R} \$ 0,29$ \\
nov/02 & 9 & $0,83 \%$ & $0,77 \%$ & $\mathrm{R} \$ 0,22$ & $\mathrm{R} \$ 0,29$ & $\mathrm{R} \$ 0,29$ \\
dez/02 & 10 & $0,83 \%$ & $0,86 \%$ & $\mathrm{R} \$ 0,22$ & $\mathrm{R} \$ 0,28$ & $\mathrm{R} \$ 0,28$ \\
$\ldots$ & $\ldots$ & $\ldots$ & $\ldots$ & $\mathrm{R} \$ 0,32$ & $\mathrm{R} \$ 0,12$ & $\mathrm{R} \$ 0,11$ \\
set/14 & 151 & $0,42 \%$ & $0,59 \%$ & $\mathrm{R} \$ 0,33$ & $\mathrm{R} \$ 0,12$ & $\mathrm{R} \$ 0,11$ \\
out/14 & 152 & $0,42 \%$ & $0,60 \%$ & $\mathrm{R} \$ 0,33$ & $\mathrm{R} \$ 0,12$ & $\mathrm{R} \$ 0,11$ \\
nov/14 & 153 & $0,42 \%$ & $0,55 \%$ & $\mathrm{R} \$ 0,33$ & $\mathrm{R} \$ 0,12$ & $\mathrm{R} \$ 0,12$ \\
dez/14 & 154 & $0,42 \%$ & $0,61 \%$ & $\mathrm{R} \$ 0,34$ & $\mathrm{R} \$ 0,12$ & $\mathrm{R} \$ 0,12$ \\
jan/15 & 155 & $0,46 \%$ & $0,59 \%$ & $\mathrm{R} \$ 0,34$ & $\mathrm{R} \$ 0,12$ & $\mathrm{R} \$ 0,12$ \\
fev/15 & 156 & $0,46 \%$ & $0,52 \%$ & $\mathrm{R} \$ \mathbf{2 7}, 7 \mathbf{3}$ & $\mathrm{R} \$ \mathbf{2 8 , 2 3}$ \\
\hline \multicolumn{7}{c}{ Economia Total de Energia por Kwh em toda a vida útil: }
\end{tabular}

Por essa metodologia, estimamos que a economia efetiva por kilowatt-hora é de $\mathrm{R} \$$ 27,73 ou $\mathrm{R} \$ 28,23$, a depender da taxa de desconto intertemporal utilizada. Importante destacar que este cálculo diz respeito ao valor da tarifa de energia elétrica já incorporando os impostos devidos, e calculados sobre a tarifa média em âmbito nacional.

A tabela 15 mostra o valor da disposição a pagar e seu respectivo intervalo de confiança, para os modelos Logit Condicinal e Mixed Logit com que escolhemos trabalhar nas seções anteriores. Como podemos observar, o valor presente da economia de energia na redução de $1 \mathrm{kwh} /$ mês de consumo está dentro do intervalo de confiança. Isto significa que, em geral, os consumidores avaliam corretamente a economia de energia na decisão de compra de refrigeradores mais eficientes. 
Tabela 15: Disposição a Pagar por unidade de Eficiência Energética de Refrigeradores

\begin{tabular}{rccc}
\hline Modelo & Média & S.E. & Intervalo de Confiança $\mathbf{( 9 5 \% )}$ \\
\hline Logit Condional & 20,78 & 6,509 & 8,02 a 33,54 \\
Mixed Logit & 17,83 & 3,334 & 11,30 a 24,36 \\
\hline
\end{tabular}

Como notamos, não apenas o valor estimado da disposição a pagar dos modelos Mixed Logit são menores, mas ktambém seu erro-padrão é menor. Por este tipo de modelagem corrigir os problemas de independência das alternativas irrelevantes, ele torna os padrões de substituição mais próximos do vivenciado pelos consumidores, e parece portanto repreentar melhor a realidade.

Assim, tendemos a escolher o modelo Mixed Logit, em particular os resultados apresentados pelo modelo ML3 para medirmos a disposição a pagar dos consumidores.

Da tabela 14, vemos que a estimativa de economia efetiva total ao se reduzir o consumo de energia em $1 \mathrm{kwh} /$ mês é algo em torno de $\mathrm{R} \$ 27,73$. Assim, considerando este valor e comparando com os valores obtidos da disposição a pagar mostrados na tabela 15 , vemos que o valor monetário da economia de energia está acima do limite superior do intervalo de confiança encontrado.

Assim, temos evidência de que os consumidores estão, em média, subavaliando a economia gerada por uma redução de $1 \mathrm{kwh} /$ mês no consumo de energia em um refrigerador $^{2}$. Isto abre espaço para uma série de políticas públicas voltadas ao aumento desta disposição a pagar, seja com campanhas de incentivo ao uso do Selo Procel, de conscientização dos consumidores com relação à economia de energia, seja por meio de incentivos e subsídios à indústria para a produção de modelos mais eficientes.

2 É importante destacar que, uma vez que os parâmetros de preços são aleatórios e se comportam conforme uma distribuição normal, deveríamos, em princípio, estruturar uma distribuição para o intervalo de confiança, baseados no desvio-padrão estimado do preço (parte aleatória). No entanto, por questão de compatibilização e comparatibilidade com o modelo Logit Condicional, calculamos somente o intervalo de confiança baseados no valor médio dos parâmetros. 


\subsection{Considerações Finais}

Este trabalho teve por objetivo mensurar o quanto o consumidor valoriza uma unidade extra de eficiência de energia. Para tanto, focamos nos modelos de refrigeradores comprados entre 2002 e 2005 pelos domicílios entrevistados pela pesquisa de campo da Procel/Eletrobrás.

Com base nos modelos de refrigeradores e seus respecitvos preços e características, estimamos um modelo de preços hedônicos para obtermos uma estimativa de preço para os modelos cuja informação não estava disponível.

A fim de estimarmos a disposição a pagar dos consumidores, focamos nossa análise num modelo de demanda do tipo Logit Condicional, segundo o qual podemos analisar a decisão de escolha dos consumidores frente às diversas opções com que se deparam.

Os resultados se mostraram robustos, embora apresentem certa limitação por problemas de IIA, decorrente da escolha da modelagem. Os resultados apontam uma disposição a pagar em torno de $R \$ 20,77$, com intervalo de confiança entre $R \$ 10,07$ e $R \$$ 31,48 .

Para corrigir as limitações impostas pelo modelo Logit, introduzimos um modelo com parâmetros aleatórios, de forma que o problema da independência das alternativas irrelevantes pudesse ser resolvido.

As estimativas com o Mixed Logit foram igualmente robustas e significativas. Baseados nesta modelagem, estimamos que a disposição a pagar está em torno de $\mathrm{R} \$ 17,83$, com intervalo de confiança entre $\mathrm{R} \$ 11,30$ e $\mathrm{R} \$ 24,36$.

Com base nos valores de tarifa elétrica residencial, pudemos calcular o valor presente da redução de consumo energético em 1 kwh/mês ao longo da vida útil de um refrigerador. Os resultados apontam para uma economia em torno de $\mathrm{R} \$ 27,73$.

Assim, nossos resultados indicam que o consumidor subestima o valor da economia de energia decorrente de uma unidade adicional de eficiência energética. Este resultado abre espaço para a discussão e implementação de políticas voltadas à maior conscientização da população com relação à importância da economia de eletricidade, e/ou políticas industriais voltadas ao incentivo à produção de bens mais eficientes em termos de energia. 


\section{Referências}

ALLCOTT, H.; WOZNY, N. Gasoline prices, fuel economy, and the energy paradox. Review of Economics and Statistics, MIT Press, v. 96, n. 5, p. 779-795, 2014. Citado na página 24.

BANERJEE, A.; SOLOMON, B. D. Eco-labeling for energy efficiency and sustainability: a meta-evaluation of us programs. Energy Policy, Elsevier, v. 31, n. 2, p. 109-123, 2003. Citado na página 23.

BARDELIN, C. E. A. Os efeitos do Racionamento de Energia Elétrica ocorrido no Brasil em 2001 e 2002 com Ênfase no Consumo de Energia Elétrica. 113 p. Dissertação (Mestrado), 2004. Citado 2 vezes nas páginas 15 e 16.

CAMERON, A. C. Microeconometrics: methods and applications. [S.l.]: Cambridge university press, 2005. Citado 2 vezes nas páginas 30 e 32.

CARDOSO, A. R. Estudo da Disposição a Pagar por Unidade de Eficiência Energética: O caso dos Refrigeradores no Brasil. Dissertação (Mestrado) - Universidade de São Paulo, 2015. Citado na página 8.

CARDOSO, A. R. Willigness to Pay for more Efficient Energy-Saver Household Appliances: the Case of Refrigerators in Brazil. Dissertação (Mestrado) - University of São Paulo, 2015. Citado na página 9.

CARDOSO, R. B. Avaliação da economia de Energia Atribuída ao Programa Selo PROCEL em freezers e Refrigeradores. Tese (Doutorado) — UNIVERSIDADE FEDERAL DE ITAJUBÁ, 2008. Citado na página 42.

DUBIN, J. A.; MCFADDEN, D. L. An econometric analysis of residential electric appliance holdings and consumption. Econometrica: Journal of the Econometric Society, JSTOR, p. 345-362, 1984. Citado 3 vezes nas páginas 8, 9 e 29.

GERARD, F. Energy crisis management, temporary incentives, long-term effects: Evidence from the 2001 brazilian electricity crisis. Temporary Incentives, Long-Term Effects: Evidence from the, 2013. Citado 2 vezes nas páginas 15 e 22.

GOODMAN, A. C. Andrew court and the invention of hedonic price analysis. Journal of Urban Economics, Elsevier, v. 44, n. 2, p. 291-298, 1998. Citado na página 47.

GREENE, W. H. Econometric analysis, 6th. [S.l.: s.n.], 2008. Citado 3 vezes nas páginas 30,31 e 32 .

HANEMANN, W. M. Discrete/continuous models of consumer demand. Econometrica: Journal of the Econometric Society, JSTOR, p. 541-561, 1984. Citado 3 vezes nas páginas 26, 27 e 29 .

HEINZLE, S.; WÜSTENHAGEN, R. Consumer survey on the new format of the european energy label for televisions-comparison of a"ag closed"versus a"beyond a"scale format. St. Gallen: University of St. Gallen, 2009. Citado 2 vezes nas páginas 21 e 22. 
JAFFE, A. B.; STAVINS, R. N. The energy paradox and the diffusion of conservation technology. Resource and Energy Economics, Elsevier, v. 16, n. 2, p. 91-122, 1994. Citado 2 vezes nas páginas 23 e 24.

JANNUZZI, G. D. M. Aumentando a eficiência nos usos finais de energia no brasil. Sustentabilidade na Geração e o Uso da Energia no Brasil: os próximos 20 anos, 2002. Citado 2 vezes nas páginas 35 e 42 .

MCFADDEN, D. The measurement of urban travel demand. Journal of public economics, Elsevier, v. 3, n. 4, p. 303-328, 1974. Citado na página 29.

MELO, C. A. de. Padrões de eficiência energética para equipamentos elétricos de uso residencial. Tese (Doutorado) - Universidade Etadual de Campinas, Faculdade de Engenharia Mecânica, 2009. Citado 5 vezes nas páginas 35, 42, 43, 46 e 71.

MILLS, B.; SCHLEICH, J. What's driving energy efficient appliance label awareness and purchase propensity? Energy Policy, Elsevier, v. 38, n. 2, p. 814-825, 2010. Citado na página 21.

MURRAY, A. G.; MILLS, B. F. Read the label! energy star appliance label awareness and uptake among us consumers. Energy Economics, Elsevier, v. 33, n. 6, p. 1103-1110, 2011. Citado na página 22.

NERI, M. C. et al. A nova classe média. Rio de Janeiro: FGV/IBRE, CPS, 2008. Citado 3 vezes nas páginas 16,36 e 38 .

SALLEE, J.; WEST, S.; FAN, W. Vdo consumers recognize the value of fuel economy. Evidence from Used Car Prices and Gasoline Price Fluctuations. V Work in Progress, Macalester College (January), 2011. Citado na página 24.

SAMMER, K.; WÜSTENHAGEN, R. The influence of eco-labelling on consumer behaviour-results of a discrete choice analysis for washing machines. Business Strategy and the Environment, Wiley Online Library, v. 15, n. 3, p. 185-199, 2006. Citado 4 vezes nas páginas 8, 9, 22 e 31.

SEIDERS, D. et al. Study of life expectancy of home components. National Association of Home Builders, Washington, DC, 2007. Citado na página 61.

SUTHERLAND, R. J. Market barriers to energy-efficiency investments. The Energy Journal, JSTOR, p. 15-34, 1991. Citado 2 vezes nas páginas 21 e 24.

WARD, D. O. et al. Consumer willingness to pay for appliances produced by green power partners. Energy Economics, Elsevier, v. 33, n. 6, p. 1095-1102, 2011. Citado na página 22 .

WARD, D. O. et al. Factors influencing willingness-to-pay for the energy star ${ }^{\circledR}$ label. Energy Policy, Elsevier, v. 39, n. 3, p. 1450-1458, 2011. Citado na página 22. 
Apêndices 


\section{APÊNDICE A - Identificação dos SKUs}

A seguir seguem os detalhes sobre a identificação dos SKUs presentes nas bases de preço. O algoritmo de filtros e etapas segue descrito junto do texto da dissertação.

Basicamente, há três formas de SKUs na base: os que apresentam o código do SKU no tag da descrição do aparelho; os que apresentam características suficientes para uma identificação parcial do aparelho (marca / número de portas / litragem); e os que não podem ser identificados (por não possuírem algumas das características para identificação parcial supracitadas ou por conter informações conflitantes / erradas no tag).

\section{A.0.1 SKUs Identificáveis}

O primeiro subconjunto de informações trabalhadas se refere aos dados de preços cuja informação de SKU é perfeitamente identificável. De forma geral, os tags das descrições dos modelos vêm no seguinte formato:

REFRIGERADOR DOMÉSTICO TIPO LITRAGEM MOD.: MODELO MARCA (UNID)

No qual, TIPO pode ser "SIMPLES" ou "DUPLEX", indicando a presença de 1 ou 2 portas; LITRAGEM representa a capacidade do eletrodoméstico, em litros, e pode ser bruta ou de armazenamento, embora não seja identificado qual o tipo de litragem que se trata (e.g. "360 LITROS"); MODELO representa o SKU, na maioria das vezes indicando a versão do refrigerador (e.g. "BRM42A"); e $M A R C A$ indica a marca do refrigerador.

Para o caso da litragem, foi adotada a seguinte estratégia: para modelos com mais de uma litragem disponível, adotou-se a mais elevada como capacidade bruta do aparelho, e a mais baixa como capacidade de armazenamento. Já para os modelos em que não havia duas ou mais litragens disponíveis, adotou-se a litragem como capacidade bruta e, tanto quanto possível, foi investigada a capacidade de amazenamento segundo os manuais de uso e/ou boletins técnicos disponíveis.

Em termos de identificação, os modelos de refrigeradores da base PPH/Procel tem algumas fortes limitações como já visto acima. Com a pesquisa em manuais de uso e/ou boletins técnicos, conjuntamente com o cruzamento das informações disponíveis na base FGV/IBRE, foi possível identificar a grande maioria dos modelos, mas num formato mais simples de SKU (sem indicar a versão do refrigerador).

Já as informações da base FGV/IBRE que são explicitamente identificáveis em termos de SKU, geralmente informam o código mais completo, contendo informações 
de versões dos modelos. Para compatibilização das bases, padronizamos as SKUs para o formato mais simples, sem indicação de versão do aparelho. Portanto, cada código passará a indicar um modelo, e não mais um modelo de determinada versão. Mesmo esta padronização requeriu alguns cuidados especiais, dado que a forma de codificar cada SKU difere substancialmente entre fabricante. Os boletins técnicos, com descrição explícita do significado de cada letra/sigla, favoreceram a melhor identificação e padronização desses códigos.

\section{A.0.2 SKUs Parcialmente Identificáveis}

Embora muitas das descrições dos tags de preços incluam informações explicitas do código dos respectivos SKUs, há muitos casos em que este código não está presente, mas há uma gama de informações suficientes para uma identificação parcial das principais características dos refrigeradores.

Assim, muitos dos tags considerados como parcialmente identifcados contêm informações tais como "SIMPLES" ou "DUPLEX" (ou ainda "BIPLEX" em alguns casos); muitos explicitam o termo "FROST FREE"; todos identificam a capacidade (em alguns casos bruta, em outras possivelmente de armazenamento); além de informar a marca dos modelos.

Dessa forma, embora não seja possível identificar exatamente os modelos por seu código SKU, podemos inferir uma série de características relevantes acerca dos modelos.

Em termos de padronização, para os casos de SKUs parcialmente identificados, procedemos da mesma forma que o fizemos para os modelos da base PPH/Procel que não puderam ser exatamente identificados: formulamos um tag genérico com informações de marca, número de portas, e capacidade (e.g. "CONSULBIPLEX390").

Mesmo com o nome mais genérico, alguns modelos, principalmente da marca Consul, puderam ser identificados pelos manuais de uso e/ou boletins técnicos. Assim, modelos como "CONSUL300" ou "CONSUL120" puderam ser identifcados porque os próprios manuais constavam na capa de nomes como "CONSUL 300", por exemplo. No entanto, uma grande parcela permaneceu ainda com o nome genérico.

Uma vez que a própria base PPH/Procel continha alguns modelos igualmente com nomes genéricos, utilizamo-nos desses tags parcialmente identificados para fazermos o matching de preços. Não é a forma mais acurada e ideal, mas dadas as limitações de ambas as bases e, considerando os matchings perfeitos das características disponíveis, foi o melhor ajuste que pudemos fazer de forma a aproveitar ao máximo todas as informações disponíveis.

Dentre as informações que puderam ser exata ou parcialmente identificáveis, após todos os ajustes, foi possível identificar 143 diferentes modelos de refrigeradores. Houve 
ainda 4 casos de modelos com códigos perfeitamente identificáveis que foram considerados "unbranded" e desconsiderados das estimações por terem códigos de SKU que não eram compatíveis com as marcas descritas nos tags dos modelos (e.g. "MOD:CRA28B BRASTEMP (UNID)": CRA28A indica que é Consul de 1 porta, 280 litros e primeira versão (versão A), mas o tag indica marca como se fosse BRASTEMP). Os 4 modelos que se encaixam neste caso foram descartados porque não se pode inferir se o erro aconteceu na indicação da Marca ou do código do modelo.

Com esta forma de identificação, foi possível nomear 77 modelos distintos, alguns com informações mais completas, e outros com menos informações. Em termos de modelagem, no entanto, somente os modelos nos quais encontramos todas as informações completas (marca, número de portas, forma de degelo e capacidade) é que puderam ser utilizadas.

\section{A.0.3 SKUs Não Identificáveis}

Não obstante os casos de modelos parcial ou exatamente identificados, um considerável conjunto de modelos compôs o que chamamos de modelos não identificáveis. Estes correspondem aos casos em que, apesar de haver informações de marca, e em alguns casos até indicação de número de portas ou forma de degelo, o range indicando capacidade era amplo, tornando uma série de modelos distintos de refrigeradores compatíveis com a categoria descrita no tag. Este é o caso, por exemplo, do "BOSCHDUPLEX300A360": pode-se inferir a marca (Bosch), o número de portas (Duplex $=2)$, mas a capacidade (300 Litros a 360 Litros) pode envolver uma série de refrigeradores nessa faixa. Assim, estes dados foram identificados da mesma forma que os parcialmente identificados, mas agora com o respectivo intervalo de capacidade.

Duas coisas são importantes esclarecer a respeito desse conjunto de informações. O primeiro é que, uma vez que não se pode inferir exatamente o modelo, eles foram desconsiderados dos cálculos por não podermos obter as caracteríticas exatas dos mesmos. Um segundo ponto é que, da forma descrita, não se pode inferir se se tratam de modelos quaisquer que se encaixam na categoria ou se o valor do preço dessas categorias é, na verdade, uma média dos preços dos refrigeradores que se encontram nesse intervalo de capacidade.

No primeiro caso, a ausência das caracteríticas dos modelos impõem falta de dados que naturalmente os exclui das estimações de preços hedônicos. Já no segundo caso, se os preços desses tags forem uma média dos modelos parcial ou exatamente identificados, a exclusão das médias dos modelos não seria ruim, uma vez que temos os próprios modelos identificados. Se, no entanto, esses tags constituírem um refrigerador específico que se enquadre no intervalo de volume indicado, então é fortemente recomendado que se excluam esses dados do modelo, por serem poucos confiáveis quanto à consistência da coleta (não 
se pode então garantir que todos os meses tenham sido coletados preços para o mesmo modelo/SKU).

Dessa forma, seja por uma razão ou outra apresentada, não consideramos estes casos no momento da estimação dos modelos hedônicos. Com isto, 77 "modelos" deixaram de ser utillizados. Comparado à quantidade de modelos identificados, pode parecer um número pequeno, mas sua representatividade na amostra de preços é muito significativa.

Em termos de volume de informações, cerca de $81 \%$ dos tags descritos na base são modelos não identificáveis. Descartadas essas informações, resta-nos um total de 11.027 informações de preços que podem ser utilizados. Apesar da forte redução de dados disponíveis, os dados que restaram representam uma variedade de modelos grande o suficiente para que os resultados sejam robustos.

Acerca das descrições genéricas ainda, estas informações podem ter sido geradas simplesmente por conta de erros no momento de extrairem os dados dos sistema. No processo de obtenção da lista de informações de preços a partir do sistema do IBRE, pode ser que o mesmo tenha liberado não apenas os preços coletados, mas também as médias e resumos de informações por marca e/ou range de capacidade. Neste caso, as cerca de 11.000 informações seriam a base para a obtenção das médias representadas pelos tags genéricos. Assim, a exclusão deles não seria de fato um problema. 


\section{APÊNDICE B - Tabelas Consumo Energético}

As tabelas a seguir resumem os modelos/SKUs de refrigeradores presentes na base $\mathrm{PPH} /$ Procel, junto das respectivas informações de consumo energético e classe de consumo (Selo Procel). Para as colunas de consumo energético, a sigla CM representa os consumos advindos do trabalho de Melo (2009), enquanto que a coluna Procel contém informações advindas dos catálogos Procel pesquisados. A coluna Outros contém informações de outras fontes.

Tabela 16: Descrição de Modelos Brastemp presentes na base PPH/Procel de 2005

\begin{tabular}{|c|c|c|c|c|c|}
\hline $\begin{array}{l}\text { Cód } \\
\text { Procel }\end{array}$ & Nome Fantasia & Modelo/SKU & $\begin{array}{l}\text { Consumo } \\
\text { (CM) }\end{array}$ & $\begin{array}{l}\text { Classe } \\
(\mathrm{CM})\end{array}$ & $\begin{array}{c}\text { Consumo } \\
\text { (Procel) }\end{array}$ \\
\hline 100 & brastemp (marca) & BRASTEMP & & & \\
\hline 101 & brastemp quality 260 litros & $\begin{array}{l}\text { BRASTEMP } \\
\text { SIMPLES260 }\end{array}$ & 32 & $\mathrm{D}$ & \\
\hline 102 & brastemp clean 340 litros & $\begin{array}{l}\text { BRASTEMP } \\
\text { SIMPLES340 }\end{array}$ & 25,5 & A & \\
\hline 103 & brastemp all refrigerator 360 litros & BRF36 & 26,5 & $\mathrm{~B}$ & 26,5 \\
\hline 104 & brastemp duplex clean 320 litros & BRM32 & 44 & A & \\
\hline 105 & brastemp duplex clean 410 litros & BRM41 & 53 & A & \\
\hline 106 & brastemp duplex clean frost free 390 litros & BRM39 & 58,2 & $\mathrm{~A}$ & \\
\hline 107 & brastemp duplex clean frost free (zyrium) & BRG43 & 57,6 & & 62,4 \\
\hline 108 & brastemp bottom freezer frost free 420 litros & BRI42 & 57,7 & A & 58,2 \\
\hline 109 & brastemp duplex frost free 340 eletronico & BRM34 & 51,5 & $\mathrm{C}$ & 47,2 \\
\hline 110 & brastemp duplex frost free 440 eletronico & BRM44 & 56 & $\mathrm{~A}$ & 50,5 \\
\hline 111 & brastemp duplex frost free 440 unique & BRV44 & 56 & A & 43 \\
\hline 112 & brastemp duplex frost free 440 eletronico ice magic & BRN44 & & & 57,7 \\
\hline 113 & brastemp duplex frost free 440 eletronico zyrium & BRG44 & & & 59,9 \\
\hline 114 & brastemp inside freezer 350 & BRO35 & & & \\
\hline 115 & brastemp bottom freezer 330 & BRH33 & & & 44,1 \\
\hline 116 & brastemp duplex 360 & $\begin{array}{l}\text { BRASTEMP } \\
\text { DUPLEX360 }\end{array}$ & 46 & $\mathrm{~A}$ & \\
\hline 117 & brastemp duplex 460 & BRD46 & 55 & $\mathrm{~A}$ & 52,4 \\
\hline 118 & brastemp side by side 700 & BRS70 & 86,4 & & 81,5 \\
\hline
\end{tabular}


Tabela 17: Descrição de Modelos Consul presentes na base PPH/Procel de 2005

\begin{tabular}{clcccc}
\hline $\begin{array}{c}\text { Cód } \\
\text { Procel }\end{array}$ & \multicolumn{1}{c}{ Nome Fantasia } & Modelo/SKU & $\begin{array}{c}\text { Consumo } \\
(\mathbf{C M})\end{array}$ & $\begin{array}{c}\text { Classe } \\
\text { (CM) }\end{array}$ & $\begin{array}{c}\text { Consumo } \\
\text { (Procel) }\end{array}$ \\
\hline 200 & consul (marca) & CONSUL & & & \\
201 & consul compacto 50 & CRT05 & 19,9 & $\mathrm{~B}$ & 17,9 \\
202 & consul compacto 80 & CRT08 & 18,1 & $\mathrm{~B}$ & 18,1 \\
203 & consul compacto 120 & CRT12 & 19 & $\mathrm{~A}$ & 22,8 \\
204 & consul 240 & CRC24 & 30,5 & $\mathrm{E}$ & \\
205 & consul 320 & CRA32 & 24,5 & $\mathrm{~A}$ & 24,9 \\
206 & consul 320 360 degelo seco & CONSUL360 & 25,5 & $\mathrm{~A}$ & \\
207 & consul pratice 300 & CONSUL300 & 25,5 & $\mathrm{~A}$ & \\
208 & consul biplex 420 frost free & CRM42 & 55,5 & $\mathrm{~A}$ & 58,2 \\
209 & consul biplex 360 390 & CONSULBIPLEX390 & 47,3 & $\mathrm{~A}$ & \\
210 & consul biplex rural 215 & CQG22D & 30,5 & $\mathrm{E}$ & \\
211 & consul biplex 450 & CRD45 & 51 & $\mathrm{~A}$ & 53 \\
240 & supostamente é consul 240 & OUTROS & & & \\
280 & supostamente é consul 280 & OUTROS & & & \\
\hline
\end{tabular}

Tabela 18: Descrição de Modelos Electrolux/Prodóscimo presentes na base PPH/Procel de 2005

\begin{tabular}{|c|c|c|c|c|c|c|}
\hline $\begin{array}{l}\text { Cód } \\
\text { Procel }\end{array}$ & Nome Fantasia & Modelo/SKU & $\begin{array}{l}\text { Consumo } \\
\text { (CM) }\end{array}$ & $\begin{array}{l}\text { Classe } \\
(\mathrm{CM})\end{array}$ & $\begin{array}{c}\text { Consumo } \\
\text { (Procel) }\end{array}$ & $\begin{array}{c}\text { Consumo } \\
\text { (Outros) }\end{array}$ \\
\hline 300 & electrolux (marca) & ELECTROLUX & & & & \\
\hline 302 & electrolux smile r27 & $\mathrm{R} 27$ & 24,8 & $\mathrm{~B}$ & & \\
\hline 303 & electrolux smile t27 & $\mathrm{T} 27$ & 24,8 & $\mathrm{~B}$ & & \\
\hline 304 & electrolux smile d41 & D41 & 55,4 & $\mathrm{~A}$ & & \\
\hline 306 & electrolux 1 porta re26 & RE26 & 24,8 & A & 24,1 & \\
\hline 307 & electrolux 1 porta re29 & RE29 & 24,8 & $\mathrm{~B}$ & 24,8 & \\
\hline 308 & electrolux 1 porta rde32 & RDE32 & 25,4 & $\mathrm{~A}$ & 25,7 & \\
\hline 309 & electrolux 1 porta rde37 & RDE37 & 29,7 & $\mathrm{~B}$ & 27,3 & \\
\hline 310 & electrolux 2 portas dc38 & DC38 & 29,2 & $\mathrm{~B}$ & 48,8 & \\
\hline 311 & electrolux 2 portas dc 47 & DC47 & 58,1 & $\mathrm{~A}$ & 59 & \\
\hline 316 & electrolux frost free dfw 45 & DFW45 & & & 55,4 & \\
\hline 317 & electrolux frost free ds600 & DS600 & & & & \\
\hline 318 & electrolux bottom freezer db580 & DB580 & & & & \\
\hline 319 & electrolux side by side ss 650 & SS650 & & & & 105 \\
\hline 320 & electrolux side by side ss680 & SS680 & & & & 122 \\
\hline 321 & electrolux side by side $\operatorname{ss} 74 \mathrm{x}$ & SS74X & & & & \\
\hline
\end{tabular}

Tabela 19: Descrição de Outros Modelos presentes na base PPH/Procel de 2005

\begin{tabular}{clcccc}
\hline $\begin{array}{c}\text { Cód } \\
\text { Procel }\end{array}$ & Nome Fantasia & Modelo/SKU & $\begin{array}{c}\text { Consumo } \\
\text { (CM) }\end{array}$ & $\begin{array}{c}\text { Classe } \\
\text { (CM) }\end{array}$ & $\begin{array}{c}\text { Consumo } \\
\text { (Procel) }\end{array}$ \\
\hline 400 & general electric (marca) & GE & & & \\
401 & general electric ge 13 & GE13 & 20 & & \\
402 & general electric tbx 112c 329 litros & TBX11 & 46 & $\mathrm{~A}$ & \\
403 & general electric tbx 112c 366 litros & TBX13 & 47 & $\mathrm{~A}$ & \\
404 & general electric tbx 16 jax & TBX16 & & \\
501 & climax (marca) & CLIMAX & 80 & \\
501 & climax & CLIMAX & & \\
601 & frigidaire (marca) & FRIGIDAIRE & 80 & & \\
601 & frigidaire & FRIGIDAIRE & & & \\
701 & esmaltec (marca) & ESMALTEC & 33,1 & $\mathrm{~A}$ & \\
701 & esmaltec & ESMALTEC & & \\
800 & outras & OUTROS & & \\
\hline
\end{tabular}




\section{APÊNDICE C - Tabelas Logit Multinomial}

A tabela abaixo incorpora as variáveis de renda familiar, consumo energético máximo do domicílio, número de moradores, área construída, além de informações de número de refrigeradores e freezers já existentes no domicílio. Os comentários e discussões sobre os resultados se encontram na página 56 .

Tabela 20: Modelos Logit Condicional

Variáveis Alternative Contínuas e Case Specific Contínuas

\begin{tabular}{|c|c|c|c|c|}
\hline & $\begin{array}{c}\text { Modelo } 5 \\
\text { b/se }\end{array}$ & $\begin{array}{c}\text { Modelo } 6 \\
\text { b/se }\end{array}$ & $\begin{array}{c}\text { Modelo } 7 \\
\text { b/se }\end{array}$ & $\begin{array}{c}\text { Modelo } 8 \\
\text { b/se }\end{array}$ \\
\hline Consumo Energético & $\begin{array}{c}-0,0117^{*} \\
(0,0069)\end{array}$ & $\begin{array}{c}-0,0203^{* * *} \\
(0,0059)\end{array}$ & $\begin{array}{c}-0,0346^{* *} \\
(0,0165)\end{array}$ & $\begin{array}{c}0,0069 \\
(0,0097)\end{array}$ \\
\hline Capacidade & $\begin{array}{c}0,0061^{* * *} * \\
(0,0011)\end{array}$ & $\begin{array}{c}0,0041^{* * *} \\
(0,0009)\end{array}$ & $\begin{array}{c}0,0016 \\
(0,0026)\end{array}$ & $\begin{array}{c}0,0068 * * * \\
(0,0015)\end{array}$ \\
\hline Preço & $\begin{array}{c}-0,0024^{* * *} \\
(0,0002)\end{array}$ & $\begin{array}{c}-0,0015^{* * *} \\
(0,0002)\end{array}$ & $\begin{array}{c}0,0004 \\
(0,0005)\end{array}$ & $\begin{array}{c}-0,0019^{* * *} \\
(0,0003)\end{array}$ \\
\hline Controles (Case-Spec.) & Renda Familiar & Consumo Máx. & $\begin{array}{c}\text { № Moradores } \\
\text { № Refrigeradores } \\
\text { № Freezeres }\end{array}$ & Área Construída \\
\hline $\begin{array}{l}\text { Willingness to Pay (WTP) } \\
\text { WTP: p-value (p.p.) } \\
\text { Log-Likelihood } \\
\text { № Observações }\end{array}$ & $\begin{array}{c}4,89 \\
0,1208 \\
-2.753,17 \\
33.630\end{array}$ & $\begin{array}{c}13,80 \\
0,0070 \\
-4.133,91 \\
50.046\end{array}$ & $\begin{array}{c}-94,71 \\
0,4141 \\
-3.943,95 \\
50.046\end{array}$ & $\begin{array}{c}-3,56 \\
0,4463 \\
-3.598,23 \\
43.890\end{array}$ \\
\hline
\end{tabular}

${ }^{*} \mathrm{p}<0.10,{ }^{* *} \mathrm{p}<0.05,{ }^{* * *} \mathrm{p}<0.01$ 
A tabela a seguir inclui, como case specifics, ou a variável de renda familiar ou o consumo energético máximo. As especificações, no entanto, são baseados no conjunto de alternative specifics mais completo que na tabela anterior, incluindo agora as variáveis de número de portas e forma de degelo, além de dummies para as marcas. Os comentários a respeito destes modelos se encontram na página 57.

Tabela 21: Modelos Logit Condicional

Variáveis Alternative Contínuas e Discretas e Case Specific Contínuas

\begin{tabular}{|c|c|c|c|c|}
\hline & $\begin{array}{c}\text { Modelo } 9 \\
\text { b/se }\end{array}$ & $\begin{array}{c}\text { Modelo } 10 \\
\text { b/se }\end{array}$ & $\begin{array}{c}\text { Modelo } 11 \\
\text { b/se }\end{array}$ & $\begin{array}{c}\text { Modelo } 12 \\
\text { b/se }\end{array}$ \\
\hline Consumo Energético & $\begin{array}{c}-0,0073 \\
(0,0069)\end{array}$ & $\begin{array}{c}-0,0146^{* *} \\
(0,0059)\end{array}$ & $\begin{array}{c}-0,0050 \\
(0,0095)\end{array}$ & $\begin{array}{c}-0,0239^{* * *} \\
(0,0080)\end{array}$ \\
\hline Capacidade & $\begin{array}{c}0,0066^{* * *} \\
(0,0010)\end{array}$ & $\begin{array}{c}0,0050^{* * * *} \\
(0,0009)\end{array}$ & $\begin{array}{c}0,0087^{* * *} * \\
(0,0012)\end{array}$ & $\begin{array}{c}0,0066^{* * *} \\
(0,0010)\end{array}$ \\
\hline Preço & $\begin{array}{c}-0,0026^{* * *} \\
(0,0002)\end{array}$ & $\begin{array}{c}-0,0019^{* * *} \\
(0,0002)\end{array}$ & $\begin{array}{c}-0,0029^{* * *} \\
(0,0003)\end{array}$ & $\begin{array}{c}-0,0020^{* * *} \\
(0,0002)\end{array}$ \\
\hline Electrolux & $\begin{array}{c}-1,0755^{* * *} \\
(0,1656)\end{array}$ & $\begin{array}{c}-1,0968^{* * *} \\
(0,1512)\end{array}$ & & \\
\hline Brastemp & $\begin{array}{c}0,0639 \\
(0,1639)\end{array}$ & $\begin{array}{c}0,4797^{* * *} \\
(0,1388)\end{array}$ & & \\
\hline Frost Free & & & $\begin{array}{c}2,8547^{* * *} \\
(0,3205)\end{array}$ & $\begin{array}{c}2,9646^{* * *} \\
(0,3343)\end{array}$ \\
\hline 2 Portas & & & $\begin{array}{c}-2,5564^{* * *} \\
(0,3738)\end{array}$ & $\begin{array}{c}-2,3443^{* * *} \\
(0,3678)\end{array}$ \\
\hline Controles (Case-Spec.) & Renda Familiar & Consumo Máx. & Renda Familiar & Consumo Máx \\
\hline Willingness to Pay (WTP) & 2,86 & 7,52 & 1,73 & 11,91 \\
\hline WTP: p-value (p.p.) & 0,3108 & 0,0343 & 0,5978 & 0,0037 \\
\hline Log-Likelihood & $-2.726,31$ & $-4.083,00$ & $-2.701,06$ & $-4.078,34$ \\
\hline № Observações & 33.630 & 50.046 & 33.630 & 50.046 \\
\hline
\end{tabular}


A tabela a seguir testa as mesmas especificações já testadas anteriormente, mas agora incluindo ambas as variáveis de renda familiar e consumo energético máximo como controles. Comentários e discussões na página 57.

Tabela 22: Modelos Logit Condicional

Variáveis Alternative Contínuas e Discretas e Case Specific Contínuas

\begin{tabular}{|c|c|c|c|c|}
\hline & $\begin{array}{l}\text { Modelo } 13 \\
\text { b/se }\end{array}$ & $\begin{array}{l}\text { Modelo } 14 \\
\text { b/se }\end{array}$ & $\begin{array}{l}\text { Modelo } 15 \\
\text { b/se }\end{array}$ & $\begin{array}{c}\text { Modelo } 16 \\
\text { b/se }\end{array}$ \\
\hline Consumo Energético & $\begin{array}{c}-0,0202^{* *} \\
(0,0079)\end{array}$ & $\begin{array}{c}-0,0193^{* *} \\
(0,0080)\end{array}$ & $\begin{array}{l}-0,0117 \\
(0,0110)\end{array}$ & $\begin{array}{l}-0,0075 \\
(0,0111)\end{array}$ \\
\hline Capacidade & $\begin{array}{c}0,0059^{* * *} \\
(0,0012)\end{array}$ & $\begin{array}{c}0,0060^{* * *} \\
(0,0012)\end{array}$ & $\begin{array}{c}0,0074^{* * *} \\
(0,0014)\end{array}$ & $\begin{array}{c}0,0073^{* * *} \\
(0,0014)\end{array}$ \\
\hline Preço & $\begin{array}{c}-0,0023^{* * *} \\
(0,0002)\end{array}$ & $\begin{array}{c}-0,0025^{* * *} \\
(0,0003)\end{array}$ & $\begin{array}{c}-0,0026^{* * *} \\
(0,0003)\end{array}$ & $\begin{array}{c}-0,0025^{* * *} \\
(0,0003)\end{array}$ \\
\hline Electrolux & $\begin{array}{c}-1,0143^{* * *} \\
(0,1711)\end{array}$ & $\begin{array}{c}-0,9130 * * * \\
(0,1856)\end{array}$ & & $\begin{array}{c}-0,7721^{* * *} \\
(0,1779)\end{array}$ \\
\hline Brastemp & & $\begin{array}{c}0,2700 \\
(0,1886)\end{array}$ & & \\
\hline Frost Free & & & $\begin{array}{c}2,7988^{* * * *} \\
(0,3968)\end{array}$ & $\begin{array}{c}2,4884^{* * *} \\
(0,4025)\end{array}$ \\
\hline 2 Portas & & & $\begin{array}{c}-2,7433^{* * *} \\
(0,4534)\end{array}$ & $\begin{array}{c}-2,5761^{* * *} \\
(0,4537)\end{array}$ \\
\hline Controles (Case-Spec.) & $\begin{array}{l}\text { Renda Familiar } \\
\text { Consumo Máx }\end{array}$ & $\begin{array}{l}\text { Renda Familiar } \\
\text { Consumo Máx. }\end{array}$ & $\begin{array}{l}\text { Renda Familiar } \\
\text { Consumo Máx }\end{array}$ & $\begin{array}{l}\text { Renda Familiar } \\
\text { Consumo Máx }\end{array}$ \\
\hline Willingness to Pay (WTP) & 8,77 & 7,76 & 4,59 & 2,94 \\
\hline WTP: p-value (p.p.) & 0,0297 & 0,0376 & 0,2822 & 0,4967 \\
\hline Log-Likelihood & $-2.660,83$ & $-2.659,81$ & $-2.642,73$ & $-2.633,23$ \\
\hline № Observações & 33.630 & 33.630 & 33.630 & 33.630 \\
\hline
\end{tabular}

${ }^{*} \mathrm{p}<0.10,{ }^{* *} \mathrm{p}<0.05,{ }^{* * *} \mathrm{p}<0.01$ 
Os modelos da tabela abaixo testam a inclusão de dummies de frost free e número de portas em separado. Comentários sobre os modelos na página 57.

Tabela 23: Modelos Logit Condicional

Variáveis Alternative Contínuas e Discretas e Case Specific Contínuas

\begin{tabular}{lcc}
\hline & $\begin{array}{c}\text { Modelo } 17 \\
\mathrm{~b} / \mathrm{se}\end{array}$ & $\begin{array}{c}\text { Modelo } 18 \\
\mathrm{~b} / \mathrm{se}\end{array}$ \\
\hline Consumo Energético & $-0,0461^{* * *}$ & 0,0060 \\
& $(0,0103)$ & $(0,0112)$ \\
Capacidade & $0,0086^{* * *}$ & $0,0043^{* * *}$ \\
& $(0,0013)$ & $(0,0013)$ \\
Preço & $-0,0029^{* * *}$ & $-0,0019^{* * *}$ \\
& $(0,0003)$ & $(0,0003)$ \\
Electrolux & $-0,8577^{* * *}$ & $-1,0095^{* * *}$ \\
& $(0,1749)$ & $(0,1722)$ \\
Frost Free & $1,2647^{* * *}$ & \\
& $(0,2868)$ & \\
2 Portas & & $-1,0654^{* * *}$ \\
& & $(0,3545)$ \\
\hline Controles (Case-Spec.) & Renda Familiar & Renda Familiar \\
& Consumo Máx & Consumo Máx. \\
\hline \hline Willingness to Pay (WTP) & 15,81 & $-3,12$ \\
WTP: p-value (p.p.) & 0,0001 & 0,5968 \\
Log-Likelihood & $-2.651,04$ & $-2.656,33$ \\
No Observações & 33.630 & 33.630 \\
\hline * p $<0.10, * *$ p $<0.05, * * *$ p $<0.01$ &
\end{tabular}


A tabela a seguir acrescenta case specifics discretas, tais como o peso da conta de energia no orçamento familiar, região do domicílio e região geográfica, e dummy indicando a pretensão de trocar refrigerador por modelo mais eficiente. Comentários sobre os modelos na página 58.

Tabela 24: Modelos Logit Condicional: Inclusão de Alternative-Specific Discretas

Case-specific de controle: Salário Real e Nível de Consumo

\begin{tabular}{|c|c|c|c|c|c|}
\hline & $\begin{array}{c}\text { Modelo } 27 \\
\text { b/se }\end{array}$ & $\begin{array}{c}\text { Modelo } 28 \\
\text { b/se }\end{array}$ & $\begin{array}{c}\text { Modelo } 29 \\
\text { b/se }\end{array}$ & $\begin{array}{c}\text { Modelo } 30 \\
\text { b/se }\end{array}$ & $\begin{array}{c}\text { Modelo } 31 \\
\text { b/se }\end{array}$ \\
\hline Consumo Energético & $\begin{array}{c}-0,0339^{* * *} \\
(0,0130)\end{array}$ & $\begin{array}{c}-0,0207^{* *} \\
(0,0105)\end{array}$ & $\begin{array}{c}-0,0350^{* *} \\
(0,0152)\end{array}$ & $\begin{array}{c}-0,0262^{* *} \\
(0,0110)\end{array}$ & $\begin{array}{c}-0,0520^{* * *} \\
(0,0151)\end{array}$ \\
\hline Capacidade & $\begin{array}{c}0,0041^{* *} \\
(0,0017)\end{array}$ & $\begin{array}{c}0,0085^{* * *} \\
(0,0015)\end{array}$ & $\begin{array}{l}0,0042^{*} \\
(0,0023)\end{array}$ & $\begin{array}{c}0,0040^{* *} \\
(0,0016)\end{array}$ & $\begin{array}{c}0,0086 * * * \\
(0,0018)\end{array}$ \\
\hline Preço & $\begin{array}{c}-0,0020^{* * *} \\
(0,0004)\end{array}$ & $\begin{array}{c}-0,0033^{* * *} \\
(0,0004)\end{array}$ & $\begin{array}{c}-0,0012^{* * *} \\
(0,0004)\end{array}$ & $\begin{array}{c}-0,0019^{* * *} \\
(0,0003)\end{array}$ & $\begin{array}{c}-0,0027^{* * *} \\
(0,0005)\end{array}$ \\
\hline Controles (Case-Spec.) & $\begin{array}{l}\text { Renda Familiar } \\
\text { Consumo Máx. } \\
\text { Peso da Conta }\end{array}$ & $\begin{array}{l}\text { Renda Familiar } \\
\text { Consumo Máx. } \\
\text { Região do } \\
\text { Domicílio }\end{array}$ & $\begin{array}{c}\text { Renda Familiar } \\
\text { Consumo Máx. } \\
\text { Região } \\
\text { Geográfica }\end{array}$ & $\begin{array}{l}\text { Renda Familiar } \\
\text { Consumo Máx. } \\
\text { Refrigerador } \\
\text { Mais Eficiente }\end{array}$ & $\begin{array}{l}\text { Renda Familiar } \\
\text { Consumo Máx. } \\
\text { Área Construída }\end{array}$ \\
\hline Willingness to Pay (WTP) & 17,05 & 6,22 & 30,31 & 13,88 & 19,47 \\
\hline WTP: p-value (p.p.) & 0,0569 & 0,0820 & 0,1636 & 0,0623 & 0,0186 \\
\hline Log-Likelihood & $-2.473,66$ & $-2.485,83$ & $-2.451,85$ & $-2.225,95$ & $-2.181,07$ \\
\hline № Observações & 32.908 & 32.832 & 33.630 & 28.614 & 29.678 \\
\hline
\end{tabular}


Anexos 


\section{ANEXO A - Questionário PPH/PROCEL 2005}

Esta seção contempla as perguntas envolvidas na pesquisa de campo da $\mathrm{PPH} /$ PROCEL 2005, assim como os anexos dos questionários e o manual de preenchimento dos mesmos. 


\title{
Anexo 3 - Questionário aplicado
}

\author{
ELETROBRÁS / PROCEL - IEPUC / ECOLUZ \\ PESQUISA DE POSSE DE EQUIPAMENTOS E HÁBITOS DE USO
}

QUESTIONÁRIO 1: RESIDENCIAL - BT

\section{IDENTIFICAÇÃO:}

CONCESSIONÁRIA.

1.1 - No QUEST.

1.2 - ENTREVISTADOR:

1.3 - ENTREVISTADO:

1.4 - ENDEREÇO:

1.5 - BAIRRO:

1.6 - MUNICÍPIO:

1.7 - TELEFONE: 1.8 - DATA DA ENTREVISTA:

1.9 - HORA DE INÍCIO DA ENTREVISTA:

1.10 - LISTE AS PESSOAS QUE MORAM NESTE DOMICÍLIO, ESPECIFICANDO GRAU DE PARENTESCO OU RELAÇÃO COM O(A) CHEFE DA FAMÍLIA, IDADE, SEXO, NIIVEL DE INSTRUÇÃO E PERÍODO HABITUAL DE PERMANÊNCIA NO DOMICÍLIO:

OBS.1: Hoje a terminologia é ensino fundamental (1 a a $8^{\text {a }}$ série) e ensino médio (1 a a $3^{\text {a }}$ série do $2^{\circ} \mathrm{grau}$ )

OBS.2: Criança de até 7 anos, é considerada no nível de instrução, como primário incompleto

QUANTIDADE DE PESSOAS QUE MORAM NO DOMICÍLIO:

\begin{tabular}{|c|c|c|c|c|c|c|c|c|}
\hline \multirow{2}{*}{ MEMBRO } & \multirow{2}{*}{$\begin{array}{c}\text { CONDIÇÃO } \\
\text { NO } \\
\text { DOMICÍLIO } \\
(1)\end{array}$} & \multirow{2}{*}{ IDADE } & \multirow{2}{*}{$\begin{array}{c}\text { SEXO } \\
F-1 \\
M-2\end{array}$} & \multirow{2}{*}{$\begin{array}{c}\text { NÍVEL DE } \\
\text { INSTRUÇÃO } \\
\text { (2) }\end{array}$} & \multicolumn{4}{|c|}{$\begin{array}{l}\text { PERMANÊNCIA NO } \\
\text { DOMICÍLIO }\end{array}$} \\
\hline & & & & & M & $\mathrm{T}$ & $N$ & MA \\
\hline \multicolumn{9}{|l|}{ 1) } \\
\hline \multicolumn{9}{|l|}{ 2) } \\
\hline \multicolumn{9}{|l|}{ 3) } \\
\hline \multicolumn{9}{|l|}{ 4) } \\
\hline \multicolumn{9}{|l|}{ 5) } \\
\hline \multicolumn{9}{|l|}{ 6) } \\
\hline \multicolumn{9}{|l|}{ 7) } \\
\hline \multicolumn{9}{|l|}{ 8) } \\
\hline \multicolumn{9}{|l|}{ 9) } \\
\hline 10) & & & & & & & & \\
\hline
\end{tabular}

\section{CHAMADA: (1)}

(1) CHEFE DA FAMIILIA

(2) CONNJUGE/COMPANHEIRO(A)

(3) FILHO
(4) OUTRO PARENTE

(5) AGREGADO

(6) PENSIONISTA
(7) EMPREGADO DOMÉSTICO

(9) HÓSPEDE
(8) PARENTE DE EMPREGADO 
CHAMADA: (2)

(1) ATÉ PRIMÁRIO INCOMPLETO

(2) ATÉ GINASIAL INCOMPLETO

(3) ATÉ COLEGIAL INCOMPLETO
(4) ATÉ SUPERIOR INCOMPLETO

(5) CURSO SUPERIOR COMPLETO

(6) ANALFABETO

1.11 - O RELÓGIO (MEDIDOR) SERVE SÓ A ESTE DOMICÍLIO?

1..* SIM 2. • NÃO 99. •NÃO SABE/NR

1.12 - QUANTO TEMPO VOCÊS (FAMÍLIA) MORAM NESTE DOMICÍLIO? * *//ANOS // •MESES

1.13 - QUAL O TEMPO APROXIMADO DE CONSTRUÇÃO DO IMÓVEL? .//ANOS /••NS/NR

\section{CARACTERIZAÇÃO DO DOMICÍLIO}

2.1 - TIPO DE DOMICÍLIO:

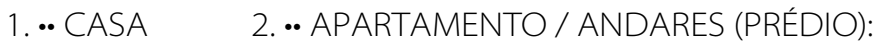

3. . OUTRO, QUAL:

CASO APARTAMENTO, OU OUTRO QUE NÃO POSSUA COBERTURA, VÁ PARA 2.3

2.2 - COBERTURA:

1. . . LAJE DE CONCRETO

4. $\cdot$ ZINCO

2. $\cdot$ TELHA DE BARRO

5. $\cdot$ MADEIRA

8. . OUTRO, QUAL:
3. $\cdot$ TELHA DE AMIANTO

6. ..PALHA

99. • NÃO SABE / NR

2.2.1 - A COBERTURA DO SEU DOMICÍLIO TEM FORRO?

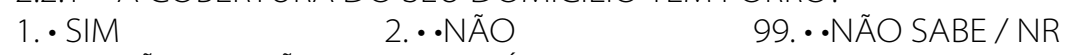

CASO NÃO OU NÃO SABE/NR, VÁ PARA 2.3

2.2.2 - SE HÁ, QUAL O TIPO?

1. FORRO DE PLÁSTICO/MATERIAL SINTÉTICO

3. • LAJE PRÉ-MOLDADA COM BLOCOS CERÂMICOS

5. . OUTRO, QUAL:

2. . FORRO DE MADEIRA

4. $\cdot$ LAJE DE CONCRETO

99. •NÃO SABE / NR

2.3 - PAREDE EXTERNA:

1...ALVENARIA REVESTIDA EXTERNAMENTE

3. -MADEIRA

2. • ALVENARIA NÃO REVESTIDA

5. $\cdot$ MATERIAL APROVEIT.

7...OUTRO, QUAL:

4. ..PALHA

6. - TAIPA NÃO REVESTIDA

99. $\cdot N \tilde{O} O \mathrm{SABE} / \mathrm{NR}$

2.4 - JANELAS (esquadrias):

1.. MADEIRA

2. . FERRO

4. . OUTRO, QUAL:

99. $\cdot N A \tilde{O} \mathrm{SABE} / \mathrm{NR}$

3.•-ALUMÍNIO

2.4.1 - OS VIDROS DAS JANELAS SÃO COLORIDOS OU RECEBEM PELÍCULAS?

1.. SIM 2. •NÃO 99. •NÃO SABE / NR

2.4.2 - HÁ PROTEÇÃO DO TIPO VENEZIANA PARA AS JANELAS?

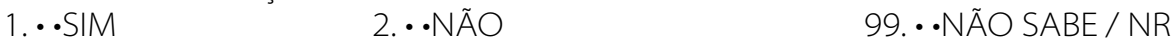

2.5 - PISO:

1. .MADEIRA

4. -MATERIAL APROVEIT.

2. ..CERÂMICA

5. - TIJOLO

3. . CIMENTO

7. - OUTRO, QUAL:

99. - NÃO SABE / NR

6. . TERRA

2.6 - ÁREA CONSTRUÍDA (m2):

1. • ATÉ 50

4. .DE 101 A 150

2. . DE 51 A 75

5.・DE 151 A 200

3. $\cdot$ DE 76 A 100

6. ACIMA DE 200 


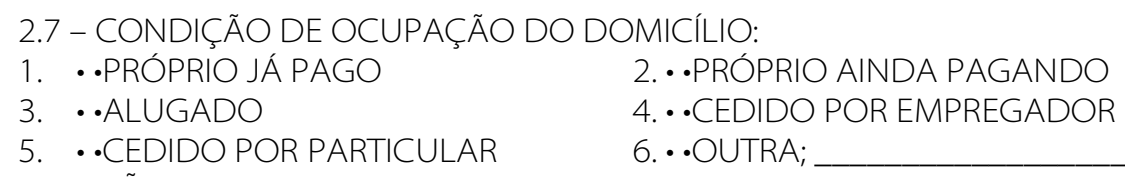

99. $\cdot N \tilde{N} O$ SABE / NR

2.8 - O DOMICÍLIO POSSUI SISTEMA DE ABASTECIMENTO DE ÁGUA:

\section{COM CANALIZAÇÃO INTERNA}

1. .REDE GERAL

2. . POÇO OU NASCENTE

3. .CARRO PIPA

4. $\cdot$ HIDRÔMETRO

5. ..PENA D'ÁGUA

6. . OUTRA FORMA

99. $\cdot N \tilde{N} O$ SABE / NR

\section{SEM CANALIZAÇÃO INTERNA}

7. $\cdot$ REDE GERAL

8. ..POÇO OU NASCENTE

9. .CARRO PIPA

10. • HIDRÔMETRO

11. .PENA D'ÁGUA

12. •OUTRA FORMA

\section{INFORMAÇÕES SOBRE ENERGIA ELÉTRICA}

3.1 - NOS ÚlTIMOS 15 DIAS HOUVE FALTA DE ENERGIA ELÉTRICA NESSA RESIDÊNCIA?
1. $\operatorname{SIM}$
2. $\cdot N \tilde{A} O$
99. $\cdots N A ̃ O S A B E / N R$

3.2 - NESSA RESIDENCIA OCORREU NOS ÚLTIMOS TRÊS MESES:

\begin{tabular}{|c|c|c|c|}
\hline OCORRÊNCIA & SIM & NÃO & NS/NR \\
\hline 1. DUAS OU MAIS QUEIMAS DE LÂMPADAS & & & \\
\hline 2. DESLIGAMENTO/QUEIMA DE DISJUNTOR/FUSÍVEL & & & \\
\hline 3. REDUÇÃO DO NIVEL DE ILUMINAÇÃO/QUEDA DE T & & & \\
\hline 4. CHOQUE ELÉTRICO EM ELETRODOMÉSTICOS & & & \\
\hline 5. AQUECIMENTO DA PAREDE & & & \\
\hline $\begin{array}{l}\text { 6. OCORRE OUTROS PROBLEMAS DE ENERGIA? } \\
\text { QUAIS: }\end{array}$ & & & \\
\hline
\end{tabular}

3.3 - CASO A COMPANHIA DE ELETRICIDADE OFEREÇA ENERGIA ELÉTRICA MAIS BARATA FORA DO PERÍODO DE 18:00 ÀS 21:00 HORAS, O(A) SR.(A) ESTARIA DISPOSTO(A) A REDUZIR O CONSUMO DE ENERGIA NESTE PERÍODO? (ESPONTÂNEA)
1. . SIM
2. - DEPENDE DO DESCONTO
3. $\cdot N \tilde{N O}$
99. •NÃO SABE / NR
3.4 - E A ILUMINAÇÃO PÚBLICA DE SUA RUA É: (ESTIMULADA)
1. ÓTIMA
2. $\cdot B O A$
5. . PÉSSIMA
3. $\cdot$ REGULAR
4. •RUIM
99. $\cdots N \tilde{N} O S A B E / N R$ 
3.5 - NA SUA OPINIÃO, A ILUMINAÇÃO PÚBLICA DE SUA CIDADE É: (ESTIMULADA)
1.. ÓTIMA
2. $\cdot \mathrm{BOA}$
3. $\cdot$ REGULAR
4. $\cdot R U I M$
5. PÉSSIMA
99. $\cdot N A \tilde{O}$ SABE / NR

3.6 - NA SUA OPINIÃO, QUEM É O RESPONSÁVEL PELA ILUMINAÇÃO PÚBLICA DE SUA CIDADE? (ESPONTÂNEA)
1. .PREFEITURA 2. •GOVERNO
3. -CONCESSIONÁRIA
4. $\cdot$ OUTROS
99. • NÃO SABE / NR

\section{ILUMINAÇÃO}

4.1 - CARACTERÍSTICAS E HÁBITOS DE USO:

\begin{tabular}{|c|c|c|c|c|c|c|c|c|c|c|c|c|c|c|c|c|c|c|c|c|c|c|c|c|c|c|c|}
\hline \multirow{2}{*}{$\begin{array}{l}\text { TIPO DE } \\
\text { CÔMODO }\end{array}$} & \multicolumn{2}{|c|}{ LÂMPADAS } & \multicolumn{25}{|c|}{$\begin{array}{l}\text { QUANTIDADE DE LÂMPADAS ACESAS POR PERÍODO } \\
\text { (EVENTUAL X HABITUAL) }\end{array}$} \\
\hline & Total & $\begin{array}{c}\text { Tipo } \\
(1)\end{array}$ & E & 0 & 1 & 2 & 3 & 4 & 5 & 6 & 7 & 8 & 9 & 10 & 11 & 12 & 13 & 14 & 15 & 16 & 17 & 18 & 19 & 20 & 21 & 22 & 23 \\
\hline \multirow{2}{*}{\multicolumn{28}{|c|}{$\begin{array}{l}\text { Sala de estar, } \\
\text { Jantar e TV }\end{array}$}} \\
\hline & & & & & & & & & & & & & & & & & & & & & & & & & & & \\
\hline \multirow{2}{*}{\multicolumn{28}{|c|}{ Quarto 1}} \\
\hline & & & & & & & & & & & & & & & & & & & & & & & & & & & \\
\hline \multicolumn{28}{|l|}{ Quarto 2} \\
\hline Quarto 2 & & & & & & & & & & & & & & & & & & & & & & & & & & & \\
\hline \multicolumn{28}{|l|}{ Quarto 3} \\
\hline enarto & & & & & & & & & & & & & & & & & & & & & & & & & & & \\
\hline \multicolumn{28}{|l|}{ Quarto 4} \\
\hline रूiars & & & & & & & & & & & & & & & & & & & & & & & & & & & \\
\hline \multirow{2}{*}{\multicolumn{28}{|c|}{ Banheiro 1}} \\
\hline & & & & & & & & & & & & & & & & & & & & & & & & & & & \\
\hline \multicolumn{28}{|l|}{ Banheiro 2} \\
\hline Б्वानि & & & & & & & & & & & & & & & & & & & & & & & & & & & \\
\hline \multicolumn{28}{|l|}{ Banheiro 3} \\
\hline Dallitens & & & & & & & & & & & & & & & & & & & & & & & & & & & \\
\hline \multicolumn{28}{|l|}{ Corredores } \\
\hline colredores & & & & & & & & & & & & & & & & & & & & & & & & & & & \\
\hline \multicolumn{28}{|l|}{ Copa/Cozinha } \\
\hline copar cozitilia & & & & & & & & & & & & & & & & & & & & & & & & & & & \\
\hline \multicolumn{28}{|l|}{$\begin{array}{l}\text { Área de } \\
\text { Servico }\end{array}$} \\
\hline Serviço & & & & & & & & & & & & & & & & & & & & & & & & & & & \\
\hline \multicolumn{28}{|l|}{ Garagem } \\
\hline enter & & & & & & & & & & & & & & & & & & & & & & & & & & & \\
\hline \multicolumn{28}{|l|}{ Área Externa } \\
\hline 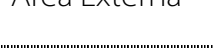 & & & & & & & & & & & & & & & & & & & & & & & & & & & \\
\hline \multirow{2}{*}{ Outras } & & & & & & & & & & & & & & & & & & & & & & & & & & & \\
\hline & & & & & & & & & & & & & & & & & & & & & & & & & & & \\
\hline
\end{tabular}

CHAMADA: (1)

(1) $25 \mathrm{~W}$ - INCANDESCENTE

(2) 4OW - INCANDESCENTE

(3) $60 \mathrm{~W}$ - INCANDESCENTE

(4) 100W - INCANDESCENTE

NOTA: (1) Na sala e na copa

pode ser feita por declaração.
(5) $150 \mathrm{~W}$ - INCANDESCENTE

(6) $20 \mathrm{~W}$ - FLUORESCENTE TUBULAR

(7) 4OW - FLUORESCENTE TUBULAR

(9) FLUORES. COMPACTA $>15 \mathrm{~W}$

(10) FLUORESCENTE CIRCULAR

(11) DICRÓICA

$\begin{array}{ll}\text { (8) FLUORESCENTE COMPACTA ATÉ 15W } & \text { (12) OUTRO }\end{array}$

$\begin{array}{ll}\text { (8) FLUORESCENTE COMPACTA ATÉ 15W } & \text { (12) OUTRO } \\ \mathrm{pa} / \text { cozinha deve ser verificada a potência na própria lâmpada, nos demais cômodos essa medida }\end{array}$ 
(2) Se não for possível identificar um horário habitual de uso marque o número de lâmpadas na coluna referente a uso eventual " $E$ ".

4.2 - VOCÊ CONHECE AS LÂMPADAS FLUORESCENTES? (MOSTRAR CARTÃO 9)

1. $\cdot$ SIM 2. $\cdot$ NÃO 99. • NÃO SABE / NR

DAR INFORMAÇÕES BÁSICAS SOBRE AS L.F.C.'S

4.3 - QUAL A TONALIDADE DE ILUMINAÇÃO PREFERIDA PARA SUA RESIDÊNCIA?
1. $\cdot$ BRANCA
2. . AMARELADA
3. •. DEPENDE DO CÔMODO
4. $\cdot$ OUTRAS
99. • NÃO SABE / NR

\section{REFRIGERADOR}

QUANTIDADE DE APARELHOS:

5.1 - CARACTERÍSTICAS

\begin{tabular}{|c|c|c|c|c|c|c|c|c|c|c|c|c|c|}
\hline \multirow{2}{*}{$\begin{array}{c}\text { No } \\
\text { REFERÊNCIA } \\
\text { DO } \\
\text { APARELHO } \\
\\
1\end{array}$} & $\begin{array}{c}\text { TIPO DE } \\
\text { APARELHO } \\
\text { (1) }\end{array}$ & \multicolumn{4}{|c|}{$\begin{array}{c}\text { UTILIZAÇÃO } \\
(2)\end{array}$} & \multicolumn{3}{|c|}{$\begin{array}{c}\text { POSIÇÃO / } \\
\text { INTENSIDADE } \\
\text { DO } \\
\text { TERMOSTATO } \\
\text { (3) }\end{array}$} & \multirow[t]{2}{*}{$\begin{array}{l}\text { ESTIMATIVA } \\
\text { DE IDADE } \\
\text { DO } \\
\text { APARELHO } \\
\text { (em anos) }\end{array}$} & \multicolumn{4}{|c|}{$\begin{array}{l}\text { PROBLEMAS } \\
\text { OCORRIDOS } \\
\text { NOS ÚLTIMOS } \\
12 \text { MESES } \\
\text { (4) }\end{array}$} \\
\hline & & 1 & 2 & 3 & 4 & 1 & 2 & 3 & & 1 & 2 & 3 & 4 \\
\hline 2 & & 1 & 2 & 3 & 4 & 1 & 2 & 3 & & 1 & 2 & 3 & 4 \\
\hline 3 & & 1 & 2 & 3 & 4 & 1 & 2 & 3 & & 1 & 2 & 3 & 4 \\
\hline
\end{tabular}

CHAMADA: (1) VEJA NO CARTÃO 1

CHAMADA: (2) (1) USO PERMANENTE
(2) DESLIGADO
(4) SÓ LIGADO EVENTUALMENTE

(3) USO PARTE DO DIA

(1) MÍNIMO

CHAMADA: (3) (1) MÍNIMO $\quad$ (2) MÉDIO(3) MÁXIMO

CHAMADA: (4) (1) MOTOR COM DEFEITO OU RUÍDO EXCESSIVO

(2) PORTA COM DIFICULDADE PARA FECHAR

(3) CONGELADOR FAZENDO GELO DEMAIS OU DE MENOS

(4) OUTROS PROBLEMAS

OBS.: A CHAMADA (4) ADMITE RESPOSTAS MÚLTIPLAS

5.2 - DO(S) REFRIGERADOR(ES) ACIMA CITADO(S), ADQUIRIU ALGUM NOVO (NA LOJA) NOS ÚLTIMOS DEZ ANOS?

1...SIM, QUANTOS?

2. ... NÃO

99. ... NÃO SABE / NR

\section{SE NÃO OU NÃO SABE /NR, VÁ PARA O ITEM 5.5}

5.3 - NESSA AQUISIÇÃO LEVOU EM CONSIDERAÇÃO O CONSUMO DO APARELHO MOSTRADO NA ETIQUETA AO ADQUIRÍ-LO?
1. . SIM
2. $\cdot N A \tilde{O}$
3. • NÃO LEMBRA
4. $\cdot$ NÃO TINHA
5. . NÃO SABIA DA EXISTÊNCIA DE ETIQUETA

5.4 - O SR.(A) TERIA INTERESSE EM ADQUIRIR UM REFRIGERADOR QUE CONSUMISSE MENOS ENERGIA E QUE FOSSE AVALIADO POR SUA CONCESSIONÁRIA OU ALGUM ORGAO COMPETENTE?
1. $\cdot S I M$
2. $\cdot \mathrm{NA} O$
99. • NÃO SABE / NR
5. $\cdot$ OUTROS
3. • DEPENDE DO PREÇO

5.5 - O SR.(A) GOSTARIA DE POSSUIR MAIS 1 REFRIGERADOR EM SUA RESIDÊNCIA?
1...SIM
2. $\cdot N A \tilde{O}$
99. • •NÃO SABE / NR 


\section{FREEZER}

QUANTIDADE DE APARELHOS:

6.1 - CARACTERÍSTICAS:

\begin{tabular}{|c|c|c|c|c|c|c|}
\hline \multirow{2}{*}{$\begin{array}{c}\text { No } \\
\text { REFERÊNCIA } \\
\text { DO } \\
\text { APARELHO } \\
1\end{array}$} & $\begin{array}{c}\text { TIPO DE } \\
\text { APARELHO } \\
\mathbf{( 1 )} \\
\text { FREEZER }\end{array}$ & \multicolumn{4}{|c|}{$\begin{array}{c}\text { UTILIZAÇÃO } \\
(2)\end{array}$} & $\begin{array}{c}\text { ESTIMATIVA } \\
\text { DE IDADE } \\
\text { DO APARELHO } \\
\text { (em anos) }\end{array}$ \\
\hline & & 1 & 2 & 3 & 4 & \\
\hline 2 & & 1 & 2 & 3 & 4 & \\
\hline 3 & & 1 & 2 & 3 & 4 & \\
\hline
\end{tabular}

CHAMADA: (1) VEJA NO CARTÃO 2

CHAMADA: (2)

(1) USO PERMANENTE

(2) DESLIGADO

(3) USO PARTE DO DIA

(4) SÓ LIGADO EVENTUALMENTE

6.2 - O SR.(A) TERIA INTERESSE EM ADQUIRIR UM FREEZER QUE CONSUMISSE MENOS ENERGIA E QUE FOSSE AVALIADO POR SUA CONCESSIONÁRIA OU ALGUM ORGAO COMPETENTE?

$\begin{array}{lll}\text { 1. } \cdot \text { SIM } & \text { 2. NÃO 99. NÃO SABE / NR }\end{array}$

6.3 - O SR.(A) GOSTARIA DE POSSUIR MAIS 1 FREEZER EM SUA RESIDÊNCIA?

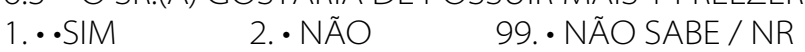

\section{CONDICIONADOR DE AR}

QUANTIDADE DE APARELHOS:

\section{1 - CARACTERÍSTICAS:}

\begin{tabular}{|c|c|c|c|c|c|c|c|}
\hline \multirow{2}{*}{$\begin{array}{c}\text { No } \\
\text { REFERÊNCIA } \\
\text { DO } \\
\text { APARELHO }\end{array}$} & \multirow{2}{*}{$\begin{array}{c}\text { TIPO DE } \\
\text { APARELHO } \\
(1) \\
\text { AR COND. }\end{array}$} & \multirow{2}{*}{$\begin{array}{l}\text { ESTIMATIVA } \\
\text { DE IDADE } \\
\text { DO } \\
\text { APARELHO } \\
\text { (em anos) }\end{array}$} & \multicolumn{3}{|c|}{$\begin{array}{l}\text { EST CÔMODO } \\
\text { RECEBE SOL? }\end{array}$} & \multicolumn{2}{|c|}{ STAND BY } \\
\hline & & & M & T & NÃO & SIM & NÃO \\
\hline \multicolumn{8}{|l|}{1} \\
\hline \multicolumn{8}{|l|}{2} \\
\hline 3 & & & & & & & \\
\hline
\end{tabular}

\section{CHAMADA: (1) VEJA NO CARTÃO 4}

NOTA: A ÚLTIMA COLUNA SE REFERE À POSIÇÃO DO APARELHO QUANDO O MESMO SE ENCONTRA DESLIGADO, OU SEJA, SE O ENTREVISTADO O DEIXA EM STAND-BY OU NẪO. 
7.2 - HÁBITOS DE USO DE ACORDO COM O CLIMA NOS DIAS DE SEMANA E FINAIS DE SEMANA.

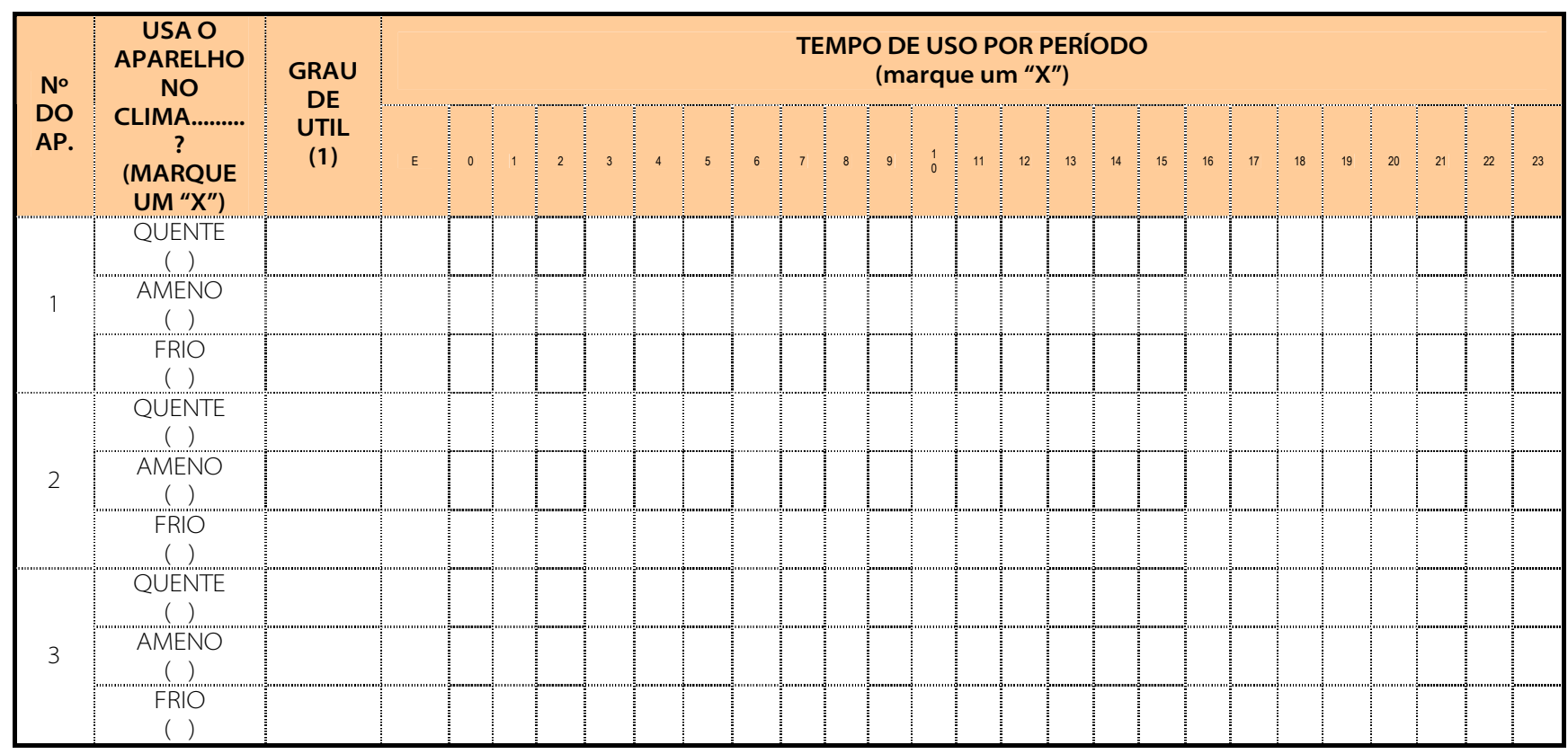

CHAMADA: (1) (1) GRANDE - UTILIZA MAIS DE 4 VEZES POR SEMANA

(2) MÉDIA - DE 1 A 3 VEZES POR SEMANA

(3) REGULAR - DE 1 A 3 VEZES POR MÊS

(4) PEQUENA - MENOS DE UMA VEZ POR MÊS

NOTA: DEVE SER EXCLUÍDO O PERÍODO EM QUE O CONDICIONADORÉ UTILIZADO APENAS NA VENTILAÇÃO.

NOTA.2: A COLUNA REFERENTE AO CLIMA, APRESENTA TEMPERATURAS ASSOCIADAS ȦS ESTAÇÕES DO ANO; COMO POR EXEMPLO: QUENTE - VERÃO / AMENO - PRIMAVERA OUTONO / FRIO - INVERNO.

\section{TELEVISÃO}

QUANTIDADE DE APARELHOS:

8.1 - CARACTERÍSTICAS:

\begin{tabular}{|c|c|c|c|c|c|c|c|c|c|c|}
\hline \multirow{3}{*}{$\begin{array}{c}\text { No } \\
\text { REFERÊNCIA } \\
\text { DO } \\
\text { APARELHO } \\
1\end{array}$} & \multicolumn{2}{|c|}{ TIPO DE APARELHO } & \multirow{3}{*}{$\begin{array}{l}\text { ESTIMATIVA } \\
\text { DE IDADE } \\
\text { DO APARELHO } \\
\text { (em anos) }\end{array}$} & \multirow{2}{*}{\multicolumn{5}{|c|}{$\begin{array}{c}\text { GRAU DE } \\
\text { UTILIZAÇÃO } \\
(2)\end{array}$}} & \multicolumn{2}{|c|}{ STAND BY } \\
\hline & \multirow{2}{*}{$\begin{array}{c}\text { MARCA } \\
(1) \\
\end{array}$} & \multirow{2}{*}{$\begin{array}{c}\text { TAMANHO } \\
\text { (POLEGADAS) }\end{array}$} & & & & & & & SIM & NÃO \\
\hline & & & & 1 & 2 & 3 & 4 & 5 & & \\
\hline 2 & & & & 1 & 2 & 3 & 4 & 5 & & \\
\hline 3 & & & & 1 & 2 & 3 & 4 & 5 & & \\
\hline 4 & & & & 1 & 2 & 3 & 4 & 5 & & \\
\hline 5 & & & & 1 & 2 & 3 & 4 & 5 & & \\
\hline
\end{tabular}

\section{CHAMADA: (1) VEJA NO CARTÃO 5}

CHAMADA: (2) (1) GRANDE - UTILIZA MAIS DE 4 VEZES POR SEMANA
(2) MÉDIA - DE 1 A 3 VEZES POR SEMANA
(3) REGULAR - DE 1 A 3 VEZES POR MÊS
(4) PEQUENA - MENOS DE UMA VEZ POR MÊS
(5) NENHUMA - NÃO UTILIZA

NOTA: A ÚLTIMA COLUNA SE REFERE À POSIÇÃO DO APARELHO QUANDO O MESMO SE ENCONTRA DESLIGADO, OU SEJA, SE O ENTREVISTADO O DEIXA EM STAND-BY OU NǍO. 
8.2 - HORÁRIOS DE USO DOS APARELHOS DE TV DE ACORDO COM O DIA DA SEMANA.

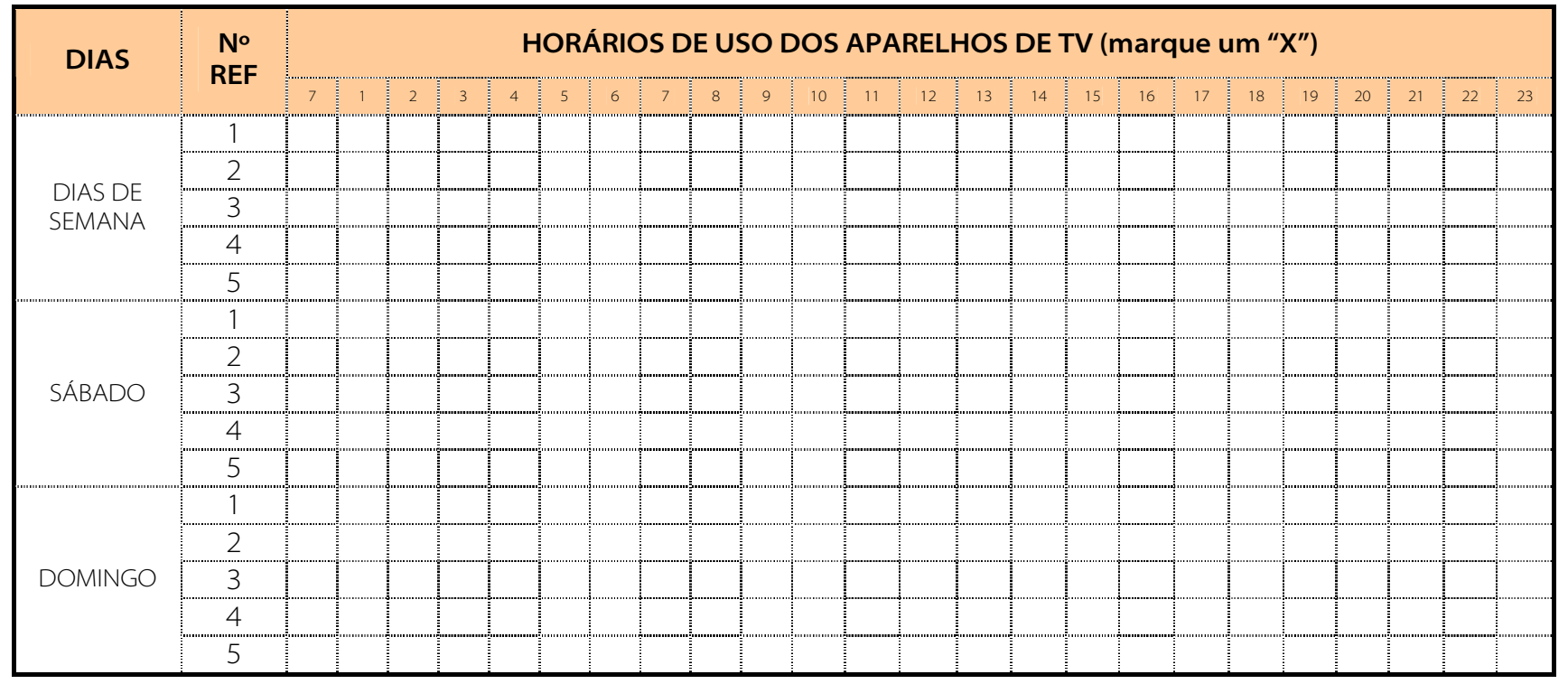

\section{OUTROS ELETRODOMÉSTICOS}

9.1 - POSSES E HÁBITOS DE USO:

\begin{tabular}{|c|c|c|c|c|c|c|c|c|c|}
\hline \multirow[t]{2}{*}{ APARELHO } & \multirow[t]{2}{*}{ QUANT } & \multirow{2}{*}{$\begin{array}{l}\text { UTIL. } \\
\text { (1) }\end{array}$} & \multicolumn{2}{|c|}{$\begin{array}{c}\text { STAND } \\
\text { BY }\end{array}$} & \multirow[t]{2}{*}{ APARELHO } & \multirow[t]{2}{*}{ QUANT } & \multirow{2}{*}{$\begin{array}{l}\text { UTIL. } \\
\text { (1) }\end{array}$} & \multicolumn{2}{|c|}{$\begin{array}{c}\text { STAND } \\
\text { BY }\end{array}$} \\
\hline & & & s & N & & & & $\mathrm{s}$ & $\mathrm{N}$ \\
\hline 1. APARELHO DE SOM & & & & & 16. CAFETEIRA ELÉTRICA & & & & \\
\hline 2. RÁDIO ELÉTRICO & & & & & 17. PANELA ELÉTRICA & & & & \\
\hline 3. VIDEO CASSETE & & & & & 18. EXAUSTOR & & & & \\
\hline 4. DVD & & & & & 19. VENTILADOR DE TETO & & & & \\
\hline 5. MICROCOMPUTADOR & & & & & 20. CIRCULADOR / VENTILADOR & & & & \\
\hline 6. IMPRESSORA & & & & & 21. AQUECEDOR DE AMBIENTE & & & & \\
\hline 7. VIDEO GAME & & & & & 22. ENCERADEIRA & & & & \\
\hline 8. FERRO & & & & & 23. ASPIRADOR DE PÓ & & & & \\
\hline 9. LAVA ROUPA & & & & & 24. BOMBA D'ÁGUA & & & & \\
\hline 10. LAVA LOUÇA & & & & & 25. TORNEIRA ELÉTRICA & & & & \\
\hline 11. SECADORA DE ROUPA & & & & & 26. HIDROMASSAGEM & & & & \\
\hline 12. FORNO MICROONDAS & & & & & 27. VAPORETTO & & & & \\
\hline 13. FORNO ELÉTRICO & & & & & 28. VAP (PRESSUR. DE ÁGUA) & & & & \\
\hline 14. LIQUIDIFICADOR & & & & & 29. MÁQUINA DE COSTURA ELÉT. & & & & \\
\hline 15. BATEDEIRA & & & & & 30. TV POR ASSINATURA (aparelho) & & & & \\
\hline
\end{tabular}

CHAMADA: (1) (1) GRANDE - UTILIZA MAIS DE 4 VEZES POR SEMANA

(2) MÉDIA - DE 1 A 3 VEZES POR SEMANA

(3) REGULAR - DE 1 A 3 VEZES POR MÊS

(4) PEQUENA - MENOS DE UMA VEZ POR MÊS

(5) NENHUMA - NÃO UTILIZA

NOTA: A ÚLTIMA COLUNA SE REFERE À POSIÇÃO DO APARELHO QUANDO O MESMO SE ENCONTRA DESLIGADO, OU SEJA, SE O ENTREVISTADO O DEIXA EM STAND-BY OU NẤO.

NOTA.2: SE NO DOMICÍLIO HOUVER OUTRO(S) EQUIPAMENTO(S) COM O USO PELO MENOS "REGULAR" - 1 A 3 VEZES POR MÊS ELE DEVE SER INCLUÍDO NA LISTA. 
9.2 - HORÁRIOS DE USO DO:
(1) APARELHO DE SOM
(2) MICROCOMPUTADOR
(3) FERRO ELÉTRICO
(4) LAVA ROUPA
(5) LAVA LOUÇA
(6) SECADOURA DE ROUPA
(7) MICROONDAS
(8) FORNO ELÉTRICO
(9) TORNEIRA ELÉTRICA

\begin{tabular}{|c|c|c|c|c|c|c|c|}
\hline \multirow{2}{*}{ HORÁRIO } & \multicolumn{7}{|c|}{ EQUIPAMENTOS UTILIZADOS X DIAS DA SEMANA } \\
\hline & SEGUNDA & TERÇA & QUARTA & QUINTA & SEXTA & SÁBADO & DOMINGO \\
\hline 0 & & & & & & & \\
\hline 1 & & & & & & & \\
\hline 2 & & & & & & & \\
\hline 3 & & & & & & & \\
\hline 4 & & & & & & & \\
\hline 5 & & & & & & & \\
\hline 6 & & & & & & & \\
\hline 7 & & & & & & & \\
\hline 8 & & & & & & & \\
\hline 9 & & & & & & & \\
\hline 10 & & & & & & & \\
\hline 11 & & & & & & & \\
\hline 12 & & & & & & & \\
\hline 13 & & & & & & & \\
\hline 14 & & & & & & & \\
\hline 15 & & & & & & & \\
\hline 16 & & & & & & & \\
\hline 17 & & & & & & & \\
\hline 18 & & & & & & & \\
\hline 19 & & & & & & & \\
\hline 20 & & & & & & & \\
\hline 21 & & & & & & & \\
\hline 22 & & & & & & & \\
\hline 23 & & & & & & & \\
\hline
\end{tabular}

NOTA: NOS ESPAÇOS DEVEM SER COLOCADOS OS NÚMEROS REFERENTES AOS EQUIPAMENTOS. 
9.3 - QUAIS DOS SEGUINTES EQUIPAMENTOS FORAM COMPRADOS PARA ESTE DOMICÍLIO NOS ÚLTIMOS DOIS ANOS? INDIQUE O MÊS E O ANO DE AQUISIÇÃO?

\begin{tabular}{|c|c|c|c|c|c|c|c|c|c|c|c|}
\hline \multicolumn{2}{|c|}{ GELADEIRA } & \multicolumn{2}{|c|}{ FREEZER } & \multicolumn{2}{|c|}{$\begin{array}{c}\text { LAVA } \\
\text { ROUPA }\end{array}$} & \multicolumn{2}{|c|}{ LAVA LOUÇA } & \multicolumn{2}{|c|}{ TV } & \multicolumn{2}{|c|}{$\begin{array}{c}\text { AR CONDICIO } \\
\text { NADO }\end{array}$} \\
\hline MÊS & ANO & MÊS & ANO & MÊS & ANO & MÊS & ANO & MÊS & ANO & MÊS & ANO \\
\hline \multicolumn{2}{|c|}{$\begin{array}{l}\text { COMPU- } \\
\text { TADOR }\end{array}$} & \multicolumn{2}{|c|}{$\begin{array}{l}\text { VIDEO } \\
\text { CASSETE }\end{array}$} & \multicolumn{2}{|c|}{$\begin{array}{l}\text { APARELHO DE } \\
\text { SOM }\end{array}$} & \multicolumn{2}{|c|}{$\begin{array}{c}\text { FORNO DE } \\
\text { MICRO } \\
\text { ONDAS }\end{array}$} & \multicolumn{2}{|c|}{$\begin{array}{l}\text { TORNEIRA } \\
\text { ELÉTRICA }\end{array}$} & \multicolumn{2}{|c|}{$\begin{array}{l}\text { OUTRO, } \\
\text { QUAL? }\end{array}$} \\
\hline MÊS & ANO & MÊS & ANO & MÊS & ANO & MÊS & ANO & MÊS & ANO & MÊS & ANO \\
\hline & & & & & & & & & & & \\
\hline
\end{tabular}

9.4 - PRETENDE COMPRAR ALGUM ELETRODOMÉSTICO NOS PRÓXIMOS SEIS MESES, PARA ESTE DOMICÍLIO; CASO SUA RENDA AUMENTE?

1. . SIM - (PREENCHA TABELA ABAIXO IDENTIFICANDO NO CARTÃO 6)

2. $\cdot N \tilde{N A}$

99. • NÃO SABE / NR

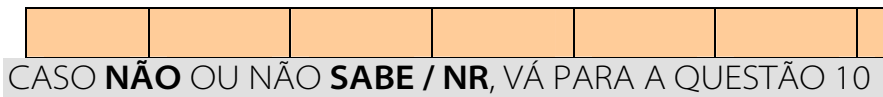

9.4.1 - CASO PRETENDA COMPRAR ALGUM DESTES ELETRODOMÉSTICOS, SENDO QUE JÁ POSSUA OUTRO DENTRO DE CASA, QUAL O DESTINO QUE VAI SER DADO PARA O ANTIGO?

\begin{tabular}{|c|c|c|c|c|c|}
\hline \multirow{2}{*}{ APARELHO } & \multicolumn{5}{|c|}{ DESTINO } \\
\hline & JOGAR FORA & $\begin{array}{l}\text { DAR PARA } \\
\text { ALGUÉM }\end{array}$ & VENDER & $\begin{array}{c}\text { FICAR COM OS } \\
\text { DOIS }\end{array}$ & NÃOSABE \\
\hline \multicolumn{6}{|l|}{ 1. GELADEIRA } \\
\hline \multicolumn{6}{|l|}{ 2. AR CONDICIONADO } \\
\hline \multicolumn{6}{|l|}{ 3. FREEZER } \\
\hline 4. APARELHO DE SOM & & & & & \\
\hline
\end{tabular}

CASO NÃO PRETENDA COMPRAR NENHUM DESTES CITADOS (JÁ POSSUINDO OUTRO DENTRO DE (ASA), PULAR PARA A PRÓXIMA QUESTÃO

\section{AQUECIMENTO DE ÁGUA PARA BANHO}

10.1 - NESTA RESIDÊNCIA, COMO É O SISTEMA DE AQUECIMENTO DA ÁGUA PARA O BANHO?

\section{AQUECIMENTO ELÉTRICO}

1... CHUVEIRO ELÉTRICO

2. . AQUECEDOR DE PASSAGEM (KDT)

3. $\cdot$ BOILER

4. . AQUECIMENTO CENTRAL

\section{AQUECIMENTO SOLAR/ OUTROS TIPOS}

9. .. AQUECEDOR SOLAR

10. . OUTRAS FORMAS DE AQUECIMENTO QUAL:

\section{AQUECIMENTO A GÁS}

5. . GÁS DE RUA

6. . GLP (GÁs DE BOTIJÃO)

7. . BOILER

8. . AQUECIMENTO CENTRAL
11. • NÃO POSSUI NENHUM TIPO DE AQUEC.

99. •• NÃO SABE / NR 
QUANTIDADE DE APARELHOS:

10.2 - CARACTERÍSTICAS:

\begin{tabular}{|c|c|c:c|c|}
\hline $\begin{array}{c}\text { No } \\
\text { REFERÊNCIA } \\
\text { DO } \\
\text { APARELHO }\end{array}$ & $\begin{array}{c}\text { TIPO DE } \\
\text { APARELHO } \\
(1)\end{array}$ & $\begin{array}{c}\text { POSIÇÃO EM QUE SE } \\
\text { No DE } \\
\text { PESSOAS } \\
\text { QUE } \\
\text { USAM }\end{array}$ & $\begin{array}{c}\text { DURANTE OS MESES DE } \\
\text { INVERNO A CHAVE FICA }\end{array}$ \\
APARELHO & NA POSIÇÃO
\end{tabular}

\section{CHAMADA: (1) VEJA NO CARTÃO 3}

10.3 - HÁBITOS DE USO DO CHUVEIRO ELÉTRICO NOS DIAS DE SEMANA.

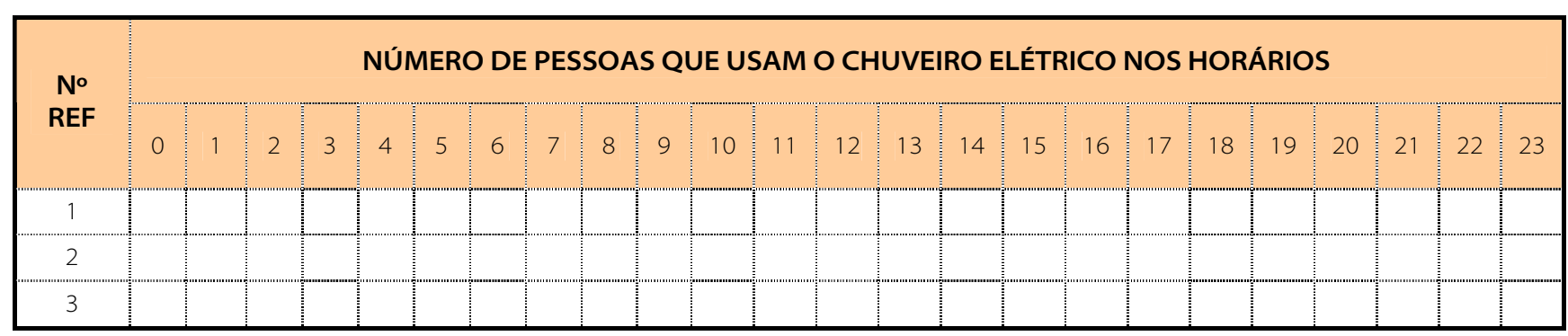

NOTA: OS CAMPOS DEVEM SER PREENCHIDOS COM O NÚMERO DE PESSOAS QUE USAM O CHUVEIRO ELÉTRICO NOS HORÁRIOS CORRESPONDENTES, ADMITINDO A POSSIBILIDADE DE UM INDIVÍDUO TOMAR MAIS DE UM BANHO POR DIA.

10.4 - HÁBITOS DE USO DO CHUVEIRO ELÉTRICO NOS FINAIS DE SEMANA.

\begin{tabular}{|c|c|c|c|c|c|c|c|c|c|c|c|c|c|c|c|c|c|c|c|c|c|c|c|c|c|}
\hline \multirow{2}{*}{$\begin{array}{l}\mathrm{N}^{\circ} \\
\text { REF }\end{array}$} & \multicolumn{25}{|c|}{ NÚMERO DE PESSOAS QUE USAM O CHUVEIRO ELÉTRICO NOS HORÁRIOS } \\
\hline & 0 & 1 & 2 & & 3 & 4 & 5 & 6 & 7 & 8 & 9 & 10 & 11 & 12 & 13 & 14 & 15 & 16 & 17 & 18 & 19 & 20 & 21 & 22 & 23 \\
\hline 1 & & & & & & & & & & & & & & & & & & & & & & & & & \\
\hline 2 & & & & & & & & & & & & & & & & & & & & & & & & & \\
\hline 3 & & & & & & & & & & & & & & & & & & & & & & & & & \\
\hline
\end{tabular}

NOTA: OS CAMPOS DEVEM SER PREENCHIDOS COM O NÚMERO DE PESSOAS QUE USAM O CHUVEIRO ELÉTRICO NOS HORÁRIOS CORRESPONDENTES, ADMITINDO A POSSIBILIDADE DE UM INDIVÍDUO TOMAR MAIS DE UM BANHO POR DIA.

10.5 - QUAL O TEMPO MÉDIO PARA O BANHO?
1.. ATÉ $10 \mathrm{MIN}$
2. $\square \cdot 10 \mathrm{~A} 20 \mathrm{MIN}$
3. $\square \cdot$ MAIS DE $20 \mathrm{MIN}$
99. $\square \cdot N \tilde{A} O S A B E / N R$

10.6 - SE O PREÇO DA ENERGIA FOSSE O DOBRO NO HORÁRIO DAS 18:00 ÀS 21:00, VOCÊ ACHA QUE A SUA FAMÍLIA EVITARIA TOMAR BANHO NESSE PERÍODO?
1. $\square \cdot \operatorname{SIM}$ 2. $\square$ NÃO
99. $\square \cdot N \tilde{A O} \mathrm{SABE} / \mathrm{NR}$
4. $\square \cdot$ UNS SIM, OUTROS NÃO 
10.7 - O(A) SR.(A) CONHECE OU JÁ OUVIU FALAR DE AQUECEDORES DE ÁGUA À GÁS PARA O BANHO? $\begin{array}{ll}\text { 1. } \square \cdot \text { SIM } & \text { 2. } \square \cdot N A ̃ O \\ \text { SE NÃO OU NÃO SABE / NR, VÁ PARA O ITEM } 10.8\end{array}$

10.7.1 - O(A) SR.(A) MUDARIA SEU SISTEMA DE AQUECIMENTO DE ÁGUA DE BANHO, PARA GÁS?
1. $\square \cdot \operatorname{SIM} 2 . \square \mathrm{NÃO}$
99. $\square \cdot N A \tilde{O}$ SABE / NR
4. $\square \cdot$ DEPENDE DO CUSTO

10.8 - O(A) SR.(A) CONHECE OU JÁ OUVIU FALAR DE AQUECEDORES DE ÁGUA SOLAR PARA O BANHO?
1. $\square \cdot \operatorname{SIM}$
2. $\square \cdot N \tilde{O} O$
99. $\square \cdot N \tilde{A} O S A B E / N R$

SE NÃO OU NÃO SABE / NR, VÁ PARA O ITEM 10.9

10.8.1 - O(A) SR.(A) MUDARIA SEU SISTEMA DE AQUECIMENTO DE ÁGUA DE BANHO, PARA SOLAR?
1. $\square \cdot \operatorname{SIM} 2 . \square \mathrm{NÃO}$
99. $\square \cdot N A \tilde{O}$ SABE / NR
4. $\square \cdot$ DEPENDE DO CUSTO

10.9 - O(A) SR(A). CONSIDERA SEU SISTEMA DE AQUECIMENTO DE ÁGUA EFICIENTE COM RELAÇÃO AO CONSUMO DE ENERGIA?
1. $\square \cdot \operatorname{SIM}$
2. $\square \cdot N \tilde{O} O$
99. $\square \cdot N A ̃ O S A B E / N R$

\section{DADOS SÓCIO-ECONÔMICOS}

11.1 - ITENS DE CONFORTO FAMILIAR:

\begin{tabular}{|l|l|l|}
\hline \multicolumn{1}{|c|}{ ITENS } & QUANTIDADE \\
\hline BANHEIRO & & \\
\hline AUTOMÓVEL & & ANO: \\
\hline EMPREGADA DOMÉSTICA & SALÁRIO: \\
\hline
\end{tabular}

(SOMENTE PARA OS QUE POSSUEM AUTOMÓVEL - 11.1.1)

11.1.1 - UTILIZA O GNV (GÁS NATURAL VEICULAR) COMO COMBUSTÍVEL DO SEU AUTOMÓVEL? (ESTIMULADA) 1. $\square$ : SIM, EM QTS? $\frac{\text { 2. } \square \text { NÃO }}{\text { SE SIM OU NÃO SABE / NR, VÁ PARA O ITEM } 11.2}$

99. $\square$ NÃO SABE / NR

11.1.2 - CASO NÃO, POR QUE? (ESTIMULADA)

1. $\square \cdot N A ̃ O C O N H E C ̧ E$

3. $\square$ - ACHA O CUSTO CARO

5. $\square$ - ACHA PERIGOSO

2. $\square$ ACHA INEFICIENTE

99. $\square \cdot N \tilde{O} O \mathrm{SABE} / \mathrm{NR}$

4. $\square$ ACHA A INFRA-ESTRUTURA PRECÁRIA

6. $\square$ OUTROS MOTIVOS:

11.2 - RENDA FAMILIAR (Piso nacional de salários)
1. $\square \cdot<1$
5. $\square \cdot 4$ a 5
9. $\square 15$ a 20
2. $\square \cdot 1$ a 2
6. $\square \cdot 5$ a 7
10. $\square \cdot 20$ a 30
3. $\square \cdot 2$ a 3
7. $\square \cdot 7$ a 10
$11 . \square \cdot 30$ a 40
4. $\square \cdot 3$ a 4
8. $\square \cdot 10$ a 15
12. $\square \cdot>40$

99. $\square$ • NÃO SABE / NR

11.3 - NESTE DOMICÍLIO É FEITO ALGUM TIPO DE TRABALHO PARA SER COMERCIALIZADO? (VEJA NO CARTÃO 7

\begin{tabular}{|l|l|l|l|l|l|l|l|l|}
\hline 1 & 2 & 3 & 4 & 5 & 6 & 7 & 8 & 9 \\
\hline
\end{tabular}

CASO NÃO SEJA FEITO NENHUM TIPO DE TRABALHO COM FIM COMERCIAL, VA PARA O ITEM 11.5.

11.4 - QUAIS SÃO OS EQUIPAMENTOS ELÉTRICOS UTILIZADOS NESTE(S) TRABALHO(S)? (IDENTIFIQUE OS EQUIPAMENTOS NO CARTÃO 6) 
11.5 - REGIÃO DO DOMICÍLIO:
1.. LUXO
2. $\square \cdot$ CLASSE MÉDIA ALTA
3. $\square \cdot$ CLASSE MÉDIA BAIXA
4. $\square \cdot$ POBRE
99. $\square \cdot N \tilde{A O}$ SABE / NR

11.6 - PRÓXIMO À FAVELA:
1. $\square \cdot \operatorname{SIM}$
2. $\square N A ̃ O$
3. $\square \cdot$ NA FAVELA 99. $\square \cdot N A ̃ O S A B E / N R$

11.7 - COMO O(A) SR.(A) CLASSIFICARIA O PESO DA CONTA DE LUZ NO SEU ORÇAMENTO FAMILIAR? (ESTIMULADA)
1. $\square$ - MUITO PESADO
2. $\square \cdot$ PESADO
4. $\square$. POUCO PESADO
5. $\square \cdot$ NADA PESADO
3. $\square \cdot$ MAIS OU MENOS PESADO
99. $\square \cdot N A ̃ O S A B E / N R$

11.8 - DÊ UMA NOTA DE O A 10, COMPARANDO OS SERVIÇOS PRESTADOS PELAS SEGUINTES EMPRESAS:
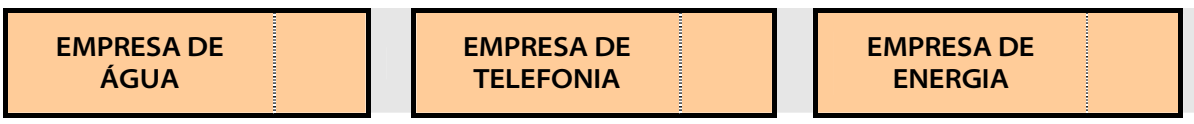

\section{NÃO SABE/NÃO} CONHECE

11.9 - ADOTANDO UMA ESCALA DE 10 PONTOS, ONDE O PONTO 1 INDICA QUE O(A) SR.(A) ACHA O PREÇO PAGO PELA ENERGIA ELÉTRICA MUITO BARATO E, O PONTO 10, QUE O(A) SR.(A) ACHA O PREÇO MUITO CARO. AVALIE OS SEGUINTES PONTOS:

\begin{tabular}{|l|c|}
\hline \multicolumn{1}{|c|}{ ITENS } & AVALIAÇÃO \\
\hline 1) PREÇO PAGO PELA ENERGIA ELÉTRICA & \\
\hline $\begin{array}{l}\text { 2) CUSTO COM ENERGIA ELÉTRICA, CONSIDERANDO OS BENEFÍCIOS QUE ELA LHE OFERECE. COMO } \\
\text { POR EXEMPLO, CONFORTO, COMODIDADE E SEGURANÇA }\end{array}$ & \\
\hline
\end{tabular}

NOTA: 11 - NÃO SABE AVALIAR 12 - NÃO RESPONDEU

\section{RACIONAMENTO E CONSERVAÇÃO DE ENERGIA}

12.1 - NESTA RESIDÊNCIA SÃO ADOTADAS MEDIDAS PARA ECONOMIZAR ENERGIA ELÉTRICA?
1. $\cdot$ SIM
2. $\square \cdot N A ̃ O$
99. $\square \cdot N A \tilde{O} S A B E / N R$

12.2 - DESTAS MEDIDAS QUE VOU LHE APRESENTAR, GOSTARIA QUE O(A) SR.(A) ME INFORMASSE QUAIS FORAM ADOTADAS ANTES, DURANTE E DEPOIS DO RACIONAMENTO? E COMO O(A) SR.(A) COMPARA A UTILIZAÇÃO ATUAL DESTAS MEDIDAS EM RELAÇÃO À UTILIZAÇÃO DAS MESMAS DURANTE O RACIONAMENTO?

\begin{tabular}{|c|c|c|c|c|c|c|c|c|c|c|c|c|c|c|c|}
\hline \multirow{2}{*}{\multicolumn{2}{|c|}{ AÇÕES }} & \multicolumn{14}{|c|}{ MEDIDAS ADOTADAS (LER CARTÃO 8) } \\
\hline & & 1 & 2 & 3 & 4 & 5 & 6 & 7 & 8 & 9 & 10 & 11 & 12 & 13 & 14 \\
\hline \multicolumn{16}{|c|}{ ANTES DO RACIONAMENTO } \\
\hline \multicolumn{16}{|c|}{ DURANTE O RACIONAMENTO } \\
\hline \multirow{4}{*}{$\begin{array}{c}\text { ATUALMENTE } \\
\text { (comparar com } \\
\text { durante) }\end{array}$} & MAIS & & & & & & & & & & & & & & \\
\hline & IGUAL & & & & & & & & & & & & & & \\
\hline & MENOS & & & & & & & & & & & & & & \\
\hline & $\tilde{N}$ ADOTOU & & & & & & & & & & & & & & \\
\hline
\end{tabular}
12.3 - AS MEDIDAS ADOTADAS PARA ATINGIR AS METAS DURANTE O PERÍODO DE RACIONAMENTO FORAM: 1. .. INSUFICIENTES
2. $\square \cdot$ SUFICIENTES
3. $\cdot$ MAIS QUE O SUFICIENTE
DIFICULDADE; $\square$ MUITO $\square \cdot$ POUCO
$\square \cdot$ NENHUMA
DIFICULDADE; $\square$ MUITO $\dot{\square} \cdot$ POUCO
- NENHUMA

99. $\cdot$ - NÃO SABE / NR 
3. $\square \cdot$ CAUSOU MUITO DESCONFORTO

99. $\square \cdot N A ̃ O S A B E / N R$

5. $\square$ • APRENDI A VIVER COM O MESMO CONFORTO ECONOMIZANDO DINHEIRO

6. $\square \cdot$ OUTRO

12.5 - DURANTE O RACIONAMENTO O(A) SR.(A) SUBSTITUIU AS LÂMPADAS INCANDESCENTES DE SUA RESIDÊNCIA POR LÂMPADAS FLUORESCENTES?

1. $\square \cdot$ SIM, QUAIS:

2. $\square \cdot N A ̃ O$

99. $\square \cdot N \tilde{N} O S A B E / N R$ (IDENTIFICAR NA CHAMADA (1))

SE NÃO OU NÃO SABE / NR, VÁ PARA 12.6

\section{CHAMADA: (1)}

(1) FLUORESCENTE COMPACTA ATÉ 15W

(2) FLUORESCENTE COMPACTA $>15 \mathrm{~W}$

(3) FLUORESCENTE TUBULAR - 20W

(4) FLUORESCENTE TUBULAR - 4OW

12.5.1 - QUANTAS?

1. $\square \cdot$ TODAS/QUASE TODAS

3. $\square \cdot$ MENOS DA METADE

2. $\square \cdot$ MAIS DA METADE

99. $\square \cdot N A \tilde{O}$ SABE / NR

12.5.2 - E, MESMO COM O FINAL DO RACIONAMENTO O(A) SR.(A) CONTINUA UTILIZANDO AS LÂMPADAS FLUORESCENTES?

1. $\square \cdot$ SIM; TODAS SUBSTITUÍDAS CONTINUAM FLUORESCENTES, MESMO AS QUE QUEIMARAM

2. $\square \cdot N A ̃ O, A Q U E L A S$ QUE QUEIMARAM FORAM SUBSTITUÍDAS POR INCANDESCENTE

3. $\square$ - MANTIVE ALGUMAS FLUORESCENTES, E SUBSTITUÍ OUTRAS POR INCANDESCENTES

99. $\square \cdot N A ̃ O S A B E / N R$

CASO NÃO,... CONTINUE, AO CONTRÁRIO VÁ PARA 12.6

12.5.3 - SE NÃO CONTINUOU COM O USO DE LÂMPADAS FLUORESCENTES, SUBSTITUIDAS POR LÂMPADAS INCANDESCENTES COMUNS, FOI POR QUE?

1. $\square \cdot$ PREÇO: MUITO CARO

2. $\square \cdot N A \tilde{O}$ DEU IMPORTÂNCIA PARA ECONOMIA DAS LÂMPADAS FLUORESCENTES

3. $\square \cdot$ OUTRO, QUAL:

99. $\square \cdot N A ̃ O S A B E / N R$

12.6 - COM O FINAL DO RACIONAMENTO O QUE O(A) SR.(A) FEZ EM RELAÇÃO AO: (ESTIMULADA)

\begin{tabular}{|c|c|}
\hline APARELHOS & RESPOSTA (1) \\
\hline 1. GELADEIRA & ( ) \\
\hline 2. AR CONDICIONADO & $($ ) \\
\hline 3. FREEZER & ( ) \\
\hline 4. CHUVEIRO ELÉTRICO & $($ ) \\
\hline 5. MÁQUINA DE LAVAR & $($ ) \\
\hline 6. APARELHO EM STAND BY & $($ ) \\
\hline 7. MICROONDAS & $($ ) \\
\hline 8. LÂMPADAS & $(\quad)$ \\
\hline 9. OUTRO. QUAL? & $($ ) \\
\hline
\end{tabular}

CHAMADA: (1)

(1) USO COMO ANTES DO RACIONAMENTO

(2) USO MENOS DO QUE USAVA ANTES DO RACIONAMENTO

(3) CONTINUA DESLIGADO

(4) ME DESFIZ DESTE APARELHO

(5) TROQUEI POR OUTRO APARELHO MENOR E/OU MAIS EFICIENTRE
(6) USO MAIS COMO PROTESTO

(7) NÃO TINHA ANTES, COMPREI DEPOIS

(8) NÃOTENHO

(9) OUTROS. QUAIS?

NOTA: O ESPAÇO NA SEGUNDA COLUNA DENTRO DA TABELA, DEVE SER PREENCHIDO CASO O ENTREVISTADO RESPONDA AO ITEM (9) OUTROS DENTRO DA CHAMADA; ESPECIFICANDO ASSIM A FINALIDADE DECLARADA. 
12.7 - COMO O(A) SR.(A) IDENTIFICA NOS APARELHOS ELETRODOMÉSTICOS O SEU CONSUMO DE ENERGIA?
1... ETIQUETA
2. $\square \cdot$ SELO PROCEL
99. $\square$ NÃO SABE / NR
4. . OUTROS

12.8 - ADOTANDO UMA ESCALA DE 10 PONTOS, ONDE O PONTO 10 INDICA QUE O(A) SR.(A) CONSIDERA MUITO IMPORTANTE, E O PONTO 1, QUE O(A) SR.(A) CONSIDERA MUITO POUCO IMPORTANTE. AVALIE A IMPORTÂNCIA DOS SEGUINTES ATRIBUTOS NO ATO DE COMPRA DE UM ELETRODOMÉSTICO:

1. MARCA OU MODELO/ FABRICANTE 2. PREÇO

3. CONSUMO MENSAL DE ENERGIA 4._ RECOMENDAÇÃO DO VENDEDOR

12.9 - O(A) SR.(A) CONHECE OS SELOS PROCEL (ENCONTRADO EM LÂMPADAS E ELETRODOMÉSTICOS)? (MOSTRAR SELO DO PROCEL)

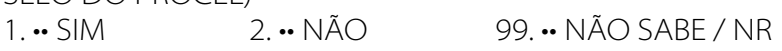

12.10 - SABE O QUE ELE REPRESENTA?
1. $\square \cdot \operatorname{SIM}$
2. $\square \cdot N \tilde{O} O$
99. $\square \cdot N \tilde{O} \mathrm{SABE} / \mathrm{NR}$

12.11 - O(A) SR.(A) SABE O QUANTO PODE ECONOMIZAR MENSALMENTE OU ANUALMENTE COM ENERGIA COM A COMPRA DE PRODUTOS EFICIENTES?

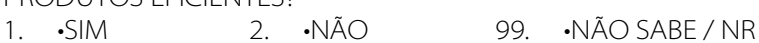

12.12.1 -O(A) SR.(A) RECEBE INFORMAÇÕES SOBRE PRODUTOS EFICIENTES E DICAS SOBRE COMO ECONOMIZAR ENERGIA?

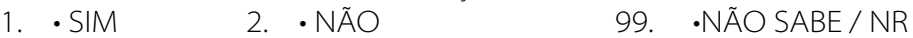
CASO NÃO OU NÃO SABE / NR, VÁ PARA O ITEM 12.13

12.12.2 - CASO SIM, QUAIS SÃO AS SUAS PRINCIPAIS FONTES?
1. $\square \cdot \mathrm{TV}$
2. $\square \cdot$ REVISTAS
4. $\square \cdot$ INTERNET
5. $\square \cdot$ CONTAS DE LUZ
3. $\square \cdot$ JORNAIS
7. $\square \cdot$ NAS LOJAS, PELOS VENDEDORES
6. $\square$. AMIGOS
8. $\square$ OUTROS, QUAIS:

99. $\square \cdot N$ ÃO SABE / NR

ADMITE RESPOSTAS MÚLTIPLAS

12.13.1 - O(A) SR.(A) POSSUI ACESSO À INTERNET?
1. $\square \cdot$ SIM
2. $\square \cdot N A ̃ O$
99. $\square \cdot N \tilde{A} O S A B E / N R$

\section{CASO NÃO OU NÃO SABE / NR, VÁ PARA O ITEM 12.14}

12.13.2 - COMO É O SEU ACESSO À INTERNET?

1. $\square$ PRÓPRIO

3. $\square$ TRABALHO

5. $\square \cdot$ OUTROS, QUAIS:

12.14 - QUAIS AS EMPRESAS, ORGANIZAÇÕES OU ENTIDADES QUE TRABALHAM E DIVULGAM A ECONOMIA DE ENERGIA NO BRASIL E QUAL A MAIS IMPORTANTE DESSE SETOR PARA O(A) SR.(A)? (ESPONTÂNEA)

\begin{tabular}{|c|c|c|c|}
\hline \multirow{2}{*}{ EMPRESA } & \multicolumn{2}{|c|}{ CONHECIMENTO } & \multirow{2}{*}{$\begin{array}{c}\text { MAIS } \\
\text { IMPORTANTE }\end{array}$} \\
\hline & SIM & NÃO & \\
\hline \multicolumn{4}{|l|}{ CONCESSIONÁRIA } \\
\hline \multicolumn{4}{|l|}{ ELETROBRÁS } \\
\hline \multicolumn{4}{|l|}{ PROCEL } \\
\hline \multicolumn{4}{|l|}{ ANEEL } \\
\hline OUTRAS, QUAIS: & & & \\
\hline
\end{tabular}

2. $\square$ • ASSOCIAÇÃO COMUNITÁRIA

4. $\square$ AMIGOS

99. $\square \cdot N \tilde{N} \bigcirc \mathrm{SABE} / \mathrm{NR}$ 


\section{SATISFAÇÃO DO CONSUMIDOR}

ESTE TÓPICO DEVE SER RESPONDIDO EM CONSIDERAÇÃO AOS DIAS ATUAIS.

\section{SATISFAÇÃO GLOBAL}

13.1 - ADOTANDO UMA ESCALA DE 10 PONTOS, ONDE O PONTO 1 INDICA QUE VOCÊ ESTA MUITO INSATISFEITO(A) COM OS SERVIÇOS DE ENERGIA ELÉTRICA E O PONTO 10 QUE VOCÊ ESTÁ MUITO SATISFEITO(A). GOSTARIA QUE VO̧CÊ AVALIASSE, DE MANEIRA GERAL, A QUALIDADE DOS SERVIÇOS PRESTADOS PELA (CITAR NOME DA CONCESSIONÁRIA)

1. NOTA DE AVALIAÇÃO

NOTA: 11 - NÃO SABE AVALIAR 12 - NÃO RESPONDEU

13.2 - VOCÊ JÁ TEVE ALGUM CONTATO COM A (CITAR NOME DA CONCESSIONÁRIA), SEJA PARA RESOLVER ALGUM PROBLEMA OU PEDIR ALGUM SERVIÇO, OU NUNCA ENTROU EM CONTATO?
1... SIM
2. $\square N \tilde{A} O$
99. $\square \cdot N \tilde{O} O S A B E / N R$

\section{DESCONFORMIDADE}

13.3 - ADOTANDO UMA ESCALA DE 10 PONTOS, ONDE O PONTO 1 INDICA QUE O SERVIÇO PRESTADO PELA EMPRESA ESTÁ MUITO PIOR QUE AQUELE QUE VOCÊ ESPERA E O PONTO 10 QUE ESTÁ MUITO MELHOR QUE AQUELE QUE VOCÊ ESPERA. GOSTARIA QUE VOCÊ AVALIASSE, DE FORMA GERAL, A QUALIDADE DOS SERVIÇOS PRESTADOS PELA (CITAR O NOME DA CONCESSIONÁRIA).

1. NOTA DE AVALIAÇÃO

NOTA: 11 - NÃO SABE AVALIAR 12 - NÃO RESPONDEU

\section{DISTÂNCIA DO IDEAL}

13.4 - ADOTANDO UMA ESCALA DE 10 PONTOS, ONDE O PONTO 1 INDICA QUE A EMPRESA ESTÁ MUITO LONGE DO IDEAL E O PONTO 10 QUE ESTÁ MUITO PRÓXIMA DO IDEAL. GOSTARIA QUE VOCÊ AVALIASSE, PENSANDO NA QUALIDADE DOS SERVIÇOS DE FORMA GERAL, COMO ESTÃO SENDO PRESTADOS PELA (CITAR O NOME DA CONCESSIONÁRIA).

1. NOTA DE AVALIAÇÃO

NOTA: 11 - NÃO SABE AVALIAR 12 - NÃO RESPONDEU 
ANEXO IV. - QUESTIONÁRIO (CARTÕES)

\begin{tabular}{|c|c|}
\hline \multicolumn{2}{|c|}{ CARTÃO 1 - (REFRIGERADOR) } \\
\hline 100) BRASTEMP & 200) CONSUL \\
\hline 101) QUALITY 260 LITROS & 201) COMPACTO - 50 \\
\hline 102) CLEAN 340 LITROS & 202) COMPACTO - 80 \\
\hline 103) ALL REFRIGERATOR 360 LITROS & 203) COMPACTO - 120 \\
\hline 104) DUPLEX CLEAN 320 LITROS & 204) CONSUL 240 \\
\hline 105) DUPLEX CLEAN 410 LITROS & 205) CONSUL 320 \\
\hline 106) DUPLEX CLEAN / FROST FREE 390 LITROS & 206) CONSUL 320/360 DEGELO SECO \\
\hline 107) DUPLEX CLEAN / FROST FREE - (ZYRIUM) & 207) PRATICE 300 \\
\hline 108) BOTTOM FREEZER FROST FREE 420 LITROS & 208) BIPLEX 420 FROST FREE \\
\hline 109) DUPLEX FROST FREE 340 ELETRÔNICO & 209) BIPLEX $360 / 390$ \\
\hline 110) DUPLEX FROST FREE 440 ELETRÔNICO & 210) BIPLEX RURAL 215 \\
\hline 111) DUPLEX FROST FREE 440 UNIQUE & 211) BIPLEX - 450 \\
\hline \multicolumn{2}{|l|}{ 112) DUPLEX FROST FREE 440 ELETRÔNICO } \\
\hline ZYRIUM & 300) ELETROLUX / PROSDÓCIMO \\
\hline 113) DUPLEX FROST FREE 440 ELETRÔNICO & 301) SMILE - R 13 \\
\hline ICE MAGIC & 302) SMILE - R 27 \\
\hline 114) INSIDE FREEZER 350 & 303) SMILE - T 27 \\
\hline 115) BOTTOM FREEZER 330 & 304) SMILE - D 41 \\
\hline 116) DUPLEX 360 & 305) COMPACTO - R130 \\
\hline 117) DUPLEX 460 & 306) 1 PORTA - RE26 \\
\hline \multirow[t]{2}{*}{ 118) SIDE BY SIDE 700} & 307) 1 PORTA - RE29 \\
\hline & 308) 1 PORTA - RDE32 \\
\hline 400) GENERAL ELECTRIC & 309) 1 PORTA - RDE37 \\
\hline 401) GE 13 & 310) 2 PORTAS - DC38 \\
\hline 402) TBX $112 C-329$ LITROS & 311) 2 PORTAS - DC47 \\
\hline 403) TBX 112C - 366 LITROS & 312) FROST FREE - DF35 \\
\hline \multirow[t]{2}{*}{ 404) TBX $16-J A X$} & 313) FROST FREE - DFF37 \\
\hline & 314) FROST FREE - DFF44 \\
\hline 500) CLIMAX & 315) FROST FREE - DF45 \\
\hline \multirow[t]{2}{*}{ 501) CLIMAX } & 316) FROST FREE - DFW45 \\
\hline & 317) FROST FREE - DS600 \\
\hline 600) FRIGIDAIRE & 318) BOTTOM FREEZER - DB580 \\
\hline \multirow[t]{2}{*}{ 601) FRIGIDAIRE } & 319) SIDE BY SIDE - SS650 \\
\hline & 320) SIDE BY SIDE - SS680 \\
\hline 700) ESMALTEC & 321) SIDE BY SIDE - SS74X \\
\hline \multicolumn{2}{|l|}{ 701) ESMALTEC } \\
\hline & 800) OUTRAS \\
\hline
\end{tabular}




\section{CARTÃO 2 - (FREEZER)}

100) BRASTEMP

101) FREEZER 260

102) FREEZER 300

103) FROST FREE ELETRÔNICO 280

104) FROST FREE 280

105) FROST FREE 240

\section{0) ELETROLUX / PROSDÓCIMO}

301) HORIZONTAL H160

302) HORIZONTAL H210

303) HORIZONTAL H30O

304) HORIZONTAL H400

305) HORIZONTAL H5OO

306) VERTICAL FE1 8

307) VERTICAL FE22

308) VERTICAL FE26

309) VERTICAL FFE24

310) SYSTEM SE54

311) SYSTEM SE61

312) SYSTEM SE63

400) EMBRACO

401) EMBRACO
200) CONSUL

201) COMPACTO VERTICAL 90

202) VERTICAL - SLIM - 170

203) VERTICAL - SLIM - 200

204) VERTICAL 260

205) PRATICE - 240

206) VERTICAL 300

207) CONTEST 28 - 280

208) HORIZONTAL 220

209) HORIZONTAL 310

210) HORIZONTAL 420

211) HORIZONTAL 530

\section{0) METALFRIO}

501) HORIZONTAL HC-1

502) HORIZONTAL HC-2

503) HORIZONTAL HC-3

600) ESMALTEC

601) ESMALTEC

\section{0) OUTRAS}




\section{CARTÃO 3 - (CHUVEIRO ELÉTRICO)}

\begin{tabular}{|c|c|}
\hline 100) LORENZETTI & 200) CORONA \\
\hline 101) 4.400W - TRADIÇÃO, RELAX E LORENDUXA & 201) $3.600 W$ - DUCHA SS \\
\hline 102) 4.400W - BELLO BANHO E MAXI BANHO & 202) 4.000W - GORDUCHA LIGHT \\
\hline 103) 4.400W - JET SET 4 E SATISFACTION & 203) $4.400 \mathrm{~W}$ - BALLERINA E DUCHA SS \\
\hline 104) 4.400W - BELLA DUCHA & 204) 4.800W - CORONA II E GORDUCHA \\
\hline 105) $5.000 \mathrm{~W}$ - BLINDUCHA & 205) 5.200W - MEGABANHO E JATO OBED. \\
\hline 106) 5.400W - TRADIÇÃO, RELAX E LORENDUXA & 206) 5.200W - DUCHA SS \\
\hline 107) 5.400W - JET TURBO J E JET MASTER JI & 207) 5.400W - BALLERINA E DUCHA SS \\
\hline 108) 5.400W - BELLO BANHO E MAXI BANHO & 208) 5.400W - CORONA II E GORDUCHA \\
\hline 109) 5.400W - JET SET 4 E SATISFACTION & 209) 5.500W - BANHO TOTAL E 4 ESTAÇÕES \\
\hline 110) 5.400W - BELLA DUCHA E SUPERBANHO & 210) 6.500W - BANHO TOTAL E 4 ESTAÇÕES \\
\hline 111) 6.400W - TRADIÇÃO E LORENDUXA & 211) $6.500 \mathrm{~W}$ - JATO OBEDIENTE \\
\hline 112) 6.400W - JET SET 4 E SATISFACTION & 212) 7.500W - MEGABANHO \\
\hline \multicolumn{2}{|l|}{ 113) 6.400W - SUPERBANHO } \\
\hline 114) 7.500W - JET TURBO BLIN. E JET MASTER BLIN. & 400) CARDAL \\
\hline 115) 7.500W - JET TURBO JI E JET MASTER JI & 401) 6.500W - DUCHA 5 STANDARD \\
\hline \multirow[t]{2}{*}{ 116) $7.500 W$ - BLINDUCHA } & 402) 6.500W - COMPACTA (BR E CR) \\
\hline & 403) 7.600W - DUCHA 5 LUXO \\
\hline 300) FAME & 404) 7.600W - SUPER LUXO (BD) E CD) \\
\hline 301) 3.000W - SUPER DUCHA (1) & 405) 7.600W - ELETRONICA LUXO \\
\hline \multicolumn{2}{|l|}{ 302) 3.000W - DUCHA JATO DIRIGÍVEL } \\
\hline 303) 3.500W - CH. TRADICIONAL CORES & 500) GRUFER \\
\hline 304) 4.200W - CH. TRADICIONAL CORES & 501) 8.800W - DUCHA IGUAÇU 4 TEMP. \\
\hline 305) 4.400W - SUPER DUCHA (1) & 502) 8.800W - DUCHA IGUAÇU E-2001 \\
\hline \multicolumn{2}{|l|}{ 306) 4.400W - DUCHA JATO DIRIGÍVEL } \\
\hline 307) 4.800W - SUPER DUCHA (1) & 600) OUTRAS \\
\hline \multicolumn{2}{|l|}{ 308) 4.800W - DUCHA JATO DIRIGÍVEL } \\
\hline \multicolumn{2}{|l|}{ 309) 5.000W - CH. TRADICIONAL CORES } \\
\hline 310) 7.000W - DUCHA JATO FORTE & \\
\hline
\end{tabular}




\section{0) BRASTEMP}

101) ELETETRÔNICO TOTAL AIR 7.500 BTU/H

102) TOTAL AIR 7.500 BTU/H

103) ELETRÔNICO 7.500 BTU/H

104) ELETRÔNICO $10.000 \mathrm{BTU} / \mathrm{H}$

105) ELETRÔNICO $12.000 \mathrm{BTU} / \mathrm{H}$

106) SPLIT CICLO FRIO 12.000 BTU/H

\section{0) ELETROLUX/PROSDÓCIMO}

201) MECÂNICO - AEO7

202) ENERGY SAVER MECÂNICO - AG07

203) ENERGY SAVER MECÂNICO - AG10

204) ENERGY SAVER MECÂNICO - AG12

205) ENERGY SAVER MECÂNICO - AG18

206) ENERGY SAVER ELETRÔNICO

\section{0) SPRINGER}

301) $7.000 \mathrm{BTU} / \mathrm{H}$

302) $7.500 \mathrm{BTU} / \mathrm{H}$

303) $9.000 \mathrm{BTU} / \mathrm{H}$

304) $12.000 \mathrm{BTU} / \mathrm{H}$

305) $18.000 \mathrm{BTU} / \mathrm{H}$

306) $21.000 \mathrm{BTU} / \mathrm{H}$

307) 30.000 BTU/H

308) SPLIT

600) SANYO

601) SANYO

\section{CARTÃO 4 - (CONDICIONADOR DE AR)}

400) CONSUL

401) CONSUL 7.500 BTU/H

402) ELETRONIC $10.000 \mathrm{BTU} / \mathrm{H}$

403) CLASSE A 10.000 BTU/H

404) CLASSE A 12.000 BTU/H

405) CLASSE A 15.000 BTU/H

406) CALSSE A $18.000 \mathrm{BTU} / \mathrm{H}$

407) SPLIT 9.000 BTU/H

408) SPLIT 12.000 BTU/H

409) SPLIT 18.000 BTU/H

410) SPLIT $22.000 \mathrm{BTU} / \mathrm{H}$

411) AIR MASTER 30.000 BTU/H

412) CONSUL TIMER

413) CONSUL ELECTRONIC

414) CONSUL DIGITAL

415) CONSUL 21.000 BTU/H

500) ELGIN

501) $6.000 \mathrm{BTU} / \mathrm{H}$

502) $8.300 \mathrm{BTU} / \mathrm{H}$

503) $10.000 \mathrm{BTU} / \mathrm{H}$

504) $12.000 \mathrm{BTU} / \mathrm{H}$

505) $18.000 \mathrm{BTU} / \mathrm{H}$

506) SPLIT - 8.000 BTU/H

507) SPLIT - 12.000 BTU/H

508) SPLIT - 18.000 BTU/H

509) SPLIT - 24.000 BTU/H

800) OUTRAS 


\begin{tabular}{|c|c|c|c|}
\hline \multicolumn{4}{|c|}{ CARTÃO 5 - (TELEVISÃO) } \\
\hline (1) PHILLIPS & (5) SEMP-TOSHIBA & (9) CCE & (13) JVC \\
\hline (2) PHILCO-HITACHI & (6) SONY & (10) GRADIENTE & (14) KIREY \\
\hline (3) SHARP & (7) PANASONIC & (11) SAMSUNG & (15) RCA \\
\hline (4) MITSUBISHI & (8) SANYO & (12) ZENITH & (16) PIONEER \\
\hline
\end{tabular}

\begin{tabular}{|c|c|c|}
\hline \multicolumn{3}{|c|}{ CARTÃO 6 - (ELETRODOMÉSTICOS) } \\
\hline (1) GELADEIRA & (10) MICROONDAS & (19) LIQUIDIFICADOR \\
\hline (2) FREEZER & (11) ASPIRADOR DE PÓ & (20) BATEDEIRA \\
\hline (3) LAVA ROUPA & (12) ENCERADEIRA & (21) CAFETEIRA ELÉTRICA \\
\hline (4) LAVA LOUÇA & (13) IMPRESSORA & (22) PANELA ELÉTRICA \\
\hline (5) TELEVISÃO & (14) VIDEO GAME & (23) VENTILADOR \\
\hline (6) AR CONDICIONADO & (15) FERRO & (24) AQUECEDOR DE \\
\hline (7) MICROCOMPUTADOR & (16) SECADORA DE ROUPA & AMBIENTE \\
\hline (8) VIDEO CASSETE & (17) RÁDIO ELÉTRICO & (25) APARELHO DE SOM \\
\hline (9) DVD & (18) FORNO ELÉTRICO & (26) OUTRO \\
\hline
\end{tabular}

\begin{tabular}{|c|c|}
\hline \multicolumn{2}{|c|}{ CARTÃO 7} \\
\hline (1) COSTURA & (6) CONCERTA APARELHOS \\
\hline (2) FAZ DOCES, BOLOS OU SALGADOS & (7) PRATICA COMÉRCIO \\
\hline (3) LAVA ROUPA & (8) FAZ CONSULTORIA \\
\hline (4) DÁ AULA & (9) OUTRO TRABALHO \\
\hline (5) FAZ ALGUM TIPO DE CONSULTA & \\
\hline
\end{tabular}




\section{CARTÃO 8 - (ACEITA RESPOSTAS MÚLTIPLAS)}

(1) DESLIGA AS LÂMPADAS ACESAS QUANDO SE AUSENTA DE UM AMBIENTE POR MAIS DE 30 MINUTOS.

(2) ABRE POUCAS VEZES A GELADEIRA / FREEZER.

(3) NÃO GUARDA ALIMENTOS QUENTES NA GELADEIRA / FREEZER.

(4) NÃO COLOCA ROUPAS PARA SECAR ATRÁS DA GELADEIRA / FREEZER.

(5) VERIFICA PERIODICAMENTE SE A BORRACHA DA VEDAÇÃO DA GELADEIRA ESTÁ EM BOAS CONDIÇÕES.

(6) DIMINUI O TEMPO DO BANHO QUANDO USA O CHUVEIRO ELÉTRICO.

(7) MUDA A CHAVE DO CHUVEIRO ELÉTRICO DE "INVERNO" PARA "VERÃO" DE ACORDO COM A TEMPERATURA AMBIENTE.

(8) USA A MÁQUINA DE LAVAR ROUPA E/OU LOUÇA COM A CAPACIDADE MÁXIMA.

(9) ACUMULA ROUPAS PARA PASSAR.

(10) DESLIGA O AR CONDICIONADO QUANDO SE AUSENTA DO AMBIENTE POR MAIS DE MEIA HORA.

(11) REALIZA A LIMPEZA NO(S) APARELHO(S) DE AR CONDICIONADO

(12) DESLIGA OS APARELHOS ELETRÔNICOS (RÁDIO, SOM, TV, COMPUTADOR, ETC) QUE NÃO ESTAVAM SENDO USADOS POR MAIS DE 30 MINUTOS.

(13) NA COMPRA, ALUGUEL, REFORMA OU CONSTRUÇÃO DE UMA MORADIA VOCÊ CONSIDERA A VENTILAÇÃO E/OU A ILUMINAÇÃO NATURAL DO IMÓVEL.

(14) SE PREOCUPA COM O ESCLARECIMENTO DAS PESSOAS QUE MORAM E/OU TRABALHAM NO DOMICILIO SOBRE O USO RACIONAL DE ENERGIA EVITANDO O DESPERDICIO. 


\section{CARTÃO 9}
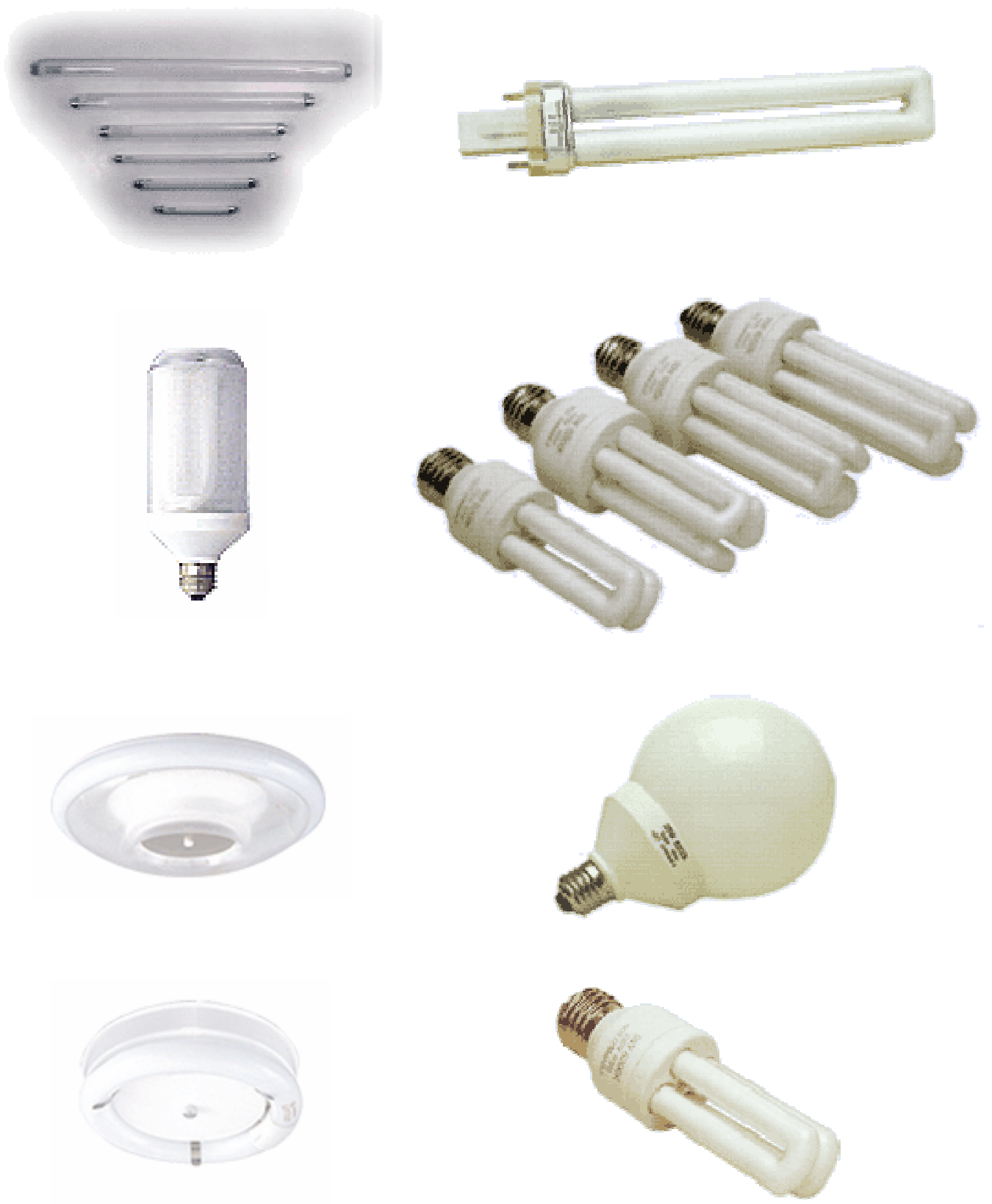

-

E: 
ANEXO V. - QUESTIONÁRIO (MANUAL DE PREENCHIMENTO)

ELETROBRÁS / PROCEL - IEPUC / ECOLUZ

QUESTIONÁRIO 1: RESIDENCIAL - BT

\section{MANUAL DE INSTRUCÕES PARA O PREENCHIMENTO DO QUESTIONÁRIO}

\section{IDENTIFICAÇÃO}

1.1 - No QUEST. : O número do questionário não deve ser preenchido pelo pesquisador. Deixa-se este campo em branco, que será preenchido pelo operacional.

1.2 - ENTREVISTADOR : nome do pesquisador que está realizando a pesquisa.

1.3 - ENTREVISTADO : nome da pessoa que está respondendo a pesquisa.

1.4 - ENDEREÇO : endereço completo de localização da residência (colocar se possível referências).

1.5 - BAIRRO/CIDADE : bairro e cidade onde se localiza a residência.

1.6 - MUNICÍPIO : município de localização da residência.

1.7 - TELEFONE : telefone de contato da residência, ou de um dos proprietários.

1.8 - DATA DA ENTREVISTA : data do início da entrevista.

1.9 - HORA DE INÍCIO DA ENTREVISTA : hora do início da entrevista.

1.10 - LISTE AS PESSOAS QUE MORAM NESTE DOMICÍLIO, ESPECIFICANDO GRAU DE PARENTESCO OU RELAÇÃO COM O(A) CHEFE DA FAMÍLIA, IDADE, SEXO, NÍVEL DE INSTRUÇÃO E PERÍODO HABITUAL DE PERMANÊNCIA NO DOMICÍLIO:

Neste item serão identificados os membros que residem neste domicílio, e suas condições.

MEMBRO: Somente o primeiro nome de cada morador.

CONDIÇÃO NO DOMICÍLIO: Verificar o grau de parentesco ou a relação do determinado membro com o chefe da família, preenchendo com o número entre parênteses especificado na chamada (1).

*CHAMADA: (1)

(1) CHEFE DA FAMÍLIA

(2) CONNJUGE/COMPANHEIRO(A)

(3) FILHO

(4) OUTRO PARENTE

(5) AGREGADO

(6) PENSIONISTA
(7) EMPREGADO DOMÉSTICO

(9) HÓSPEDE

(8) PARENTE DE EMPREGADO

IDADE: Identificar a idade de cada membro da família. Caso o entrevistado tenha dúvida, tente ajudá-lo colocando a idade aproximada com base no bom senso.

SEXO: Identificar o sexo de cada um dos membros da família, preenchendo (1) para feminino e (2) para masculino.

NÍVEL DE INSTRUÇÃO: Verificar o nível de instrução de cada membro da família e preencher com o número correspondente, especificado na chamada (2).

*CHAMADA: (2)

(1) ATÉ PRIMÁRIO INCOMPLETO

(2) ATÉ GINASIAL INCOMPLETO

(4) ATÉ SUPERIOR INCOMPLETO

(3) ATÉ COLEGIAL INCOMPLETO

(5) CURSO SUPERIOR COMPLETO

(6) ANALFABETO

OBS.1: Hoje a terminologia é ensino fundamental (1a a 8a série) e ensino médio (1a a $3^{a}$ série do $2^{\circ}$ grau)

OBS.2: Criança de até 7 anos, é considerada no nível de instrução, como primário incompleto

PERÍODO HABITUAL DE PERMANÊNCIA NO DOMICÍLIO: Verificar o período de permanência de cada membro, marcando com um " $X$ " os espaços: M-manhã, T-tarde, N-noite e MA-madrugada. (admitindo mais de um período, marcando-se mais de um espaço).

Caso no domicílio a ser entrevistado funcionar um comércio, devem ser listados somente as pessoas que realmente residem no local (durmam). 


\subsection{1 - O RELÓGIO (MEDIDOR) SERVE SÓ A ESTE DOMICÍLIO?}

Marcar com um "X" a opção adequada, de acordo com a declaração do entrevistado.

\subsection{2 - QUANTO TEMPO VOCÊS (FAMÍLIA) MORAM NESTE DOMICÍLIO?}

Especificar aproximadamente quanto tempo a família reside no domicílio.

1.13 - QUAL O TEMPO APROXIMADO DE CONSTRUÇÃO DO IMÓVEL?

Especificar aproximadamente qual o tempo de construção do imóvel. Caso o entrevistado tenha dúvida, tente ajudá-lo preenchendo o ano aproximado com base no bom senso.

\section{CARACTERÍSTICAS DO DOMICÍLIO}

Para este tópico, o pesquisador deve observar ele próprio as características do domicílio, e preencher o questionário, agilizando o processo da entrevista. Surgindo dúvidas, pedir ajuda ao entrevistado.

2.1 - TIPO DE DOMICílIO: Marcar com um "X" o tipo do domicílio. Se apartamento, especificar o número de pavimentos da edificação.

2.2 - COBERTURA: Verificar a cobertura do domicílio, marcando com um " $X$ " no espaço adequado. Esta questão não admite mais de 1 resposta, deve-se considerar sempre a opção mais freqüente dentro da residência.

Este item não deve ser respondido quando o tipo de domicílio for apartamento, neste caso passar para a questão 2.3.

\subsection{1 - A COBERTURA DO SEU DOMICÍLIO TEM FORRO?}

Observar se a cobertura tem forro, e marcar com um " $X$ " a resposta adequada. Esta questão não admite mais de 1 resposta, deve-se considerar sempre a opção mais freqüente dentro da residência.

2.2.2 - SE HÁ, QUAL O TIPO?

Observar o tipo de forro e marcar com um "X" a resposta adequada. Caso não tenha, passar para a próxima questão.

2.3 - PAREDE EXTERNA: observar o tipo de parede externa do domicílio, marcando com um " $X$ " no espaço adequado. Esta questão não admite mais de 1 resposta, deve-se considerar sempre a opção mais freqüente dentro da residência.

2.4 - JANELAS: Observar o tipo principal de esquadrias das fachadas e marcar com um " $X^{\prime \prime}$ no espaço adequado. Esta questão não admite mais de 1 resposta, deve-se considerar sempre a opção mais freqüente dentro da residência.

\subsection{1 - OS VIDROS DAS JANELAS SÃO COLORIDOS OU RECEBEM PELÍCULAS?}

Observar os vidros das janelas e marcar com um " $X$ " no espaço adequado.

2.4.2 - HÁ PROTEÇÃO DO TIPO VENEZIANA PARA AS JANELAS?

Observar se há proteção do tipo veneziana para as janelas e marcar com um " $X$ " no espaço adequado.

2.5 - PISO: Observar e marcar o tipo de piso encontrado nos principais cômodos do domicílio (sala, copacozinha). Esta questão não admite mais de 1 resposta, deve-se considerar sempre a opção mais freqüente dentro da residência.

2.6 - ÁREA CONSTRUÍDA (M2): Perguntar ao entrevistado quantos metros quadrados possui o domicílio.

2.7 - CONDIÇÃO DE OCUPAÇÃO DO DOMICÍlIO: Perguntar ao entrevistado, marcando com um "X" a condição de ocupação de domicílio.

\section{8 - O DOMICÍLIO POSSUI SISTEMA DE ABASTECIMENTO DE ÁGUA:}

Perguntar ao entrevistado como é o sistema de abastecimento de água do domicílio. Se for COM CANALIZAÇÃO INTERNA, marcar os números de 1 a 6 conforme o tipo de sistema (rede geral, poço ou nascente, carro pipa, hidrômetro, pena d'água, ou outra forma). Fazer o mesmo se for SEM CANALIZAÇÃO INTERNA, marcando os números de 7 a 12. 


\section{3 - INFORMAÇÕES SOBRE ENERGIA ELÉTRICA}

3.1 - NOS ÚlTIMOS 15 DIAS HOUVE FALTA DE ENERGIA ELÉTRICA NESSA RESIDÊNCIA? Marcar com um "X" de acordo com o entrevistado, desconsiderando "pics" de luz.

3.2 - NESSA RESIDÊNCIA OCORREU NOS ÚLTIMOS TRÊS MESES:

Citar as ocorrências listadas no quadro ao entrevistado, e marcar com um " $X$ " uma das opções (SIM, NÃO ou NS/NR) conforme declaração do entrevistado.

3.3 - CASO A COMPANHIA DE ELETRICIDADE OFEREÇA ENERGIA ELÉTRICA MAIS BARATA FORA DO PERÍODO DE 18:00 ÀS 21:00 HORAS, O(A) SR.(A) ESTARIA DISPOSTO(A) A REDUZIR O CONSUMO DE ENERGIA NESTE PERÍODO?

QUESTÃO ESPONTÂNEA

Fazer a pergunta ao entrevistado e deixá-lo à vontade para a resposta. Marcando-se com um "X" a opção mais adequada com base no bom senso.

3.4 - E A ILUMINAÇÃO PÚBLICA DE SUA RUA É:

QUESTÃO ESTIMULADA

Citar as opções de respostas para o entrevistado e marcar com um "X" a opção adequada.

3.5 - NA SUA OPINIÃO, A ILUMINAÇÃO PÚBLICA DE SUA CIDADE É:

QUESTÃO ESTIMULADA

Citar as opções de respostas para o entrevistado e marcar com um "X" a opção adequada.

3.6 - NA SUA OPINIÃO, QUEM É O RESPONSÁVEL PELA ILUMINAÇÃO PÚBLICA DE SUA CIDADE? QUESTÃO ESPONTÂNEA

Perguntar ao entrevistado, quem que para ele é o responsável pela iluminação pública da cidade, marcando com um " $X$ " na opção adequada.

\section{ILUMINAÇÃO}

4.1 - CARACTERÍSTICAS E HÁBITOS DE USO:

Este quadro se refere as características e hábitos de uso das lâmpadas do domicílio. E deve ser preenchido da seguinte forma:

A primeira coluna apresenta os TIPOS DE CÔMODO da residência. A segunda coluna se refere a quantidade e tipo de LÂMPADAS destinadas a cada um dos cômodos.

Observe que para cada cômodo, existem dois espaços para a segunda coluna; devendo ser preenchida apenas aos tipos de lâmpadas com maior índice de importância especificado na chamada (1).

A terceira coluna se refere a QUANTIDADE DE LÂMPADAS ACESAS POR PERÍODO (EVENTUAL X HABITUAL). Esta coluna vem especificada pelos números de 0 a 23, referentes às horas do dia, onde deve ser preenchido o número de lâmpadas acesas por período para cada tipo. Caso o entrevistado não saiba mensurar o uso de algumas lâmpadas, preencher na coluna "E" (eventual) o número das mesmas.

Exemplo: 
Exemplo:

\begin{tabular}{|c|c|c|c|c|c|c|c|c|c|c|c|c|c|c|c|c|c|c|c|c|c|c|c|c|c|c|c|}
\hline \multirow{2}{*}{$\begin{array}{l}\text { TIPO DE } \\
\text { CÔMODO }\end{array}$} & \multicolumn{2}{|c|}{ LÂMPADAS } & \multicolumn{25}{|c|}{$\begin{array}{l}\text { QUANTIDADE DE LÂMPADAS ACESAS POR PERÍODO } \\
\text { (EVENTUAL X HABITUAL) }\end{array}$} \\
\hline & TOTAL & $\begin{array}{c}\text { TIPO } \\
\text { (1) }\end{array}$ & E & 0 & 1 & 2 & 3 & 4 & 5 & 6 & 7 & 8 & 9 & 10 & 11 & 12 & 13 & 14 & 15 & 16 & 17 & 18 & 19 & 20 & 21 & 22 & 23 \\
\hline \multirow{2}{*}{$\begin{array}{c}\text { SALA DE } \\
\text { ESTAR, } \\
\text { JANTAR E } \\
\text { TV }\end{array}$} & 4 & 3 & & & & & & & & & & & & & 4 & 4 & 4 & 4 & & & & & & & & 2 & 2 \\
\hline & 6 & 7 & 2 & & & & & & & 1 & 1 & 1 & & & & & & & & & & & 3 & 3 & 3 & & \\
\hline
\end{tabular}

\section{*CHAMADA: (1)}
(1) 25W - INCANDESCENTE
(2) $40 \mathrm{~W}$ - INCANDESCENTE
(3) $60 \mathrm{~W}$ - INCANDESCENTE
(4) $100 \mathrm{~W}$ - INCANDESCENTE
(5) $150 \mathrm{~W}$ - INCANDESCENTE
(6) 2OW - FLUORESCENTE TUBULAR
(7) 4OW - FLUORESCENTE TUBULAR

(8) FLUORESCENTE COMPACTA ATÉ 15W
(9) FLUORES. COMPACTA > 15W

(10) FLUORESCENTE CIRCULAR

(11) DICRÓICA

(12) OUTRO

No exemplo acima, referente à sala de estar/jantar e TV, foi marcado a existência de 4 lâmpadas do tipo incandescente de 60W, conforme o número específico 3 na chamada (1); e 6 lâmpadas do tipo fluorescente tubular de 40W, conforme o número específico 7 na chamada (1).

Lembrando que estas, são as principais lâmpadas existentes nestes cômodos, podendo existir outras de menor importância. Só há espaço para 2 tipos de lâmpadas.

No cômodo citado, das 4 lâmpadas incandescentes 60W, as quatro ficam ligadas entre 11:00h às 15:00h, e somente 2 ficam ligadas entre 22:00h e 24:00. Das 6 lâmpadas fluorescentes tubular 40W, apenas 1 fica ligada entre 6:00h às 9:00h, e 3 destas lâmpadas ficam ligadas entre 19:00h às 22:00h. Repare que para 2 lâmpadas o entrevistado não soube mensurar o período de uso, preenchendo "E".

* Lembrando como especificado na nota: Na sala e na copa/cozinha deve ser verificada a potência na própria lâmpada, nos demais cômodos essa medida pode ser feita por declaração.

4.2 - VOCÊ CONHECE AS LÂMPADAS FLUORESCENTES?

Nesta questão deve ser apresentado o CARTÃO 9 com os modelos das lâmpadas, dar as informações necessárias sobre as L.F.C.'s; e marcar com um X a opção adequada.

4.3 - QUAL A TONALIDADE DE ILUMINAÇÃO PREFERIDA PARA SUA RESIDÊNCIA?

Marcar com um "X" a opção adequada, de acordo com o entrevistado.

\section{REFRIGERADOR}

Este item só deve ser respondido se o entrevistado possuir refrigerador. Caso contrário pular para o item 6.

\section{Anotar a quantidade de aparelhos existentes no domicílio de acordo com declaração do entrevistado.}

\section{1 - CARACTERÍSTICAS}

Este quadro se refere às características do aparelho refrigerador e deve ser preenchido da seguinte forma:

Na primeira coluna está listado o NúMERO DE REFERÊNCIA DO APARELHO, para o caso de o entrevistado possuir mais de um aparelho, sendo referente uma linha para cada um deles. A segunda coluna se refere ao TIPO DE APARELHO, e deve ser marcado o número da lista de aparelhos que se encontra no CARTÃO 1 (este deve ser apresentado ao entrevistado, como especificado na chamada (1)).

Na terceira coluna referente à UTILIZAÇÃO do aparelho, deve ser marcado um " $X$ " no número indicado de acordo com a chamada (2), de acordo com o entrevistado. 
Na coluna que se refere à POSIÇÃO / INTENSIDADE DO TERMOSTATO, deve ser marcado um " $\mathrm{X}$ " no número indicado de acordo com a chamada (3), com uma base aproximada de acordo com o entrevistado (se possível pedir para verificar).

*CHAMADA: (3) (1) MÍNIMO $\quad$ (2) MÉDIO(3) MÁXIMO

Na coluna que se refere à ESTIMATIVA DE IDADE DO APARELHO, deve ser marcado o número aproximado em anos. E POR FIM, NA COLUNA QUE SE REFERE AOS PROBLEMAS OCORRIDOS NOS ÚLTIMOS 12 MESES, deve ser marcado um "X" no número indicado de acordo com a chamada (4), admitindo respostas múltiplas para este item, segundo declaração do entrevistado.

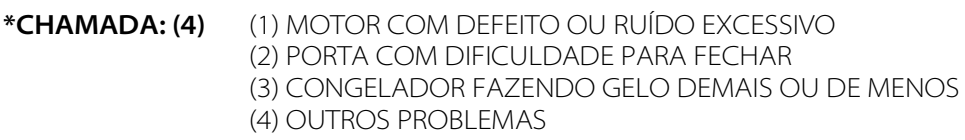

\section{2 - DO(S) REFRIGERADOR(ES) ACIMA CITADO(S), ADQUIRIU ALGUM NOVO (NA LOJA) NOS ÚLTIMOS DEZ} ANOS?

Se o entrevistado declarar que adquiriu um dos refrigeradores citados na questão anterior, na loja; marcar a opção SIM, especificar a quantidade e prosseguir para a próxima questão. Caso o entrevistado declarar a opção NÃO/NS/NR adquiriu, pular para a questão 5.5 conforme filtro.

\section{3 - NESSA AQUISIÇÃO LEVOU EM CONSIDERAÇÃO O CONSUMO DO APARELHO MOSTRADO NA ETIQUETA AO ADQUIRÍ-LO? \\ Informar ao entrevistado que os aparelhos apresentam uma etiqueta com informações sobre seu consumo de energia. Marcar com um "X" a opção adequada, de acordo com o entrevistado. \\ 5.4 - O SR.(A) TERIA INTERESSE EM ADQUIRIR UM REFRIGERADOR QUE CONSUMISSE MENOS ENERGIA E QUE FOSSE AVALIADO POR SUA CONCESSIONÁRIA OU ALGUM ORGAO COMPETENTE? \\ Marcar com um " $X$ " a opção adequada, de acordo com o entrevistado.}

5.5 - O SR.(A) GOSTARIA DE POSSUIR MAIS 1 REFRIGERADOR EM SUA RESIDÊNCIA?

Marcar com um " $X$ " a opção adequada, de acordo com o entrevistado.

\section{FREEZER}

Este item só deve ser respondido se o entrevistado possuir freezer. Caso contrário pular para o item 7.

Anotar a quantidade de aparelhos existentes no domicílio de acordo com declaração do entrevistado.

6.1 - CARACTERÍSTICAS:

Este quadro se refere às características do aparelho freezer e deve ser preenchido da seguinte forma:

Na primeira coluna está listado o NÚMERO DE REFERÊNCIA DO APARELHO, para o caso de o entrevistado possuir mais de um aparelho, sendo referente uma linha para cada um deles. A segunda coluna se refere ao TIPO DE APARELHO, e deve ser marcado o número da lista de aparelhos que se encontra no CARTÃO 2 (este deve ser apresentado ao entrevistado, como especificado na chamada (1)).

Na terceira coluna referente à UTILIZAÇÃO do aparelho, deve ser marcado um " $X$ " no número indicado de acordo com a chamada (2).
*CHAMADA: (2)
(1) USO PERMANENTE
(3) USO PARTE DO DIA
(2) DESLIGADO
(4) SÓ LIGADO EVENTUALMENTE

Na coluna que se refere à ESTIMATIVA DE IDADE DO APARELHO, deve ser marcado o número aproximado em anos da idade do aparelho.

6.2 - O SR.(A) TERIA INTERESSE EM ADQUIRIR UM FREEZER QUE CONSUMISSE MENOS ENERGIA E QUE FOSSE AVALIADO POR SUA CONCESSIONÁRIA OU ALGUM ORGAO COMPETENTE?

Marcar com um " $X$ " a opção adequada, de acordo com o entrevistado. 
6.3 - O SR.(A) GOSTARIA DE POSSUIR MAIS 1 FREEZER EM SUA RESIDÊNCIA?

Marcar com um "X" a opção adequada, de acordo com o entrevistado.

\section{CONDICIONADOR DE AR}

Este item só deve ser respondido se o entrevistado possuir condicionador de ar. Caso contrário pular para o item 8.

Anotar a quantidade de aparelhos existentes no domicílio de acordo com declaração do entrevistado.

7.1 - CARACTERÍSTICAS:

Este quadro se refere às características do aparelho condicionador de ar, e deve ser preenchido da seguinte forma:

Na primeira coluna está listado o NÚMERO DE REFERÊNCIA DO APARELHO, para o caso de o entrevistado possuir mais de um aparelho, sendo referente uma linha para cada um deles. A segunda coluna se refere ao TIPO DE APARELHO, e deve ser preenchido o número da lista de aparelhos que se encontra no CARTÃO 4 (este deve ser apresentado ao entrevistado, como especificado na chamada (1)). Na coluna que se refere à ESTIMATIVA DE IDADE DO APARELHO, deve ser preenchido o número aproximado em anos. Na coluna que se refere à ESTE CÔMODO RECEBE SOL?, deve ser marcado um " $X$ " na opção adequada de acordo com o entrevistado, sendo: M-manhã, T-tarde e NÃO-não recebe sol; caso receba sol o dia inteiro, marcar M e T. Por fim, a última coluna especificada como STAND BY, será preenchida de acordo com o entrevistado, ou seja, se ao desligar o aparelho ele (entrevistado) o deixa em stand by ou não.

7.2 - HÁBITOS DE USO DE ACORDO COM O CLIMA NOS DIAS DE SEMANA E FINAIS DE SEMANA. Este quadro se refere ao período habitual de uso do aparelho de ar condicionado, e deve ser preenchido da seguinte forma:

Na primeira coluna está listado o NúMERO DE REFERÊNCIA DO APARELHO, que deve ser seguido de acordo com respostas da questão anterior. A segunda coluna se refere à utilização do aparelho nos climas: quente, ameno e frio; e deve ser marcado com um " $X$ " de acordo com o entrevistado, admitindo mais de uma opção para este item. Na terceira coluna referente ao GRAU DE UTILIZAÇÃO do aparelho, deve ser preenchido o número especificado na chamada (1).

*CHAMADA: (1) (1) GRANDE - UTILIZA MAIS DE 4 VEZES POR SEMANA

(2) MÉDIA - DE 1 A 3 VEZES POR SEMANA

(3) REGULAR - DE 1 A 3 VEZES POR MÊS

(4) PEQUENA - MENOS DE UMA VEZ POR MÊS

A última coluna se refere ao TEMPO DE USO POR PERÍODO. Esta coluna vem especificada pelos números de 0 a 23, referentes às horas do dia, onde deve ser preenchido com um " $X$ " de acordo com declaração de uso, por período, por parte do entrevistado. E uma coluna "E" (eventual), para quando o entrevistado não souber mensurar o período.

OBSERVE QUE DEVE SER EXCLUIDOO O PERIODO EM QUE O CONDICIONADOR É UTILIZADO APENAS NA VENTILAÇÃO.

A COLUNA REFERENTE AO CLIMA, APRESENTA TEMPERATURAS ASSOCIADAS ÀS ESTAÇÕES DO ANO; COMO POR EXEMPLO: QUENTE - VERÃO / AMENO - PRIMAVERA OUTONO / FRIO - INVERNO. 


\section{TELEVISÃO}

Anotar a quantidade de aparelhos existentes no domicílio de acordo com declaração do entrevistado.

8.1 - CARACTERÍSTICAS:

Este quadro se refere às características do aparelho televisor e deve ser preenchido da seguinte forma:

Na primeira coluna está listado o NÚMERO DE REFERÊNCIA DO APARELHO, para o caso de o entrevistado possuir mais de um aparelho, sendo referente uma linha para cada um deles. A segunda coluna se refere ao TIPO DE APARELHO, e deve ser preenchido em MARCA o número da lista de aparelhos que se encontra no CARTÃO 5 (este deve ser apresentado ao entrevistado, como especificado na chamada (1)); especificando também o tamanho do aparelho em polegadas. Na coluna que se refere à ESTIMATIVA DE IDADE DO APARELHO, deve ser preenchido o número aproximado em anos. Na coluna referente ao GRAU DE UTILIZAÇÃO do aparelho, deve ser marcado um " $X$ " no número indicado de acordo com a chamada (2). Por fim, a última coluna especificada como STAND BY, será preenchida de acordo com o entrevistado, ou seja, se ao desligar o aparelho ele (entrevistado) o deixa em stand by ou não.

\section{2 - HORÁRIOS DE USO DOS APARELHOS DE TV DE ACORDO COM O DIA DA SEMANA.}

Este quadro se refere às período habitual de uso do aparelho televisor de acordo com os dias da semana, e deve ser preenchido da seguinte forma:

A primeira coluna apresenta os dias da semana. Na segunda coluna está listado o NÚMERO DE REFERÊNCIA DO APARELHO, que deve ser seguido de acordo com respostas da questão anterior.

A última coluna se refere aos HORÁRIOS DE USO DOS APARELHOS DE TV. Esta coluna vem especificada pelos números de 0 a 23, referentes às horas do dia, onde deve ser preenchido com um " $X$ " de acordo com declaração de uso, por período, por parte do entrevistado.

\section{OUTROS ELETRODOMÉSTICOS}

\section{1 - POSSES E HÁBITOS DE USO:}

Este quadro se refere à posse e hábitos de uso de outros eletrodomésticos, e deve ser preenchido da seguinte forma:

A primeira coluna apresenta os eletrodomésticos. A segunda coluna deve ser preenchida com a quantidade de cada eletrodoméstico, caso o entrevistado possua. E na coluna, que se refere ao GRAU DE UTILIZAÇÃO do aparelho, deve ser preenchido o número especificado na chamada (1).

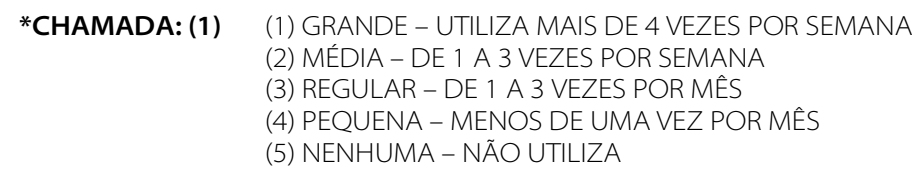

A última coluna especificada como STAND BY, será preenchida de acordo com o entrevistado, ou seja, se ao desligar o aparelho ele (entrevistado) o deixa em stand by ou não.

SE NO DOMICÍLIO HOUVER OUTRO(S) EQUIPAMENTO(S) QUE NÃO ESTEJAM LISTADOS NO QUADRO, COM O USO PELO MENOS "REGULAR" - 1 A 3 VEZES POR MÊS - ELE DEVE SER INCLUIIDO NA LISTA.

\section{2 - HORÁRIOS DE USO DO:}
(1) APARELHO DE SOM
(2) MICROCOMPUTADOR (3) FERRO ELÉTRICO
(4) LAVA ROUPA
(5) LAVA LOUÇA
(6) SECADOURA DE ROUPA
(7) MICROONDAS
(8) FORNO ELÉTRICO
(9) TORNEIRA ELÉTRICA

Este quadro se refere ao horário de uso dos eletrodomésticos citados, e deve ser preenchido da seguinte forma:

A primeira coluna apresenta o HORÁRIO de uso dos equipamentos, e vem especificada pelos números de 0 a 23, referentes às horas do dia. A segunda coluna se refere aos EQUIPAMENTOS UTILIZADOS X DIAS DA 
SEMANA, apresentando os dias da semana de segunda à domingo. Assim os espaços devem ser preenchidos com o número entre parênteses, especificado em cada um dos aparelhos, podendo ser preenchido mais de um número por célula.

9.3 - QUAIS DOS SEGUINTES EQUIPAMENTOS FORAM COMPRADOS PARA ESTE DOMICÍLIO NOS ÚLTIMOS DOIS ANOS? INDIQUE O MÊS E O ANO DE AQUISIÇÃO?

Neste quadro devem ser informado o mês e o ano de aquisição dos aparelhos citados em cada coluna, caso o entrevistado tenha comprado algum nos últimos 2 anos.

9.4 - PRETENDE COMPRAR ALGUM ELETRODOMÉSTICO NOS PRÓXIMOS SEIS MESES, PARA ESTE DOMICÍLIO; CASO SUA RENDA AUMENTE?

Marcar com um "X" a opção adequada, de acordo com o entrevistado.

Caso a resposta seja SIM, apresentar o CARTÃO 6 identificando o aparelho, e marcando na tabela o número específico do mesmo. Caso seja NÃO, pular para a questão 10, conforme filtro.

\section{AQUECIMENTO DE ÁGUA PARA BANHO}

10.1 - NESTA RESIDÊNCIA, COMO É O SISTEMA DE AQUECIMENTO DA ÁGUA PARA O BANHO?

Marcar com um "X" a opção adequada, de acordo com o entrevistado. Verificando o sistema de acordo com a forma de aquecimento, no caso de AQUECIMENTO ELÉTRICO E AQUECIMENTO A GÁS. Esta questão admite respostas múltiplas, considerando que o entrevistado possua mais de um sistema de aquecimento de água para o banho.

\section{CHUVEIRO ELÉTRICO}

(PREENCHA CASO POSSUA)

Este tópico só deve ser respondido caso o entrevistado possua chuveiro elétrico

Anotar a quantidade de aparelhos existentes no domicílio de acordo com declaração do entrevistado.

10.2 - CARACTERÍSTICAS:

Este quadro se refere às características do chuveiro elétrico e deve ser preenchido da seguinte forma:

Na primeira coluna está listado o NÚMERO DE REFERÊNCIA DO APARELHO, para o caso de o entrevistado possuir mais de um aparelho, sendo referente uma linha para cada um deles. A segunda coluna se refere ao TIPO DE APARELHO, e deve ser marcado o número da lista de aparelhos que se encontra no CARTÃO 3 (este deve ser apresentado ao entrevistado, como especificado na chamada (1)). Na terceira coluna referente ao No DE PESSOAS QUE USAM o aparelho, deve ser marcado o número de acordo com o entrevistado. Na coluna que se refere à POSIÇÃO EM QUE SE ENCONTRA A CHAVE DO APARELHO, deve ser marcado um " $X$ " nas opções: verão, inverno ou desligada; com uma base aproximada de acordo com o entrevistado (se possível pedir para verificar). E por fim, na coluna descrita com DURANTE OS MESES DE INVERNO A CHAVE FICA NA POSIÇÃO, deve ser marcado um " $X$ " seguindo os mesmos critérios da coluna anterior.

OBS.: CASO O CHUVEIRO NÃO POSSUA A CHAVE COM AS DESIGNAÇÕES: VERÃO/INVERNO; E SIM ALGUMA OUTRA DIFERENTE; MARCAR COM BASE NO BOM SENSO. EX: QUENTE PARA VERÃO, E FRIO PARA INVERNO..

10.3 - HÁBITOS DE USO DO CHUVEIRO ELÉTRICO NOS DIAS DE SEMANA.

Este quadro se refere ao número de pessoas que usam o chuveiro elétrico e seus respectivos horários nos dias de semana, e deve ser preenchido da seguinte forma:

Na primeira coluna está listado o NÚMERO DE REFERÊNCIA DO APARELHO, que deve ser seguido de acordo com respostas da questão anterior.

A segunda coluna se refere ao NÚMERO DE PESSOAS QUE USAM O CHUVEIRO ELÉTRICO NOS HORÁRIOS citados. Esta coluna vem especificada pelos números de 0 a 23, referentes às horas do dia, onde deve ser preenchido com o número de pessoas de acordo com declaração de uso, por período, por parte do entrevistado.

OS CAMPOS DEVEM SER PREENCHIDOS COM O NÚMERO DE PESSOAS QUE USAM O CHUVEIRO ELÉTRICO NOS HORÁRIOS CORRESPONDENTES, ADMITINDO A POSSIBILIDADE DE UM INDIVÍDUO TOMAR MAIS DE UM BANHO POR DIA. 
10.4 - HÁBITOS DE USO DO CHUVEIRO ELÉTRICO NOS FINAIS DE SEMANA.

Este quadro se refere ao número de pessoas que usam o chuveiro elétrico e seus respectivos horários nos finais de semana, e deve ser preenchido da seguinte forma:

Na primeira coluna está listado o NÚMERO DE REFERÊNCIA DO APARELHO, que deve ser seguido de acordo com respostas da questão anterior. A segunda coluna se refere ao NúMERO DE PESSOAS QUE USAM O CHUVEIRO ELÉTRICO NOS HORÁRIOS citados. Esta coluna vem especificada pelos números de 0 a 23, referentes às horas do dia, onde deve ser preenchido com o número de pessoas de acordo com declaração de uso, por período, por parte do entrevistado.

OS CAMPOS DEVEM SER PREENCHIDOS COM O NÚMERO DE PESSOAS QUE USAM O CHUVEIRO ELÉTRICO NOS HORÁRIOS CORRESPONDENTES, ADMITINDO A POSSIBILIDADE DE UM INDIVÍDUO TOMAR MAIS DE UM BANHO POR $D I A$.

10.5 - QUAL O TEMPO MÉDIO PARA O BANHO?

Marcar com um "X" a opção adequada, de acordo com o entrevistado.

10.6 - SE O PREÇO DA ENERGIA FOSSE O DOBRO NO HORÁRIO DAS 18:00 ÀS 21:00, VOCÊ ACHA QUE A SUA FAMÍLIA EVITARIA TOMAR BANHO NESSE PERÍODO?

Marcar com um "X" a opção adequada, de acordo com o entrevistado.

\section{AQUECIMENTO À GÁS}

(PREENCHA CASO NÃO POSSUA)

Este tópico só deve ser respondido caso o entrevistado não possua aquecimento à gás para o banho.

10.7 - O(A) SR.(A) CONHECE OU JÁ OUVIU FALAR DE AQUECEDORES DE ÁGUA À GÁS PARA O BANHO?

Marcar com um " $X$ " a opção adequada com base no bom senso, de acordo com o entrevistado. Caso a opção seja NÃO, passar para a questão 10.8 .

10.7.1 - O(A) SR.(A) MUDARIA SEU SISTEMA DE AQUECIMENTO DE ÁGUA DE BANHO, PARA GÁS? Marcar com um " $X$ " a opção adequada, de acordo com o entrevistado.

\begin{tabular}{l}
\hline AQUECIMENTO SOLAR \\
Este tópico só deve ser respondido caso o entrevistado não possua aquecimento solar para o banho.
\end{tabular}

10.8 - O(A) SR.(A) CONHECE OU JÁ OUVIU FALAR DE AQUECEDORES DE ÁGUA SOLAR PARA O BANHO? Marcar com um "X" a opção adequada com base no bom senso, de acordo com o entrevistado. Caso a opção seja NÃO, passar para a questão 10.9.

10.8.1 - O(A) SR.(A) MUDARIA SEU SISTEMA DE AQUECIMENTO DE ÁGUA DE BANHO, PARA SOLAR? Marcar com um "X" a opção adequada, de acordo com o entrevistado.

10.9 - O(A) SR(A). CONSIDERA SEU SISTEMA DE AQUECIMENTO DE ÁGUA EFICIENTE COM RELAÇÃO AO CONSUMO DE ENERGIA?

Marcar com um "X" a opção adequada, de acordo com o entrevistado.

9.4.1 - CASO PRETENDA COMPRAR ALGUM DESTES ELETRODOMÉSTICOS, SENDO QUE JÁ POSSUA OUTRO DENTRO DE CASA, QUAL O DESTINO QUE VAI SER DADO PARA O ANTIGO?

Este quadro deve ser preenchido, caso o entrevistado pretenda comprar algum destes aparelhos (geladeira, ar condicionado, freezer, aparelho de som), sendo que já possua um dentro de casa, marcando com um "X" o destino do antigo. Caso contrário pular para a próxima questão. 


\title{
11. DADOS SÓCIO-ECONÔMICOS
}

11.1 - ITENS DE CONFORTO FAMILIAR:

Neste quadro o entrevistado deve declarar a quantidade de banheiros existentes em sua residência; a quantidade de automóveis que possue, especificando o ano de cada um; e a quantidade de empregadas domésticas listando também o salário pago a cada uma delas.

\section{(SOMENTE PARA OS QUE POSSUEM AUTOMÓVEL - 11.1.1)}

11.1.1 - UTILIZA O GNV (GÁS NATURAL VEICULAR) COMO COMBUSTIVEL DO SEU AUTOMÓVEL?

\section{QUESTÃOESTIMULADA}

Esta questão só deve ser respondida se o entrevistado declarar na questão anterior que possui pelo menos 1 automóvel.

Marcar com um "X" a opção adequada, de acordo com o entrevistado. Listar a quantidade de automóveis que possuem o GNV, caso marque a opção SIM.

11.1.2 - CASO NÃO, POR QUE? QUESTÃO ESTIMULADA

Marcar com um "X" a opção adequada, de acordo com o entrevistado.

11.2 - RENDA FAMILIAR

Marcar com um "X" a opção adequada, de acordo com o entrevistado. Segundo o piso nacional de salários.

\section{3 - NESTE DOMICÍlIO É FEITO ALGUM TIPO DE TRABALHO PARA SER COMERCIALI-ZADO? (VEJA NO (ARTÃO 7)}

Apresentar o cartão 7 ao entrevistado, listando assim na tabela as opções adequadas. Caso não seja realizado nenhum tipo de trabalho com fim comercial no domicílio, passar para a questão 11.5.

\section{4 - QUAIS SÃO OS EQUIPAMENTOS ELÉTRICOS UTILIZADOS NESTE(S) TRABALHO(S)? (IDENTIFIQUE OS EQUIPAMENTOS NO $\underline{\text { CARTÃO 6) }}$}

Esta questão só deve ser respondida caso o entrevistado tenha declarado algum tipo de trabalho na questão anterior.

Apresentar o cartão 6 ao entrevistado, e listar na tabela as opções adequadas, marcando o número específico do equipamento.

\section{5 - REGIÃO DO DOMICÍLIO:}

Esta questão deve ser analisada pelo próprio pesquisador. Marcando-se, com base no bom senso, a opção adequada. Surgindo dúvidas, pedir ajuda ao entrevistado de forma sutil.

11.6 - PRÓXIMO À FAVELA:

Esta questão deve ser analisada pelo próprio pesquisador. Marcando-se, com base no bom senso, a opção adequada. Surgindo dúvidas, pedir ajuda ao entrevistado de forma sutil.

\author{
11.7 - COMO O(A) SR.(A) CLASSIFICARIA O PESO DA CONTA DE LUZ NO SEU ORÇAMENTO FAMILIAR? \\ QUESTÃO ESTIMULADA \\ Citar as opções de respostas para o entrevistado e marcar com um " $X$ " a opção adequada.
}

11.8 - DÊ UMA NOTA DE O A 10, COMPARANDO OS SERVIÇOS PRESTADOS PELAS SEGUINTES EMPRESAS: Nesta questão o entrevistado deve declarar uma nota de 0 a 10 às empresas de água, telefonia, e energia; com base a uma certa comparação entre as mesmas. Caso o entrevistado não saiba avaliar tais empresas, ou não conheça; marcar um "X" na opção NÃO CONHEÇE/ NÂO SABE.

11.9 - ADOTANDO UMA ESCALA DE 10 PONTOS, ONDE O PONTO 1 INDICA QUE O(A) SR.(A) ACHA O PREÇO PAGO PELA ENERGIA ELÉTRICA MUITO BARATO E, O PONTO 10, QUE O(A) SR.(A) ACHA O PREÇO MUITO CARO. AVALIE OS SEGUINTES PONTOS:

Com base em uma escala, onde o ponto 1 indica que o entrevistado acha o preço pago pela energia elétrica muito barato; e o ponto 10 indica que o entrevistado acha o preço muito caro. O entrevistado deve declarar uma nota para cada um dos dois itens citados na questão. Observando que caso o entrevistado não saiba avaliar algum item, deve-se marcar o número 11, e o número 12 para não respondeu; de acordo com a "NOTA DE OBSERVAÇÃO" no final da questão.

\section{RACIONAMENTO E CONSERVAÇÃO DE ENERGIA}


12.1 - NESTA RESIDÊNCIA SÃO ADOTADAS MEDIDAS PARA ECONOMIZAR ENERGIA ELÉTRICA?

Marcar com um " $X$ " a opção adequada, de acordo com o entrevistado.

12.2 - DESTAS MEDIDAS QUE VOU LHE APRESENTAR, GOSTARIA QUE O(A) SR.(A) ME INFORMASSE QUAIS FORAM ADOTADAS ANTES, DURANTE E DEPOIS DO RACIONAMENTO? E COMO O(A) SR.(A) COMPARA A UTILIZAÇÃO ATUAL DESTAS MEDIDAS EM RELAÇÃO À UTILIZAÇÃO DAS MESMAS DURANTE O RACIONAMENTO?

Este quadro se refere a medidas para economizar energia, antes, durante e depois do racionamento. E deve ser preenchido da seguinte forma.

A primeira coluna se refere as ações, ou seja, ANTES DO RACIONAMENTO, DURANTE O RACIONAMENTO,

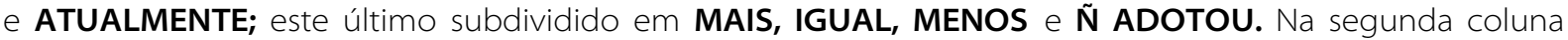
estão listados os números de 1 a 14, referentes às MEDIDAS ADOTADAS (que devem ser apresentadas ao entrevistado, através do cartão 8).

pesquisador deve perguntar ao entrevistado quais medidas foram adotadas antes do racionamento, apresentando o cartão 8 ao mesmo; e marcar com um " $X$ " nos espaços adequados. Depois, com o mesmo procedimento, deve preencher a linha referente a "durante o racionamento". Por fim, na linha que se refere aos dias atuais, o pesquisador deve mencionar ao entrevistado, que ele deve comparar a utilização das medidas atualmente, com a utilização das mesmas (quando houver) aos dias durante o racionamento, preenchendo assim as opções "mais", "igual", "menos"; e caso não tenha adotado atualmente alguma das medidas que tinha adotado durante o racionamento, marcar "ñ adotou".

12.3 - AS MEDIDAS ADOTADAS PARA ATINGIR AS METAS DURANTE O PERÍODO DE RACIONAMENTO FORAM: Marcar com um " $X$ " a opção adequada, de acordo com o entrevistado. Observando que nas opções SUFICIENTES e MAIS QUE SUFICIENTES, devem ser mencionado a dificuldade.

12.4 - COMO O(A) SR.(A) AVALIA A VARIAÇÃO DE QUALIDADE DE VIDA CAUSADA PELO RACIONAMENTO? Marcar com um " $X$ " a opção adequada, de acordo com o entrevistado. Especificar a avaliação quando a opção for OUTRO.

12.5 - DURANTE O RACIONAMENTO O(A) SR.(A) SUBSTITUIU AS LÂMPADAS INCANDESCENTES DE SUA RESIDÊNCIA POR LÂMPADAS FLUORESCENTES?

Marcar com um "X" a opção adequada, de acordo com o entrevistado. Caso a opção seja SIM, identificar na chamada (1), listando em QUAIS, O código das lâmpadas declaradas. Caso a opção seja NÃO ou NÃO LEMBRA/ NÃO SABE, passar para a questão 12.6.

CHAMADA: (1)

(1) FLUORESCENTE COMPACTA ATÉ 15W

(2) FLUORESCENTE COMPACTA $>15 \mathrm{~W}$

(5) FLUORESCENTE CIRCULAR

(3) FLUORESCENTE TUBULAR - 20W

(4) FLUORESCENTE TUBULAR - 40W

12.5.1 - QUANTAS?

Marcar com um "X" a opção adequada, de acordo com o entrevistado, com base no bom senso.

12.5.2 - E, MESMO COM O FINAL DO RACIONAMENTO O(A) SR.(A) CONTINUA UTILIZANDO AS LÂMPADAS FLUORESCENTES?

Marcar com um " $X$ " a opção adequada, de acordo com o entrevistado. Caso a opção seja SIM ou NÃO SABE, passar para a questão 12.6 .

12.5.3 - SE NÃO CONTINUOU COM O USO DE LÂMPADAS FLUORESCENTES, SUBSTITUIDAS POR LÂMPADAS INCANDESCENTES COMUNS, FOI POR QUE?

Marcar com um " $X$ " a opção adequada, de acordo com o entrevistado. Caso a opção seja OUTRO, O pesquisador deve pedir para o entrevistado citar o motivo. 
12.6 - COM O FINAL DO RACIONAMENTO O QUE O(A) SR.(A) FEZ EM RELAÇÃO AO: (QUESTÃO ESTIMULADA)

Este quadro se refere à utilização dos aparelhos com o final do racionamento, e deve ser preenchido da seguinte forma.

Na primeira coluna estão listados alguns aparelhos; caso o entrevistado queira declarar um que não esteja na lista deve acrescentar no item 9. OUTRO. QUAL?, localizado na mesma coluna. Na segunda coluna o entrevistado deve declarar a sua utilização de acordo com a chamada (1); o espaço na segunda coluna dentro da tabela, deve ser preenchido caso o entrevistado responda ao item "(9) outros. Quais?" dentro da chamada; especificando assim a finalidade declarada.

\section{*CHAMADA: (1)}

(1) USO COMO ANTES DO RACIONAMENTO

(2) USO MENOS DO QUE USAVA ANTES DO RACIONAMENTO

(3) CONTINUA DESLIGADO

(4) ME DESFIZ DESTE APARELHO

(5) TROQUEI POR OUTRO APARELHO MENOR E/OU MAIS EFICIENTRE
(6) USO MAIS COMO PROTESTO

(7) NÃO TINHA ANTES, COMPREI DEPOIS

(8) NÃO TENHO

(9) OUTROS. QUAIS?

12.7 - COMO O(A) SR.(A) IDENTIFICA NOS APARELHOS ELETRODOMÉSTICOS O SEU CONSUMO DE ENERGIA? Marcar com um "X" a opção adequada, de acordo com o entrevistado.

12.8 - ADOTANDO UMA ESCALA DE 10 PONTOS, ONDE O PONTO 10 INDICA QUE O(A) SR.(A) CONSIDERA MUITO IMPORTANTE, E O PONTO 1, QUE O(A) SR.(A) CONSIDERA MUITO POUCO IMPORTANTE. AVALIE A IMPORTÂNCIA DOS SEGUINTES ATRIBUTOS NO ATO DE COMPRA DE UM ELETRODOMÉSTICO:

Nesta questão o entrevistado deve declarar uma nota de 0 a 10 para cada um dos itens, indicando o grau de importância dos atributos listados, no ato de compra de um eletrodoméstico.

12.9 - O(A) SR.(A) CONHECE OS SELOS PROCEL (ENCONTRADO EM LÂMPADAS E ELETRODOMÉSTICOS)? (MOSTRAR SELO DO PROCEL)

Marcar com um "X" a opção adequada, de acordo com o entrevistado. O pesquisador deve apresentar o selo do Procel identificado no crachá.

12.10 - SABE O QUE ELE REPRESENTA?

Esta questão não está associada a questão anterior, pois o entrevistado pode não conhecer o selo, mas mesmo assim saber o que ele representa. Deve-se então marcar com um " $X$ " a opção adequada, de acordo com o entrevistado.

12.11 - O(A) SR.(A) SABE O QUANTO PODE ECONOMIZAR MENSALMENTE OU ANUALMENTE COM ENERGIA COM A COMPRA DE PRODUTOS EFICIENTES?

Marcar com um " $X$ " a opção adequada, de acordo com o entrevistado.

12.12.1 -O(A) SR.(A) RECEBE INFORMAÇÕES SOBRE PRODUTOS EFICIENTES E DICAS SOBRE COMO ECONOMIZAR ENERGIA?

Marcar com um " $X$ " a opção adequada, de acordo com o entrevistado.

12.12.2 - CASO SIM, QUAIS SÃO AS SUAS PRINCIPAIS FONTES?

Marcar com um " $X$ " a opção adequada, de acordo com o entrevistado. Admitindo respostas múltiplas; e especificando a fonte de informação, caso marque a opção OUTROS.

12.13.1 - O(A) SR.(A) POSSUI ACESSO À INTERNET?

Marcar com um "X" a opção adequada, de acordo com o entrevistado.

12.13.2 - COMO É O SEU ACESSO À INTERNET?

Marcar com um " $X$ " a opção adequada, de acordo com o entrevistado. E especificando a forma de acesso, caso marque a opção OUTROS. 
12.14 - QUAIS AS EMPRESAS, ORGANIZAÇÕES OU ENTIDADES QUE TRABALHAM E DIVULGAM A ECONOMIA DE ENERGIA NO BRASIL E QUAL A MAIS IMPORTANTE DESSE SETOR PARA O(A) SR.(A)?

(QUESTÃO ESPONTÂNEA)

Nesta questão deve ser feita a pergunta ao entrevistado, deixando-o livre para resposta, marcando dentro do quadro as opções mais adequadas, com base no bom senso.

Assim o pesquisador deve preencher com um " $X$ " o quadro, dizendo se o entrevistado possui ou não conhecimento de algumas empresas que se encontram listadas na primeira coluna. E, na última coluna, marcar com um " $X$ ", a empresa mais importante.

\title{
13. SATISFAÇÃO DO CONSUMIDOR
}

\author{
ESTE TÓPICO DEVE SER RESPONDIDO EM CONSIDERAÇÃO AOS DIAS ATUAIS.
}

\section{SATISFAÇÃO GLOBAL}

13.1 - ADOTANDO UMA ESCALA DE 10 PONTOS, ONDE O PONTO 1 INDICA QUE VOCÊ ESTA MUITO INSATISFEITO(A) COM OS SERVIÇOS DE ENERGIA ELÉTRICA E O PONTO 10 QUE VOCÊ ESTÁ MUITO SATISFEITO(A). GOSTARIA QUE VOCÊ AVALIASSE, DE MANEIRA GERAL, A QUALIDADE DOS SERVIÇOS PRESTADOS PELA (CITAR NOME DA CONCESSIONÁRIA).

Nesta questão o entrevistado deve declarar uma nota de 0 a 10 para o item citado. Se o entrevistado se encontra satisfeito, sua nota variará entre 7 e 10; sendo que, ele estando totalmente satisfeito, sem nenhuma restrição, a nota é 10. Se estiver insatisfeito, sua nota variará entre 1 e 4; sendo que, ele estando insatisfeito mas não muito, será 3 ou 4. Caso não esteja nem satisfeito, nem insatisfeito; a nota será 5 ou 6, estando 5 mais para insatisfeito, e 6 mais para satisfeito.

13.2 - VOCÊ JÁ TEVE ALGUM CONTATO COM A (CITAR NOME DA CONCESSIONÁRIA), SEJA PARA RESOLVER ALGUM PROBLEMA OU PEDIR ALGUM SERVIÇO, OU NUNCA ENTROU EM CONTATO? Marcar com um "X" a opção adequada, de acordo com o entrevistado.

\section{DESCONFORMIDADE}

13.3 - ADOTANDO UMA ESCALA DE 10 PONTOS, ONDE O PONTO 1 INDICA QUE O SERVIÇO PRESTADO PELA EMPRESA ESTÁ MUITO PIOR QUE AQUELE QUE VOCÊ ESPERA E O PONTO 10 QUE ESTÁ MUITO MELHOR QUE AQUELE QUE VOCÊ ESPERA. GOSTARIA QUE VOCÊ AVALIASSE, DE FORMA GERAL, A QUALIDADE DOS SERVIÇOS PRESTADOS PELA (CITAR O NOME DA CONCESSIONÁRIA)

Nesta questão o entrevistado deve declarar uma nota de 0 a 10 para o item citado. Se o entrevistado considera a qualidade dos serviços prestados acima do esperado, sua nota variará entre 7 e 10; sendo que, ele considerando muito melhor que o esperado, a nota é 10. Considerando abaixo do esperado, sua nota variará entre 1 e 4; sendo que, se estiver abaixo mas não muito, será 3 ou 4. Caso seja o esperado; a nota será 5 ou 6, estando 5 mais para abaixo do esperado, e 6 mais para acima do esperado. 


\section{DISTÂNCIA DO IDEAL}

13.4 - ADOTANDO UMA ESCALA DE 10 PONTOS, ONDE O PONTO 1 INDICA QUE A EMPRESA ESTÁ MUITO LONGE DO IDEAL E O PONTO 10 QUE ESTÁ MUITO PRÓXIMA DO IDEAL. GOSTARIA QUE VOCÊ AVALIASSE, PENSANDO NA QUALIDADE DOS SERVIÇOS DE FORMA GERAL, COMO ESTÃO SENDO PRESTADOS PELA (CITAR O NOME DA CONCESSIONÁRIA).

Nesta questão o entrevistado deve declarar uma nota de 0 a 10 para o item citado. Seguindo os mesmos termos da questão anterior o entrevistado deve responder a distância que ele acha que existe entre a qualidade do serviço prestado pela concessionária, e o que ele considera um serviço ideal.

14. HORA DE TÉRMINO DA ENTREVISTA: Marcar a hora de término da entrevista 